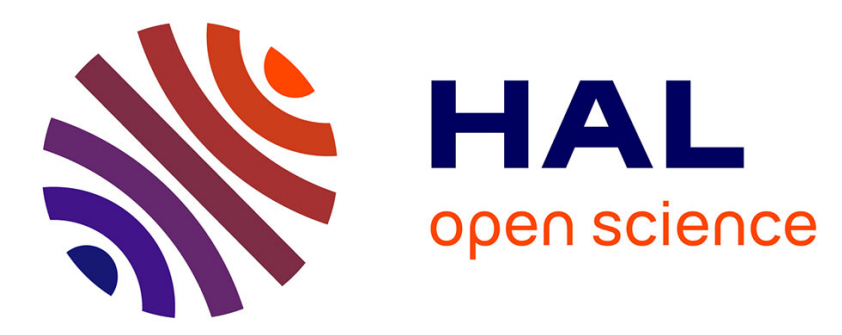

\title{
Ductile sliding between mineral crystals followed by rupture of collagen crosslinks: Experimentally supported micromechanical explanation of bone strength
}

Andreas Fritsch, Christian Hellmich, Luc Dormieux

\section{- To cite this version: \\ Andreas Fritsch, Christian Hellmich, Luc Dormieux. Ductile sliding between mineral crystals followed by rupture of collagen crosslinks: Experimentally supported micromechanical explanation of bone strength. Journal of Theoretical Biology, 2009, 260 (2), pp.230. 10.1016/j.jtbi.2009.05.021 . hal- 00554614}

\author{
HAL Id: hal-00554614 \\ https://hal.science/hal-00554614
}

Submitted on 11 Jan 2011

HAL is a multi-disciplinary open access archive for the deposit and dissemination of scientific research documents, whether they are published or not. The documents may come from teaching and research institutions in France or abroad, or from public or private research centers.
L'archive ouverte pluridisciplinaire HAL, est destinée au dépôt et à la diffusion de documents scientifiques de niveau recherche, publiés ou non, émanant des établissements d'enseignement et de recherche français ou étrangers, des laboratoires publics ou privés. 


\section{Author's Accepted Manuscript}

Ductile sliding between mineral crystals followed by rupture of collagen crosslinks: Experimentally supported micromechanical explanation of bone strength

Andreas Fritsch, Christian Hellmich, Luc Dormieux

PII:

S0022-5193(09)00239-2

DOI: doi:10.1016/j.jtbi.2009.05.021

Reference: YJTBI 5569

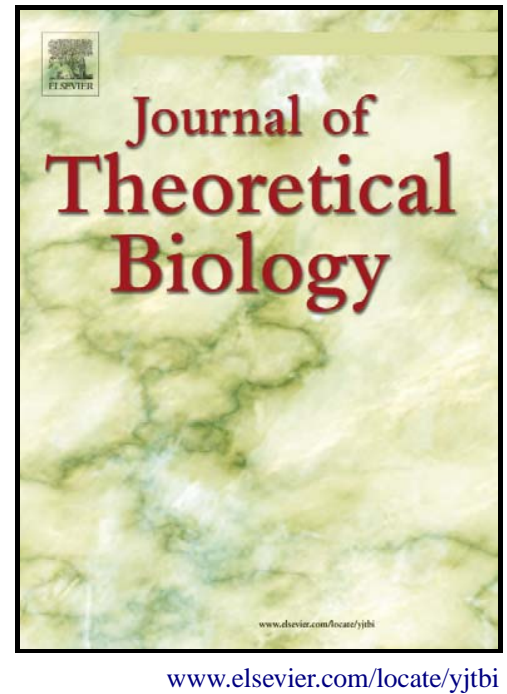

To appear in: $\quad$ Journal of Theoretical Biology

Received date: 17 December 2008

Revised date: $\quad 12$ May 2009

Accepted date: $\quad 16$ May 2009

Cite this article as: Andreas Fritsch, Christian Hellmich and Luc Dormieux, Ductile sliding between mineral crystals followed by rupture of collagen crosslinks: Experimentally supported micromechanical explanation of bone strength, Journal of Theoretical Biology, doi:10.1016/j.jtbi.2009.05.021

This is a PDF file of an unedited manuscript that has been accepted for publication. As a service to our customers we are providing this early version of the manuscript. The manuscript will undergo copyediting, typesetting, and review of the resulting galley proof before it is published in its final citable form. Please note that during the production process errors may be discovered which could affect the content, and all legal disclaimers that apply to the journal pertain. 


\title{
Ductile sliding between mineral crystals followed by rupture of collagen crosslinks: experimentally supported micromechanical explanation of bone strength
}

\author{
Andreas Fritsch, \\ Institute for Mechanics of Materials and Structures, \\ Vienna University of Technology (TU Wien), 1040 Vienna, Austria \\ Christian Hellmich* \\ Institute for Mechanics of Materials and Structures, \\ Vienna University of Technology (TU Wien), 1040 Vienna, Austria
}

Luc Dormieux

École des Ponts Paris Tech, 77455 Marne-la-Vallée, France

\begin{abstract}
There is an ongoing discussion on how bone strength could be explained from its internal structure and composition. Reviewing recent experimental and molecular dynamics studies, we here propose a new vision on bone material failure: mutual ductile sliding of hydroxyapatite mineral crystals along layered water films is followed by rupture of collagen crosslinks. In order to cast this vision into a mathematical form, a multiscale continuum micromechanics theory for upscaling of elastoplastic properties is developed, based on the concept of concentration and influence tensors for eigenstressed microheterogeneous materials. The model reflects bone's hierarchical organization, in terms of representative volume elements for cortical bone, for extravascular and extracellular bone material, for mineralized fibrils and the extrafibrillar space, and for wet collagen. In order to get access to the stress states at the interfaces between crystals, the extrafibrillar mineral is resolved into an infinite amount of cylindrical material phases oriented in all directions in space. The multiscale micromechanics model is shown to be able to satisfactorily predict the strength characteristics of different bones from different species, on the basis of their mineral/collagen content, their intercrystalline, intermolecular, lacunar, and vascular porosities, and the elastic and strength properties of hydroxyapatite and (molecular) collagen.
\end{abstract}


Key words: bone, strength, multiscale continuum micromechanics, hydroxyapatite, collagen

\section{Introduction}

Explanation of the highly diverse mechanical properties of the material bone from its internal structure and composition has been a biomechanician's wish [Fung, 2002, Martin et al., 1998], ever since the establishment of this scientific field. This wish has motivated (i) comprehensive mechanical testing series over all types of tissues and vertebrates (led by Currey and colleagues [Currey, 1959, Reilly and Burstein, 1974a, Keaveny et al., 1993]), (ii) the incorporation of the theory of anisotropic elasticity in the framework of ultrasonic testing (driven forward by Katz and colleagues [Katz, 1980, Ashman et al., 1984]), and (iii) the complementation of the aforementioned two activities with chemical and physical measurements revealing micro and nanostructural features of mineralized collagenous tissues (pioneered in an unparalleled experimental campaign by Lees and colleagues [Lees et al., 1979b,a, 1983, Lees, 1987]). The huge experimental legacy following from the aforementioned activities was theoretically integrated in the context of validating micromechanical models holding for bone materials across different species, ages and anatomical locations [Hellmich and Ulm, 2002a, Hellmich et al., 2004a, Hellmich and Ulm, 2005, Fritsch and Hellmich, 2007, Hellmich et al., 2009]. Such micromechanical models predict, on the basis of mechanical properties of bone elementary constituents (hydroxyapatite, collagen, water), the (poro-)elasticity tensors at the different hierarchical levels of the material, from tissue-specific composition data, such as porosities and mineral/collagen content. There-

\footnotetext{
* Corresponding author. Tel.: +4315880120220; fax: +4315880120299. Email addresses: Andreas.Fritsch@tuwien.ac.at (Andreas Fritsch), Christian.Hellmich@tuwien.ac .at (Christian Hellmich), dormieux@lmsgc.enpc.fr (Luc Dormieux).
} 
fore, morphological features such as Haversian and lacunar, intercrystalline, and intermolecular porosities, mineralized fibrils and collagen-free extrafibrillar space, plate or needle-type hydroxyapatite crystals and long crosslinked collagen molecules were represented in the framework of continuum micromechanics, also referred to as random homogenization theory [Hill, 1963, Suquet, 1997, Zaoui, 2002]. A key feature of these micromechanical models is the explicit consideration of the extrafibrillar mineral crystals whose existence was evidenced earlier [Lees et al., 1984a, 1994, Prostak and Lees, 1996, Pidaparti et al., 1996, Benezra Rosen et al., 2002], and further confirmed by the kinetics of recent demineralization experiments [Balooch et al., 2008]. In this sense, the challenge of micromechanics-supported, consistently upscaled microstructure-property relationships for poroelasticity in bone has been met quite reasonably.

However, the case of explaining bone strength from its internal structure and composition seems to be fairly unsettled: while scaling relations for the strength of trabecular bone as function of porosity have become classical [Gibson, 1985, Gibson and Ashby, 1997], the micro and nanostructural origin of bone strength remains an open question: While several researchers favor the idea of brittle mineral crystals embedded in a compliant ductile organic (collagenous) matrix [Currey, 1969, Katz, 1980, 1981, Sasaki, 1991, Mammone and Hudson, 1993, Jäger and Fratzl, 2000, Kotha and Guzelsu, 2003] (still, explanation of a large number of experimental data through only one model and realistic prediction of measured stress-strain curves are somewhat out of sight), experiments show that collagen may actually fail in a quasi-brittle fashion [Christiansen et al., 2000, Gentleman et al., 2003], and this observation is confirmed by latest molecular dynamics simulations [Buehler, 2006a, Bhowmik et al., 2007]. Such computations are essential tools for understanding the interaction of huge numbers of molecules, but, due to computational constraints, the largest models which can be realized nowadays are of the or- 
der of some hundreds of nanometers [Buehler, 2006a], far away from the larger length scales spanned by the material bone up to its macroscopic appearance at the millimeter to centimeter scale. What further complicates the matter is that once the elementary constituents mineral and collagen have failed, a complex series of crack propagation events starts, spanning length scales between tens of nanometers and ultimately several millimeters. Related toughening strategies in bone have been intensively studied [Burr et al., 1998, Reilly and Currey, 2000, Akkus and Rimnac, 2001, Okumura and Gennes, 2001, Taylor et al., 2003, Ballarini et al., 2005, O’Brien et al., 2007, Koester et al., 2008], but a consistent mathematical theory for relating them to the overall, tissuespecific bone strength seems to be an enormously difficult task. Given this highly challenging situation, we ask: Can continuum micromechanics help to explain not only bone elasticity, but also bone strength from the material's internal structure and composition?

It is often felt that, in contrast to the elastic case, homogenization techniques which often refer to strains or stresses averaged over the material's constituents, might not help for the explanation of bone strength, where stress peaks are likely to govern material failure. Fortunately, this is not necessarily true: one remedy lies in the resolution of one material constituent into an infinite amount of sub-phases - e.g. the mineral phase may be split into an infinite amount of differently oriented needles, giving access to information on local needle-specific stress peaks. It was recently shown [Fritsch et al., 2009] that based on such a concept, the brittle failure of various hydroxyapatite biomaterials characterized by different porosities could be explained from the failure characteristics of individual crystals (quantified in terms of two strength values only) and from the microstructure these crystals build up.

This recent micromechanics model can deliver important input, in terms of the strength properties of single hydroxyapatite crystals, for a micromechanics model explaining bone strength - the latter is the focus of the present paper. It 
is organized as follows: Reviewing recent experimental and molecular dynamics studies, we first propose a new vision on bone material failure: mutual ductile sliding of mineral crystals along layered water films is followed by rupture of collagen crosslinks. In order to cast this vision into a mathematical form, we then present a continuum micromechanics theory for upscaling of elastoplastic properties. Thereafter, this theory is applied to a multiscale representation of bone materials. Conclusively, it is shown that the corresponding multiscale model can satisfactorily predict the stress-strain curves and the strength values of different bones from different species, on the basis of their mineral/collagen content, their intercrystalline, intermolecular, lacunar, and vascular porosities, and the elastic and strength properties of hydroxyapatite and collagen.

\section{A new proposition for bone failure: layered water-induced ductile sliding of minerals, followed by rupture of collagen crosslinks}

Classically, the strength of bone materials is thought to be related to the strength properties of collagen, to the strength properties of hydroxyapatite, and/or the interfaces between these constituents. However, more recent works extend and modify this traditional picture, by indicating the great role of water for the failure properties of bone. In this context, molecular dynamics studies on collagen molecules being detached from hydroxyapatite in solvated conditions, revealed that the interaction energies between hydroxyapatite and water, and between collagen and water, are by orders of magnitude larger than that between hydroxyapatite and collagen [Bhowmik et al., 2007, 2009]. This implies that water probably plays a central role in 'glueing' together the material's elementary constituents, mineral with mineral, collagen with collagen, and also mineral with collagen. The latter interaction was confirmed by solid state Nuclear Magnetic Resonance $\left({ }^{1} \mathrm{H}\right.$ NMR) studies [Wilson et al., 2006]. As concerns the water-hydroxyapatite interactions, molecular dynamics simulations of crystal systems surrounded by water molecules revealed two to three 
well-organized water layers on the crystal surfaces, these structured water layers having ice-like features [Pan et al., 2007]. These features were shown to chemically stabilize the crystals, ALONG VERY STABLE APATITE/WATER INTERFACES SHOWN BY MOLECULAR DYNAMICS SIMULATIONS OF ZAHN AND HoCHREIN [2003], ZAHN ET AL. [2007]. In the present contribution, we will discuss the possibility that they also mechanically stabilize the interaction between mineral crystals: More specifically, we consider the case when the mineral crystals will not break or detach one from another once a critical stress threshold is reached (as in dry conditions), but when the intra- and intercrystalline loads accumulated up to the elastic limit, will be maintained through the (hydrated) crystals starting to glide upon each other, along the ice-like features, which prevent the sliding hydroxyapatite surfaces from disintegration (see Figure 1 for a multiscale view of bone, focusing on this gliding effect). The latter is also prevented by the collagen fibrils interweaving the extracellular bone matrix. This vision is consistent with an elastoplastic interface behavior between hydrated hydroxyapatite. However, from a mathematical viewpoint, modeling interfaces between non-spherical objects is extremely expending (or extremely complex), so that we will benefit from the recent finding [Fritsch et al., 2009] that the effect of 'micro'-interface behavior of elongated 1D particles, on the overall 'macroscopic' material can be mimicked by equivalent 'bulk' failure properties of the elongated phases. In case of hydroxyapatite polycrystals, we even know the (brittle) failure properties of the single hydroxyapatite crystals, and we will use them as elastic limits in the framework of full elastoplastic analysis of the hierarchical mineral-collagen-water composites called 'bone'. Therefore, it is appropriate to present a continuum micromechanics theory for elastoplasticity next. Thereby, our focus is on the plastic gliding mechanisms between mineral crystals, and we only proceed our computations until a critical stress in the collagen is reached. Potentially plastic behavior or microcracking events/crack bridging occuring thereafter [Nalla et al., 2004] are beyond our present scope. The critical stress of collagen is derived from 
direct mechanical experiments on collagen, showing a brittle behavior of this constituent [Catanese et al., 1999, Christiansen et al., 2000, Gentleman et al., 2003], which is in agreement with some molecular dynamics studies [Buehler, 2006a, 2008, Vesentini et al., 2005b]. In particular, the latter work shows that collagen rupture is likely to be related to failure of crosslinks, such as the decorin molecule [see Figure 1(a)].

\section{Fundamentals of continuum micromechanics - random homoge- nization of elastoplastic properties}

\subsection{Representative volume element}

In continuum micromechanics [Hill, 1963, Suquet, 1997, Zaoui, 1997, 2002], a material is understood as a macro-homogeneous, but micro-heterogeneous body filling a representative volume element (RVE) with characteristic length $\ell, \ell \gg d, d$ standing for the characteristic length of inhomogeneities within the RVE (see Figure 2), and $\ell \ll \mathcal{L}, \mathcal{L}$ standing for the characteristic lengths of geometry or loading of a structure built up by the material defined on the RVE.

In general, the microstructure within one RVE is so complicated that it cannot be described in complete detail. Therefore, quasi-homogeneous subdomains with known physical quantities (such as volume fractions or elastoplastic properties) are reasonably chosen. They are called material phases. The 'homogenized' mechanical behavior of the overall material, i.e. the relation between homogeneous deformations acting on the boundary of the RVE and resulting (average) stresses, including the ultimate stresses sustainable by the RVE, can then be estimated from the mechanical behavior of the aforementioned homogeneous phases (representing the inhomogeneities within the RVE), their dosages within the RVE, their characteristic shapes, and their interactions. 
If a single phase exhibits a heterogeneous microstructure itself, its mechanical behavior can be estimated by introduction of an RVE within this phase, with dimensions $\ell_{2} \leq d$, comprising again smaller phases with characteristic length $d_{2} \ll \ell_{2}$, and so on, leading to a multistep homogenization scheme (see Figure 2).

\subsection{Upscaling of elastoplastic properties}

We consider an RVE consisting of $n_{r}$ material phases, $r=1, \ldots, n_{r}$, exhibiting elastoplastic material behavior, i.e. following the constitutive laws of ideal associated elastoplasticity,

$$
\begin{array}{r}
\boldsymbol{\sigma}_{r}=\mathbb{C}_{r}:\left(\boldsymbol{\varepsilon}_{r}-\boldsymbol{\varepsilon}_{r}^{p}\right) \\
\dot{\boldsymbol{\varepsilon}_{r}^{p}}=\dot{\lambda}_{r} \frac{\partial \mathfrak{f}_{r}}{\partial \boldsymbol{\sigma}_{r}}, \quad \dot{\lambda}_{r} \mathfrak{f}_{r}\left(\boldsymbol{\sigma}_{r}\right)=0, \quad \dot{\lambda}_{r} \geq 0, \quad \mathfrak{f}_{r}\left(\boldsymbol{\sigma}_{r}\right) \leq 0
\end{array}
$$

In Eq. (2), $\boldsymbol{\sigma}_{r}$ and $\boldsymbol{\varepsilon}_{r}$ are the stress and (linearized) strain tensors averaged over phase $r$ with elasticity tensor $\mathbb{C}_{r} ; \boldsymbol{\varepsilon}_{r}^{p}$ are the average plastic strains in phase $r, \lambda_{r}$ is the plastic multiplier of phase $r$, and $\mathfrak{f}_{r}\left(\boldsymbol{\sigma}_{r}\right)$ is the yield function describing the (ideally) plastic characteristics of phase $r$. The RVE is subjected to Hashin boundary conditions, i.e. to 'homogeneous' ('macroscopic') strains $\boldsymbol{E}$ at its boundary, so that the kinematically compatible phase strains $\boldsymbol{\varepsilon}_{r}$ inside the RVE fulfill the average condition

$$
\boldsymbol{E}=\sum_{r} f_{r} \varepsilon_{r}
$$

with $f_{r}$ as the volume fraction of phase $r$. In a similar way, the equilibrated phase stresses $\boldsymbol{\sigma}_{r}$ fulfill the stress average condition

$$
\boldsymbol{\Sigma}=\sum_{r} f_{r} \boldsymbol{\sigma}_{r}
$$

with $\boldsymbol{\Sigma}$ as the 'macroscopic' stresses. 
The superposition principle (following from linear elasticity and linearized strain) implies that the phase strains $\varepsilon_{r}$ are linearly related to both the macroscopic strains $\boldsymbol{E}$, and to the free strains $\varepsilon_{r}^{p}$ (which can be considered as independent loading parameters),

$$
\boldsymbol{\varepsilon}_{r}=\mathbb{A}_{r}: \boldsymbol{E}+\sum_{s} \mathbb{a}_{r s}: \boldsymbol{\varepsilon}_{s}^{p}
$$

with $\mathbb{A}_{r}$ as the fourth-order concentration tensor [Hill, 1965], and $\mathbb{a}_{r s}$ as the fourth-order influence tensors [Dvorak, 1992]. The latter quantify the phase strains $\varepsilon_{r}$ resulting from plastic strains $\varepsilon_{s}^{p}$, while the overall RVE is free from deformation, $\boldsymbol{E}=\mathbf{0}$.

In absence of plastic strains $\left[\mathfrak{f}_{r}<0, \boldsymbol{\varepsilon}_{r}^{p}=\mathbf{0}\right.$ in Eqs. (1)-(2)], the RVE behaves fully elastically, so that (5), (4), (3), and (1) yield a macroscopic elastic law of the form

$$
\boldsymbol{\Sigma}=\mathbb{C}^{\text {hom }}: \boldsymbol{E} \quad \text { with } \quad \mathbb{C}^{\text {hom }}=\sum_{r} f_{r} \mathbb{C}_{r}: \mathbb{A}_{r}
$$

as the homogenized elastic stiffness tensor characterizing the material within the RVE. In case of non-zero 'free' plastic strains $\varepsilon_{r}^{p}$, (6) can be extended to the form

$$
\Sigma=\mathbb{C}^{h o m}:\left(\boldsymbol{E}-\boldsymbol{E}^{p}\right)
$$

(7), together with (1), (4), (5), and (6) gives access to the macroscopic plastic strains $\boldsymbol{E}^{p}$, reading as

$$
\begin{array}{r}
\boldsymbol{E}^{p}=-\left[\sum_{r} f_{r} \mathbb{C}_{r}: \mathbb{A}_{r}\right]^{-1}: \\
\left\{\sum_{r} f_{r} \mathbb{C}_{r}:\left[\left(\mathbb{A}_{r}: \boldsymbol{E}+\sum_{s} \mathbb{a}_{r s}: \varepsilon_{s}^{p}\right)-\varepsilon_{r}^{p}\right]\right\}+\boldsymbol{E}
\end{array}
$$




\subsection{Matrix-inclusion based estimation of concentration and influence tensors}

We estimate the concentration and influence tensors from matrix-inclusion problems, as it is standardly done in the field of elasticity homogenization. However, we consider not only elastic, but also free (plastic) strains in both the inclusion (with stiffness $\mathbb{C}_{i n c}$ ) and surrounding infinite matrix (with stiffness $\left.\mathbb{C}^{0}\right)$; these plastic strains are denoted by $\varepsilon_{i n c}^{p}$ and $\boldsymbol{E}^{0, p}$. At its infinite boundary, the infinite matrix is subjected to homogeneous strains $\boldsymbol{E}^{\infty}$. Then, the strains in the inhomogeneity can be given in the form [Zaoui, 2002]

$$
\boldsymbol{\varepsilon}_{i n c}=\left[\mathbb{\square}+\mathbb{P}_{i n c}^{0}:\left(\mathbb{C}_{i n c}-\mathbb{C}^{0}\right)\right]^{-1}:\left[\boldsymbol{E}^{\infty}+\mathbb{P}_{i n c}^{0}:\left(\mathbb{C}_{i n c}: \varepsilon_{i n c}^{p}-\mathbb{C}^{0}: \boldsymbol{E}^{0, p}\right)\right]
$$

We estimate the strains in phase $r, \varepsilon_{r}$, as those of an inclusion of the same shape as the phase, i.e. we identify $\varepsilon_{i n c}=\varepsilon_{r}$ in (9), and insert this result into the strain average rule (3), which yields a relation between $\boldsymbol{E}^{\infty}$ and $\boldsymbol{E}$,

$$
\begin{aligned}
& \boldsymbol{E}^{\infty}=\left\{\sum_{r} f_{r}\left[\mathbb{[}+\mathbb{P}_{r}^{0}:\left(\mathbb{C}_{r}-\mathbb{C}^{0}\right)\right]^{-1}\right\}^{-1}: \\
& \left\{\boldsymbol{E}-\sum_{s} f_{s}\left[\mathbb{[}+\mathbb{P}_{s}^{0}:\left(\mathbb{C}_{s}-\mathbb{C}^{0}\right)\right]^{-1}: \mathbb{P}_{s}^{0}:\left(\mathbb{C}_{s}: \varepsilon_{s}^{p}-\mathbb{C}^{0}: \boldsymbol{E}^{0, p}\right)\right\}
\end{aligned}
$$

Use of Eq. (10) in (9) specified for $\varepsilon=\varepsilon_{r}$ yields

$$
\begin{array}{r}
\boldsymbol{\varepsilon}_{r}=\left[\mathbb{\square}+\mathbb{P}_{r}^{0}:\left(\mathbb{C}_{r}-\mathbb{C}^{0}\right)\right]^{-1}:\left\{\left\{\sum_{i} f_{i}\left[\mathbb{\square}+\mathbb{P}_{i}^{0}:\left(\mathbb{C}_{i}-\mathbb{C}^{0}\right)\right]^{-1}\right\}^{-1}:\right. \\
\left\{\boldsymbol{E}-\sum_{s} f_{s}\left[\mathbb{\square}+\mathbb{P}_{s}^{0}:\left(\mathbb{C}_{s}-\mathbb{C}^{0}\right)\right]^{-1}: \mathbb{P}_{s}^{0}:\left(\mathbb{C}_{s}: \varepsilon_{s}^{p}-\mathbb{C}^{0}: \boldsymbol{E}^{0, p}\right)\right\} \\
\left.+\mathbb{P}_{r}^{0}:\left(\mathbb{C}_{r}: \varepsilon_{r}^{p}-\mathbb{C}^{0}: \boldsymbol{E}^{0, p}\right)\right\}
\end{array}
$$

In (11), the properties of the fictitious matrix, $\mathbb{C}^{0}$ and $\boldsymbol{E}^{0, p}$, still need to be chosen. As regards $\mathbb{C}^{0}$, its choice governs the interactions between the phases inside the RVE: $\mathbb{C}^{0}=\mathbb{C}^{\text {hom }}$ relates to a dispersed arrangement of phases where all phases 'feel' the overall homogenized material, and the correspond- 
ing homogenization scheme is standardly called self-consistent [Hershey, 1954, Kröner, 1958], well-suited for polycrystalline materials. On the other hand, the matrix may be identified as a phase $M$ itself, $\mathbb{C}^{0}=\mathbb{C}_{M}$, which relates to a matrix-inclusion-type composite, and the corresponding homogenization scheme is standardly referred to as Mori-Tanaka scheme [Mori and Tanaka, 1973, Benveniste, 1987]. Herein, we have to make an additional choice, relating to the plastic (free) strains in the fictitious matrix, $\boldsymbol{E}^{0, p}$. For a matrix-inclusion composite (Mori-Tanaka scheme), it seems natural to identify $\boldsymbol{E}^{0, p}$ with the free strain in the matrix phase, $\varepsilon_{M}^{p}$. In case of the self-consistent scheme, however, we have to remember that the fictitious matrix does not exhibit any volume fractions - therefore, it cannot host any free strains, and $\boldsymbol{E}^{0, p}$ is set zero in that case. In particular, one is not allowed to set $\boldsymbol{E}^{0, p}$ equal to the macroscopic plastic strains prevailing at the RVE level, since this would be in conflict with the concentration relation (5).

Concentration relation (5) remains to be specified for the polycrystals and matrix-inclusion composites: For the former (self-consistent scheme, $\mathbb{C}^{0}=$ $\left.\mathbb{C}^{\text {hom }}, \boldsymbol{E}^{0, p}=\mathbf{0}\right),(11)$ reads as

$$
\begin{aligned}
\boldsymbol{\varepsilon}_{r}= & {\left[\mathbb{\square}+\mathbb{P}_{r}^{0}:\left(\mathbb{C}_{r}-\mathbb{C}^{h o m}\right)\right]^{-1}:\left\{\left\{\sum_{i} f_{i}\left[\mathbb{\square}+\mathbb{P}_{i}^{0}:\left(\mathbb{C}_{i}-\mathbb{C}^{h o m}\right)\right]^{-1}\right\}^{-1}:\right.} \\
& \left.\left\{\boldsymbol{E}-\sum_{s} f_{s}\left[\mathbb{\square}+\mathbb{P}_{s}^{0}:\left(\mathbb{C}_{s}-\mathbb{C}^{h o m}\right)\right]^{-1}: \mathbb{P}_{s}^{0}: \mathbb{C}_{s}: \varepsilon_{s}^{p}\right\}+\mathbb{P}_{r}^{0}: \mathbb{C}_{r}: \boldsymbol{\varepsilon}_{r}^{p}\right\}
\end{aligned}
$$

Comparing (12) with (5), we can identify the concentration and influence tensors as

$$
\mathbb{A}_{r}=\left[\llbracket+\mathbb{P}_{r}^{0}:\left(\mathbb{C}_{r}-\mathbb{C}^{h o m}\right)\right]^{-1}:\left\{\sum_{s} f_{s}\left[\llbracket+\mathbb{P}_{s}^{0}:\left(\mathbb{C}_{s}-\mathbb{C}^{h o m}\right)\right]^{-1}\right\}^{-1}
$$

and 


$$
\begin{aligned}
& \mathbb{a}_{r s}=\mathbb{a}_{r r}=\left(-f_{r} \mathbb{A}_{r}+\mathbb{\square}\right):\left(\mathbb{A}_{r}^{\infty}: \mathbb{P}_{r}^{0}: \mathbb{C}_{r}\right) \quad \text { if } \quad r=s \\
& \text { otherwise } \\
& \mathbb{a}_{r s}=-f_{s} \mathbb{A}_{r}: \mathbb{A}_{s}^{\infty}: \mathbb{P}_{s}^{0}: \mathbb{C}_{s}
\end{aligned}
$$

whereby

$$
\mathbb{A}_{r}^{\infty}=\left[\mathbb{0}+\mathbb{P}_{r}^{0}:\left(\mathbb{C}_{r}-\mathbb{C}^{h o m}\right)\right]^{-1}
$$

For the Mori-Tanaka case $\left(\mathbb{C}^{0}=\mathbb{C}_{M}, \boldsymbol{E}^{0, p}=\varepsilon_{M}^{p}\right),(11)$ reads as

$$
\begin{array}{r}
\boldsymbol{\varepsilon}_{r}=\left[\mathbb{\square}+\mathbb{P}_{r}^{0}:\left(\mathbb{C}_{r}-\mathbb{C}_{M}\right)\right]^{-1}:\left\{\left\{\sum_{i} f_{i}\left[\mathbb{\square}+\mathbb{P}_{i}^{0}:\left(\mathbb{C}_{i}-\mathbb{C}_{M}\right)\right]^{-1}\right\}^{-1}:\right. \\
\left\{\boldsymbol{E}-\sum_{s} f_{s}\left[\mathbb{\square}+\mathbb{P}_{s}^{0}:\left(\mathbb{C}_{s}-\mathbb{C}_{M}\right)\right]^{-1}:\left[\mathbb{P}_{s}^{0}:\left(\mathbb{C}_{s}: \boldsymbol{\varepsilon}_{s}^{p}-\mathbb{C}_{M}: \varepsilon_{M}^{p}\right)\right]\right\} \\
\left.+\mathbb{P}_{r}^{0}:\left(\mathbb{C}_{r}: \varepsilon_{r}^{p}-\mathbb{C}_{M}: \varepsilon_{M}^{p}\right)\right\}
\end{array}
$$

Comparing (17) with (5), we can identify the concentration and influence tensors as

$$
\mathbb{A}_{r}=\left[\mathbb{q}+\mathbb{P}_{r}^{0}:\left(\mathbb{C}_{r}-\mathbb{C}_{M}\right)\right]^{-1}:\left\{\sum_{s} f_{s}\left[\mathbb{\square}+\mathbb{P}_{s}^{0}:\left(\mathbb{C}_{s}-\mathbb{C}_{M}\right)\right]^{-1}\right\}^{-1}
$$

and

$$
\begin{gathered}
\mathbb{a}_{r s}=\mathbb{a}_{r r}=\left(-f_{r} \mathbb{A}_{r}+\mathbb{q}\right):\left(\mathbb{A}_{r}^{\infty}: \mathbb{P}_{r}^{0}: \mathbb{C}_{r}\right) \quad \text { if } \quad r=s \\
\mathbb{a}_{r s}=\mathbb{a}_{r M}=\mathbb{A}_{r}:\left(-f_{M} \mathbb{A}_{M}^{\infty}: \mathbb{P}_{M}^{0}: \mathbb{C}_{M}+\right. \\
\left.\sum_{i} f_{i} \mathbb{A}_{i}^{\infty}: \mathbb{P}_{i}^{0}: \mathbb{C}_{M}\right)--\mathbb{A}_{r}^{\infty}: \mathbb{P}_{r}^{0}: \mathbb{C}_{M} \text { if } s=M \\
\text { otherwise } \\
\mathbb{a}_{r s}=-f_{s} \mathbb{A}_{r}: \mathbb{A}_{s}^{\infty}: \mathbb{P}_{s}^{0}: \mathbb{C}_{s}
\end{gathered}
$$

\section{Application of microelastoplastic theory to bone}

In the following, we will apply the above developed microelastoplastic theory to the material 'cortical bone'. Therefore, we will employ a slight adaptation of 
a recently proposed and validated multiscale material model for bone elasticity [Fritsch and Hellmich, 2007], see Figure 3. The adaptation lies in considering different orientations of non-spherical mineral crystals, as this precision of morphological resolution is mandatory for the appropriate prediction of the material's strength properties, as has been shown for other materials such as hydroxyapatite biomaterials [Fritsch et al., 2009], concrete [Pichler et al., 2009, 2008], or gypsum [Sanahuja et al., 2008]. As the basis for such a multiscale micromechanics model, the mechanical properties of the elementary components, of hydroxyapatite, of collagen, and of water, are required. They will be discussed first.

\subsection{Elastic properties of hydroxyapatite, collagen, and water}

Concerning the tissue-independent ('universal') phase properties of the elementary constituents of bone, being the same for all tissues discussed herein, we consider the following experiments (see also [Fritsch and Hellmich, 2007]): Tests with an ultrasonic interferometer coupled with a solid media pressure

apparatus [Katz and Ukraincik, 1971, Gilmore and Katz, 1982] reveal the isotropic elastic properties of hydroxyapatite powder (Table 1), which, in view of the largely disordered arrangement of POORLY CRYSTALLINE minerals [Lees et al., 1994, Fratzl et al., 1996, Peters et al., 2000, Epple, 2001, Hellmich and Ulm, 2002a, 2003, Hellmich et al., 2004a], are sufficient for the characterization of the mineral phase [Hellmich and Ulm, 2002b, Hellmich et al., 2004b, Fritsch et al., 2006]. Given the absence of direct measurements of (molecular) collagen, the elastic properties of (molecular) collagen are approximated by those of dry rat tail tendon, a tissue consisting almost exclusively of collagen. By means of Brillouin light scattering, Cusack and Miller [1979] have determined the respective five independent elastic constants of a transversely isotropic material (Table 1). We assign the standard bulk modulus of water (Table 1) to phases comprising water with mechanically insignificant non-collagenous 
organic matter.

\subsection{Failure properties of hydroxyapatite crystals and collagen}

Recent work on porous hydroxyapatite biomaterials [Fritsch et al., 2009] has revealed that the elastic limit of single (needle-type) hydroxyapatite crystals can be appropriately characterized through a criterion of the form:

$$
\psi=0, \ldots, 2 \pi: \mathfrak{f}_{H A \varphi \vartheta}\left(\boldsymbol{\sigma}_{H A \varphi \vartheta}\right)=\beta \max _{\psi}\left|\sigma_{H A}^{N n}\right|+\sigma_{H A}^{N N}-\sigma_{H A}^{u l t, t}=0
$$

with spherical coordinates $\varphi$ and $\vartheta$ defining the crystal needle orientation vector $\underline{N}=\underline{e}_{r}$ in the reference frame $\left(\underline{e}_{1}, \underline{e}_{2}, \underline{e}_{3}\right)$, and with $\psi$ defining the orientation of vector $\underline{n}$ related to shear stresses (see Figure 4$) \cdot \beta=\sigma_{H A}^{u l t, t} / \sigma_{H A}^{u l t, s}$ is the ratio between the uniaxial tensile strength $\sigma_{H A}^{u l t, t}$ and the shear strength $\sigma_{H A}^{u l t, s}$ of pure hydroxyapatite (abbreviated ' $\mathrm{HA}$ '), and $\sigma_{H A}^{N n}=\underline{N} \cdot \boldsymbol{\sigma}_{H A \varphi \vartheta} \cdot \underline{n}$ and $\sigma_{H A}^{N N}=\underline{N} \cdot \boldsymbol{\sigma}_{H A \varphi \vartheta} \cdot \underline{N}$ are the normal and shear stress components related to a surface with normal $\underline{N}(\varphi, \vartheta)$. These strength values can be gained from experiments of Akao et al. [1981] and Shareef et al. [1993], see [Fritsch et al., 2009] for further details, and they amount to 52.2 $\mathrm{MPa}$ and 80.3 MPa, respectively (see also Table 2 ). Beyond the elastic regime, we consider associated ideal plasticity according to Eq. (2) - having in mind a mathematically feasible strategy for mimicking layered water-induced ductile sliding between crystals, which maintains the crystals' stress levels reached at the elastic limit. Use of (22) in (2) yields the flow and consistency rules as

$$
\begin{array}{r}
\dot{\varepsilon}_{H A \varphi \vartheta}^{p}=\dot{\lambda}_{H A}\left[\underline{N} \otimes \underline{N}+\beta \operatorname{sgn}\left(\sigma_{H A}^{N n}\right)(\underline{N} \otimes \underline{n}+\underline{n} \otimes \underline{N})\right], \\
\dot{\lambda}_{H A}\left(\beta \max _{\psi}\left|\sigma_{H A}^{N n}\right|+\sigma_{H A}^{N N}-\sigma_{H A}^{u l t, t}\right)=0, \\
\dot{\lambda}_{H A} \geq 0, \\
\beta \max _{\psi}\left|\sigma_{H A}^{N n}\right|+\sigma_{H A}^{N N}-\sigma_{H A}^{u l t, t} \leq 0,
\end{array}
$$

Experiments on collagen fibrils have evidenced the quasi-brittle failure char- 
acteristics of this material [Christiansen et al., 2000, Gentleman et al., 2003]. Failure of the crosslinks between the cylindrical collagen molecules is standardly agreed upon as the primary cause of collagen failure in the longitudinal direction of the molecules (fibrils) [Buehler, 2006a, Vesentini et al., 2005b]. We here represent this fact by a failure criterion of the form

$$
\mathfrak{f}_{c o l}\left(\boldsymbol{\sigma}_{c o l}\right)=\left|\underline{e}_{3} \cdot \boldsymbol{\sigma}_{c o l} \cdot \underline{e}_{3}\right|-\sigma_{c o l}^{u l t} \leq 0
$$

where the direction three coincides with the principal orientation direction of collagen (see Figure 3). Once the equal sign holds in criterion (24), we consider that the strengths of both the collagenous phase and of the overall bone materials are reached, while any potential plastic or, more probably, microcracking and crack bridging events leading to toughening in the post-peak regime [Nalla et al., 2004], are beyond the scope of the present manuscript. Given the aforementioned role of the collagen crosslinks for the strength of molecular collagen, a non-mineralized collagenous tissue with crosslinking characteristics close to that of bone is the favorable access to the strength of molecular collagen. As before, we will rely on rat tail tendon, which, under wet conditions, exhibits a strength of $106.1 \mathrm{MPa}$ (Table 2 in [Gentleman et al., 2003]). Again, we have to consider close packing of collagen as to get access to properties of molecular collagen. It is known from neutron diffraction studies [Lees et al., 1984a, Lees, 1987] that diffractional spacing (a measure for the lateral distance of collagen molecules) reduces from $1.5 \mathrm{~nm}$ (for wet collagen) to $1.1 \mathrm{~nm}$ (for maximally packed (dry) collagen). Accordingly, the cross sectional area of a tensile specimen would reduce by the ratio 1.5/1.1, so that the strength of molecular collagen follows to be 1.5/1.1 times higher than that of wet collagen, i.e. 144.7 $\mathrm{MPa}$ (see Table 2). 


\subsection{Homogenization over wet collagen}

An RVE of wet collagen [see Figure 3(a)] hosts cylindrical intermolecular pores (labeled by suffix ' $\mathrm{im}$ ') being embedded into a matrix of crosslinked molecular collagen (labeled by suffix 'col'), which is suitably considered through a Mori-Tanaka scheme. Unless collagen rupture criterion (24) is fulfilled, the RVE behaves purely elastically $\left(\varepsilon_{c o l}^{p}=\varepsilon_{i m}^{p}=\mathbf{0}\right)$, with a homogenized stiffness $\mathbb{C}_{\text {wetcol }}^{M T}$ following from specification of $(6)$ for $r=[\mathrm{col}, \mathrm{im}]$. Thereby, the volume fractions fulfill $\dot{f}_{i m}+\dot{\circ}_{c o l}=1$, and the concentration tensors $\mathbb{A}_{c o l}$ and $\mathbb{A}_{i m}$, respectively, are given through specification of (18) for $\mathbb{P}_{i m}^{0}=\mathbb{P}_{c y l}^{c o l}, \mathbb{C}_{M}=\mathbb{C}_{c o l}$, as well as for $\mathbb{C}_{r}=\mathbb{C}_{c o l}$ and $\mathbb{C}_{r}=\mathbb{C}_{i m}=3 k_{H_{2} O} \mathbb{J}$, respectively. $J_{i j k l}=1 / 3 \delta_{i j} \delta_{k l}$ is the volumetric part of the fourth order unity tensor 『; see Table 1 for $k_{\mathrm{H}_{2} \mathrm{O}}$. According to the aforementioned specifications, the concentration relation (17) for the matrix of molecular collagen within an RVE of wet collagen reads as

$$
\boldsymbol{\varepsilon}_{c o l}=\left\{\left(1-\stackrel{\circ}{f}_{i m}\right) \mathbb{\square}+\stackrel{\circ}{f}_{i m}\left[\mathbb{\square}+\mathbb{P}_{c y l}^{c o l}:\left(\mathbb{C}_{i m}-\mathbb{C}_{c o l}\right)\right]^{-1}\right\}^{-1}: \boldsymbol{E}_{\text {wetcol }}
$$

whereby the components of morphology tensor $\mathbb{P}_{c y l}^{c o l}$ are given in the Appendix.

\subsection{Homogenization over mineralized collagen fibril}

An RVE of mineralized collagen fibrils [see Figure 3(b)] hosts crystal clusters (represented through spherical hydroxyapatite inclusions, labeled by suffix ' $H A$ ') and cylindrical microfibrils of wet collagen (labeled by suffix 'wetcol'), which are mutually intertwingled. In order to consider this morphology, a selfconsistent scheme is appropriate. Unless the wet collagen phase does not fail [see Subsections 4.3 and 4.2, in particular Eq. (24)], the RVE behaves purely elastically $\left(\varepsilon_{H A}^{p}=\varepsilon_{\text {wetcol }}^{p}=\mathbf{0}\right)$, with a homogenized stiffness $\mathbb{C}_{f i b}^{S C S}$ following from specification of (6), for $r=[H A$, wetcol $]$. Thereby, the volume fractions fulfill $\breve{f}_{\text {wetcol }}+\breve{f}_{H A}=1$, and the concentration tensors $\mathbb{A}_{H A}$ and $\mathbb{A}_{\text {wetcol }}$, respec- 
tively, are given through specification of (13) for $\mathbb{C}^{h o m}=\mathbb{C}_{f i b}^{S C S}$, for $\mathbb{P}_{H A}^{0}=\mathbb{P}_{s p h}^{f i b}$ and $\mathbb{P}_{\text {wetcol }}^{0}=\mathbb{P}_{c y l}^{f i b}$, respectively, as well as for $\mathbb{C}_{r}=\mathbb{C}_{H A}=3 k_{H A} \rrbracket+2 \mu_{H A} \mathbb{K}$, and

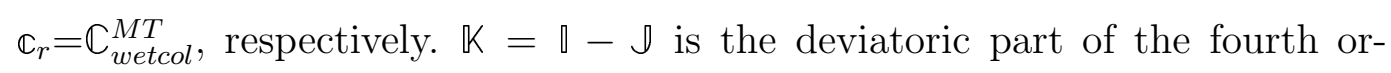
der unity tensor $\llbracket$; see Table 1 for $k_{H A}$ and $\mu_{H A}$. According to the aforementioned specifications, the concentration relation (12) for the phase "wet collagen' within an RVE of mineralized collagen fibril reads as

$$
\begin{aligned}
& \varepsilon_{\text {wetcol }}=\left[\mathbb{\square}+\mathbb{P}_{c y l}^{f i b}:\left(\mathbb{C}_{\text {wetcol }}^{M T}-\mathbb{C}_{f i b}^{S C S}\right)\right]^{-1}: \\
& \left\{\breve{f}_{\text {wetcol }}\left[\mathbb{\square}+\mathbb{P}_{c y l}^{f i b}:\left(\mathbb{C}_{\text {wetcol }}^{M T}-\mathbb{C}_{f i b}^{S C S}\right)\right]^{-1}+\right. \\
& \left.\breve{f}_{H A}\left[\mathbb{\square}+\mathbb{P}_{s p h}^{f i b}:\left(\mathbb{C}_{H A}-\mathbb{C}_{f i b}^{S C S}\right)\right]^{-1}\right\}^{-1}: \boldsymbol{E}_{f i b}
\end{aligned}
$$

whereby the components of $\mathbb{P}_{s p h}^{f i b}$ and $\mathbb{P}_{c y l}^{f i b}$ are given in the Appendix - and $\boldsymbol{\varepsilon}_{\text {wetcol }}$ (here the 'microscopic' strain) is identical to $\boldsymbol{E}_{\text {wetcol }}$ of Eq. (25), there being the 'macroscopic' strain.

\subsection{Homogenization over extrafibrillar space (hydroxyapatite foam)}

An RVE of extrafibrillar space [see Figure 3(c)] hosts crystal needles (represented through cylindrical hydroxyapatite inclusions, labeled by suffix ' $H A$ ') being oriented in all space directions, and spherical, water-filled pores (intercrystalline space, labeled by suffix ' $i c$ '). The corresponding polycrystal-type morphology is appropriately represented through a self-consistent scheme. Sliding between crystals is modeled through criterion (23), leading to plastic strains $\varepsilon_{H A}^{p}$, and no plasticity occurs in the intercrystalline space $\left(\varepsilon_{i c}^{p}=\mathbf{0}\right)$. The homogenized stiffness of an RVE of extrafibrillar space, $\mathbb{C}_{e f}^{S C S I I}$, follows from specification of (6) for $r=[H A, i c]$. Thereby, the volume fractions fulfill $\check{f}_{H A}+\check{f}_{i c}=1$, and the concentration tensors $\mathbb{A}_{H A \varphi \vartheta}$ and $\mathbb{A}_{i c}$, respectively, are given through specification of $(13)$ for $\mathbb{C}^{h o m}=\mathbb{C}_{e f}^{S C S I I}$, for $\mathbb{P}_{H A}^{0}=\mathbb{P}_{c y l}^{e f}(\vartheta, \varphi)$ and

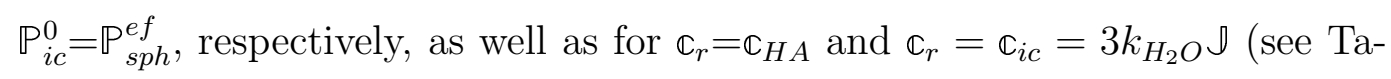
ble 1), respectively. Thereby, summation over all crystal orientations is done 
by integration over angles $\vartheta=0, \ldots, \pi$ and $\varphi=0, \ldots, 2 \pi$. Accordingly, the concentration-influence relation (17) for the hydroxyapatite phase oriented in a specific direction $(\vartheta, \varphi)$ within an RVE of extrafibrillar space reads as

$$
\begin{aligned}
& \varepsilon_{H A \varphi \vartheta}=\left[\mathbb{\square}+\mathbb{P}_{c y l}^{e f}(\vartheta, \varphi):\left(\mathbb{C}_{H A}-\mathbb{C}_{e f}^{S C S I I}\right)\right]^{-1}: \\
& \left\{\check{f}_{H A} \int_{\phi=0}^{2 \pi} \int_{\theta=0}^{\pi}\left[\mathbb{q}+\mathbb{P}_{c y l}^{e f}(\theta, \phi):\left(\mathbb{C}_{H A}-\mathbb{C}_{e f}^{S C S I I}\right)\right]^{-1} \frac{\sin \theta \mathrm{d} \theta \mathrm{d} \phi}{4 \pi}+\right. \\
& \left.+\check{f}_{i c}\left[\mathbb{\square}+\mathbb{P}_{s p h}^{e f}:\left(\mathbb{C}_{i c}-\mathbb{C}_{e f}^{S C S I I}\right)\right]^{-1}\right\}^{-1}: \\
& \left\{\boldsymbol{E}_{e f}-\check{f}_{H A} \int_{\phi=0}^{2 \pi} \int_{\theta=0}^{\pi}\left[\mathbb{\square}+\mathbb{P}_{c y l}^{e f}(\theta, \phi):\left(\mathbb{C}_{H A}-\mathbb{C}_{e f}^{S C S I I}\right)\right]^{-1}:\right. \\
& \left.\left.\mathbb{P}_{c y l}^{e f}(\theta, \phi): \mathbb{C}_{H A}: \varepsilon_{H A \vartheta \varphi}^{p} \frac{\sin \theta \mathrm{d} \theta \mathrm{d} \phi}{4 \pi}\right\}+\mathbb{P}_{c y l}^{e f}(\vartheta, \varphi): \mathbb{C}_{H A}: \varepsilon_{H A \vartheta \varphi}^{p}\right\}
\end{aligned}
$$

whereby the components of $\mathbb{P}_{s p h}^{e f}$ and $\mathbb{P}_{c y l}^{e f}$ are given in the Appendix. According to (8) applied to the present homogenization step, plastic strains $\varepsilon_{H A}^{p}$ in the hydroxyapatite phases imply a plastic strain $\boldsymbol{E}_{e f}^{p}$ at the level of the RVE of extrafibrillar space.

\subsection{Homogenization over extracellular bone matrix}

An RVE of extracellular bone matrix or ultrastructure [see Figure 3(d)] hosts cylindrical mineralized fibrils (labeled by suffix ' $f i b$ ') being embedded into a matrix of extrafibrillar space (labeled by suffix ' $e f$ '). This morphology is suitably modeled by means of a Mori-Tanaka scheme. As discussed in the previous Subsection 4.5, the extrafibrillar matrix may be subjected to plastic strains, while we do not consider plastic strains in the mineralized fibrils $\left(\varepsilon_{f i b}^{p}=\mathbf{0}\right)$. The homogenized stiffness of an RVE of extracellular bone matrix, $\mathbb{C}_{\text {excel }}^{M T I I}$, follows from specification of (6) for $r=[f i b, e f]$. Thereby, the volume fractions fulfill $\bar{f}_{f i b}+\bar{f}_{e f}=1$, and the concentration tensors $\mathbb{A}_{f i b}$ and $\mathbb{A}_{e f}$,

respectively, follow from specification of (18) for $\mathbb{C}_{M}=\mathbb{C}_{e f}^{S C S I I}$, for $\mathbb{P}_{f i b}^{0}=\mathbb{P}_{c y l}^{e f}$, as well as for $\mathbb{C}_{r}=\mathbb{C}_{f i b}^{S C S}$ and $\mathbb{C}_{r}=\mathbb{C}_{e f}^{S C S I I}$, respectively. Accordingly, the concentra- 
tion influence relation (17) for the phase extrafibrillar space within an RVE of extracellular bone matrix reads as

$$
\begin{aligned}
& \boldsymbol{\varepsilon}_{e f}=\left\{\bar{f}_{e f} \llbracket+\bar{f}_{f i b}\left[\mathbb{\square}+\mathbb{P}_{c y l}^{e f}:\left(\mathbb{C}_{f i b}^{S C S}-\mathbb{C}_{e f}^{S C S I I}\right)\right]^{-1}\right\}^{-1}: \\
& \left\{\boldsymbol{E}_{\text {excel }}-\bar{f}_{f i b}\left[\mathbb{\square}+\mathbb{P}_{c y l}^{e f}:\left(\mathbb{C}_{f i b}^{S C S}-\mathbb{C}_{e f}^{S C S I I}\right)\right]^{-1}: \mathbb{P}_{c y l}^{e f}:\left(-\mathbb{C}_{e f}^{S C S I I}: \varepsilon_{e f}^{p}\right)\right\}
\end{aligned}
$$

whereby the components of $\mathbb{P}_{c y l}^{e f}$ are given in the Appendix. According to (8) applied to the present homogenization step, plastic strains in the extrafibrillar space (see Subsection $4.5, \varepsilon_{e f}^{p}=\boldsymbol{E}_{e f}^{p}$ ) imply a plastic strain $\boldsymbol{E}_{e x c e l}^{p}$ at the level of the RVE of the extracellular bone matrix.

\subsection{Homogenization over extravascular bone material}

An RVE of extravascular bone material [see Figure 3(e)] hosts spherical empty pores called lacunae (labeled by suffix ' $l a c$ ') being embedded into a matrix of extracellular bone matrix (labeled by suffix 'excel'). This morphology is suitably modeled by means of a Mori-Tanaka scheme. As discussed in the previous Subsection 4.6, the extracellular bone matrix may be subjected to plastic strains while we do not consider plastic strains in the lacunae $\left(\varepsilon_{l a c}^{p}=\mathbf{0}\right)$.

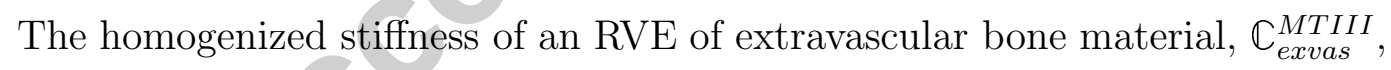
follows from specification of (6) for $r=[l a c$, excel]. Thereby, the volume fractions fulfill $\tilde{f}_{\text {lac }}+\tilde{f}_{\text {excel }}=1$, and the concentration tensors $\mathbb{A}_{\text {lac }}$ and $\mathbb{A}_{\text {excel }}$, respectively, follow from specification of (18) for $\mathbb{C}_{M}=\mathbb{C}_{\text {excel }}^{M T I I}$, for $\mathbb{P}_{\text {lac }}^{0}=\mathbb{P}_{\text {sph }}^{\text {excel }}$, as well as for $\mathbb{C}_{r}=\mathbb{C}_{\text {lac }}=\mathbb{O}$ and $\mathbb{C}_{r}=\mathbb{C}_{\text {excel }}^{M T I I}$, respectively. $\mathbb{C}_{\text {lac }}=\mathbb{O}$ relates to the fact that the lacunar pores are empty (drained) in all experiments considered in Section 6 - for undrained situations, $\mathbb{C}_{l a c}=3 k_{\mathrm{H}_{2} \mathrm{O}} \mathbb{\rrbracket}$ would be appropriate, see [Fritsch and Hellmich, 2007] for details. According to the aforementioned specifications, the concentration-influence relation (17) for the phase 'extrafibrillar space' within an RVE of extracellular bone matrix reads as 


$$
\begin{aligned}
& \varepsilon_{\text {excel }}=\left\{\tilde{f}_{\text {excel }} \mathbb{\square}+\tilde{f}_{\text {lac }}\left[\mathbb{\square}-\mathbb{P}_{\text {sph }}^{\text {excel }}: \mathbb{C}_{\text {excel }}^{\text {MTII }}\right]^{-1}\right\}^{-1}: \\
& \left\{\boldsymbol{E}_{\text {exvas }}-\tilde{f}_{\text {lac }}\left[\mathbb{\square}-\mathbb{P}_{\text {sph }}^{\text {excel }}: \mathbb{C}_{\text {excel }}^{M T I I}\right]^{-1}: \mathbb{P}_{\text {sph }}^{\text {excel }}:\left(-\mathbb{C}_{\text {excel }}^{M T I I}: \varepsilon_{\text {excel }}^{p}\right)\right\}
\end{aligned}
$$

whereby the components of $\underset{s p h}{\text { excel }}$ are given in the Appendix. According to (8) applied to the present homogenization step, plastic strains in the extracellular bone matrix (see Subsection 4.6, $\varepsilon_{\text {excel }}^{p}=\boldsymbol{E}_{\text {excel }}^{p}$ ) imply a plastic strain $\boldsymbol{E}_{\text {exvas }}^{p}$ at the level of the RVE of the extravascular bone material.

\subsection{Homogenization over cortical bone material}

An RVE of cortical bone material [see Figure 3(f)] hosts cylindrical empty pores called Haversian canals or vascular space (labeled by suffix 'vas') being embedded into a matrix of extravascular bone material (labeled by suffix 'exvas'). This morphology is suitably modeled by means of a Mori-Tanaka scheme. As discussed in the previous Subsection 4.7, the extravascular bone material may be subjected to plastic strains, while we do not consider plastic strains in the Haversian canals $\left(\varepsilon_{v a s}^{p}=\mathbf{0}\right)$. The homogenized stiffness of an

RVE of cortical bone material, $\mathbb{C}_{c o r t}^{M T I V}$, follows from specification of (6) for $r=[$ vas, exvas $]$. Thereby, the volume fractions fulfill $f_{\text {vas }}+f_{\text {exvas }}=1$, and the concentration tensors $\mathbb{A}_{\text {vas }}$ and $\mathbb{A}_{\text {exvas }}$, respectively, follow from specification of (18) for $\mathbb{C}_{M}=\mathbb{C}_{\text {exvas }}^{M T I I I}$, for $\mathbb{P}_{\text {vas }}^{0}=\mathbb{P}_{\text {cyl }}^{\text {exvas }}$, as well as for $\mathbb{C}_{r}=\mathbb{C}_{\text {vas }}=\mathbb{O}$ and $\mathbb{C}_{r}=\mathbb{C}_{\text {exvas }}^{\text {MTII }}$, respectively. $\mathbb{C}_{\text {vas }}=\mathbb{O}$ relates to the fact that the Haversian canals are empty (drained) in all experiments considered in Section 6. According to the aforementioned specifications, the concentration-influence relation (17) for the phase 'extravascular bone material' within an RVE of cortical bone material reads as

$$
\begin{aligned}
& \varepsilon_{\text {exvas }}=\left\{f_{\text {exvas }} \mathbb{\square}+f_{\text {vas }}\left[\mathbb{\square}-\mathbb{P}_{\text {cyl }}^{\text {exvas }}: \mathbb{C}_{\text {exvas }}^{\text {MTII }}\right]^{-1}\right\}^{-1}: \\
& \left\{\boldsymbol{E}_{\text {cort }}-f_{\text {vas }}\left[\mathbb{\square}-\mathbb{P}_{\text {cyl }}^{\text {exvas }}: \mathbb{C}_{\text {exvas }}^{\text {MTII }}\right]^{-1}: \mathbb{P}_{\text {cyl }}^{\text {exvas }}:\left(-\mathbb{C}_{\text {exvas }}^{\text {MTII }}: \varepsilon_{\text {exvas }}^{p}\right)\right\}
\end{aligned}
$$


whereby the components of $\mathbb{P}_{\text {cyl }}^{\text {exvas }}$ are given in the Appendix. According to (8) applied to the present homogenization step, plastic strains in the extravascular bone material (see Subsection $4.7, \boldsymbol{\varepsilon}_{\text {exvas }}^{p}=\boldsymbol{E}_{\text {exvas }}^{p}$ ) imply a plastic strain $\boldsymbol{E}_{\text {cort }}^{p}$ at the level of the RVE of the cortical bone material.

\section{$5 \quad$ Algorithmic aspects}

We are left with using the partially incremental constitutive relations developed in Sections 3 and 4 for computation of stress-strain relations. This requires some algorithmic deliberations which we will describe in view of a stress-strain curve for uniaxial stress applied to an RVE of cortical bone, $\Sigma_{\text {cort }}=\Sigma_{33} \underline{e}_{3} \otimes \underline{e}_{3}$, the loading direction $\underline{e}_{3}$ coinciding with the longitudinal (axial) direction of the bone material (see Figure 3). This stress is applied in load increments labeled by $n$, starting at $\Sigma_{33}=0$, and being accumulated up to failure of the material. Accordingly, flow rule (2) and (23) is considered in a discretized fashion: It is evaluated for a finite number of needle orientation directions ('families'), and it is integrated over the $n$-th load step,

$$
\Delta \varepsilon_{H A \varphi \vartheta, n+1}^{p}=\Delta \lambda_{H A, n+1}\left[\underline{N} \otimes \underline{N}+\beta \operatorname{sgn}\left(\sigma_{H A}^{N n}\right)(\underline{N} \otimes \underline{n}+\underline{n} \otimes \underline{N})\right]
$$

with

$$
\varepsilon_{H A \varphi \vartheta, n+1}^{p}=\varepsilon_{H A \varphi \vartheta, n}^{p}+\Delta \varepsilon_{H A \varphi \vartheta, n+1}^{p}
$$

At the beginning of the very first load step, there are neither plastic strains $\left(\boldsymbol{E}_{\text {cort }, 0}^{p}=\mathbf{0}\right)$ nor total strains $\left(\boldsymbol{E}_{\text {cort }, 0}=\mathbf{0}\right)$; at the end of an arbitrary later load step with label $n$, there may be plastic strains $\boldsymbol{E}_{c o r t, n}^{p}$ and total strains $\boldsymbol{E}_{\text {cort }, n}$, both related to stresses $\boldsymbol{\Sigma}_{\text {cort }, n}=\Sigma_{33, n} \underline{e}_{3} \otimes \underline{e}_{3}$. Then, the general task is to compute the strain increments $\Delta \boldsymbol{E}_{\text {cort }, n+1}^{p}$ and $\Delta \boldsymbol{E}_{\text {cort }, n+1}$, leading to total strains $\boldsymbol{E}_{\text {cort }, n+1}^{p}=\boldsymbol{E}_{\text {cort }, n}^{p}+\Delta \boldsymbol{E}_{\text {cort }, n+1}^{p}$ and $\boldsymbol{E}_{\text {cort }, n+1}=\boldsymbol{E}_{\text {cort }, n}+\Delta \boldsymbol{E}_{\text {cort }, n+1}$, following from the stress increment $\Delta \Sigma_{\text {cort }, n+1}=\Delta \Sigma_{33, n+1} \underline{e}_{3} \otimes \underline{e}_{3}$. 
To fulfill this task, an iterative procedure is applied: First, the macroscopic strains are estimated from specification of (7) for an RVE of cortical bone, on the assumption that no plastic strains would occur during the $(n+1)$-st load step, which may be referred to as a 'trial step' in the line of classical computational elastoplasticity [Simo and Taylor, 1985],

$$
\boldsymbol{E}_{\text {cort }, n+1}^{\text {trial }}=\mathbb{C}_{\text {cort }}^{M T I V}: \boldsymbol{\Sigma}_{\text {cort }, n+1}+\boldsymbol{E}_{\text {cort }, n}^{p}
$$

Then, these trial strains are concentrated into the lower-scale RVEs, by means of Eqs. (25)-(30), all specified for $\boldsymbol{E}_{\text {cort }}=\boldsymbol{E}_{\text {cort }, n+1}^{\text {trial }} ; \boldsymbol{\varepsilon}_{\text {exvas }}^{p}=\varepsilon_{\text {exvas }, n}^{p}, \boldsymbol{\varepsilon}_{\text {exvas }}=$ $\boldsymbol{E}_{\text {exvas }}=\varepsilon_{\text {exvas }, n+1}^{\text {trial }}=\boldsymbol{E}_{\text {exvas }, n+1}^{\text {trial }} ; \varepsilon_{\text {excel }}^{p}=\varepsilon_{\text {excel }, n}^{p}, \boldsymbol{\varepsilon}_{\text {excel }}=\boldsymbol{E}_{\text {excel }}=\varepsilon_{\text {excel }, n+1}^{\text {trial }}=$ $\boldsymbol{E}_{e x c e l, n+1}^{\text {trial }} ; \varepsilon_{e f}^{p}=\varepsilon_{e f, n}^{p}, \varepsilon_{e f}=\boldsymbol{E}_{e f}=\varepsilon_{e f, n+1}^{\text {trial }}=\boldsymbol{E}_{e f, n+1}^{\text {trial }} ; \varepsilon_{H A \varphi \vartheta}^{p}=\varepsilon_{H A \varphi \vartheta, n}^{p}$, $\varepsilon_{H A \varphi \vartheta}=\varepsilon_{H A \varphi \vartheta, n+1}^{t r i a l}$. Within the RVE of extrafibrillar material, the trial stress states in hydroxyapatite phases follow to be

$$
\boldsymbol{\sigma}_{H A \varphi \vartheta, n+1}^{\text {trial }}=\mathbb{C}_{H A}:\left[\varepsilon_{H A \varphi \vartheta, n+1}^{\text {trial }}-\varepsilon_{H A \varphi \vartheta, n}^{p}\right]
$$

and this trial stress allows one to identify the plasticizing mineral phases in load step $n+1$ :

$$
\begin{aligned}
& \mathfrak{f}_{H A \varphi \vartheta}\left(\boldsymbol{\sigma}_{H A \varphi \vartheta, n+1}^{\text {trial }}\right) \leq 0 \leftrightarrow \Delta \lambda_{H A \varphi \vartheta, n+1}=0 \\
& \mathfrak{f}_{H A \varphi \vartheta}\left(\boldsymbol{\sigma}_{H A \varphi \vartheta, n+1}^{\text {trial }}\right)>0 \leftrightarrow \Delta \lambda_{H A \varphi \vartheta, n+1}>0
\end{aligned}
$$

In the first case, the load step is elastic, $\Delta \boldsymbol{E}_{\text {cort }, n+1}^{p}=\mathbf{0}$ and $\boldsymbol{E}_{\text {cort }, n+1}^{\text {trial }}=$ $\boldsymbol{E}_{\text {cort }, n+1}$, and the computation can proceed to the next load step, $n+2$. In the second case, the load step is elastoplastic, the plastic multiplier $\Delta \lambda_{H A \varphi \vartheta, n+1}$ and the plastic strain increment $\Delta \varepsilon_{H A \varphi \vartheta, n+1}^{p}$ need to be determined. In the line of classical computational elastoplasticity, this is done by means of the so-called return map algorithm, also called projection algorithm [Simo and Taylor, 1985]: A trial stress state $\boldsymbol{\sigma}_{H A \varphi \vartheta, n+1}^{\text {trial }}$ which lies outside the elastic domain has to be projected back onto the failure surface $\mathfrak{f}_{H A \varphi \vartheta}=\mathfrak{f}_{1}$ in Figure 5, which gives a first approximation of the stresses in the HA phase, 


$$
\begin{aligned}
& \boldsymbol{\sigma}_{H A \varphi \vartheta, n+1}^{(1)}=\boldsymbol{\sigma}_{H A \varphi \vartheta, n+1}^{\text {trial }}-\mathbb{C}_{H A}: \Delta \lambda_{H A \varphi \vartheta, n+1}[\underline{N} \otimes \underline{N}+ \\
& \left.+\beta \operatorname{sgn}\left(\sigma_{H A}^{N n}\right)(\underline{N} \otimes \underline{n}+\underline{n} \otimes \underline{N})\right], \\
& \mathfrak{f}\left(\boldsymbol{\sigma}_{H A, n+1}^{(1)}\right)=0 \\
& \rightarrow \Delta \lambda_{H A \varphi \vartheta, n+1}= \\
& =\frac{\left(3 k_{H A}-2 \mu_{H A}\right) \bar{\varepsilon}_{11}+\left(3 k_{H A}-2 \mu_{H A}\right) \bar{\varepsilon}_{22}+\left(3 k_{H A}+4 \mu_{H A}\right) \bar{\varepsilon}_{33}}{3 k_{H A}+4 \mu_{H A}+6 \beta^{2} \mu}+ \\
& +\frac{\operatorname{sgn}\left(\sigma_{H A}^{N n}\right) 6 \beta \mu \bar{\varepsilon}_{13}-3 \sigma_{H A}^{u l t, t}}{3 k_{H A}+4 \mu_{H A}+6 \beta^{2} \mu}
\end{aligned}
$$

whereby the components of the difference $\left(\varepsilon_{H A \varphi \vartheta, n+1}-\varepsilon_{H A \varphi \vartheta, n}^{p}\right), \bar{\varepsilon}_{i j}$, are given in a local base frame $\left(\underline{e}_{r}, \underline{e}_{\vartheta}, \underline{e}_{\varphi}\right)$, see Figure 4 .

Use of $\Delta \lambda_{H A \varphi \vartheta, n+1}$ in (31), and insertion of the result into (8) specified for the extrafibrillar RVE, for the extracellular RVE, for the extravascular RVE, and for the cortical RVE, yields a first approximation of $\boldsymbol{E}_{\text {cort }, n+1}^{p(1)}$ and $\Delta \boldsymbol{E}_{\text {cort }, n+1}^{p(1)}$. These plastic strains are inserted into (33) where $\boldsymbol{E}_{c o r t, n}^{p}$ is replaced by $\boldsymbol{E}_{c o r t, n+1}^{p(1)}$, and the aforementioned procedure is repeated, leading to strains $\Delta \boldsymbol{E}_{\text {cort }, n+1}^{p(2)}$ and $\boldsymbol{E}_{c o r t, n+1}^{p(2)}$. Further repetitions of the aforementioned procedure are performed, the $k$-th performance yielding strains $\boldsymbol{E}_{c o r t, n+1}^{p(k)}$; and this is done until $\Delta \boldsymbol{E}_{c o r t, n+1}^{p(k)}$ approaches zero up to a prescribed tolerance so that satisfactorily precise values for $\boldsymbol{E}_{\text {cort }, n+1}^{p}$ and $\boldsymbol{E}_{\text {cort }, n+1}$ have been attained. Then, the next load step, $(n+2)$, is tackled.

A particular case deserves further discussion: If the trial stress state $\boldsymbol{\sigma}_{H A \varphi \vartheta, n+1}^{\text {trial }}$ lies within the gray shaded area of Figure 5, projection step (36) may deliver negative values for $\left|\sigma_{N n}\right|$, which is not admissible. In this case, a two-surface failure criterion is employed, the second surface being defined through

$$
\mathfrak{f}_{2, H A \varphi \vartheta}\left(\boldsymbol{\sigma}_{H A \varphi \vartheta, n+1}\right)=\sigma_{H A}^{N N}-\sigma_{N N, H A}^{u l t, t}=0
$$

and Eq. (31) is extended according to Koiter's flow rule [Koiter, 1960]

$$
\Delta \varepsilon_{H A \varphi \vartheta, n+1}^{p}=\Delta \lambda_{1, H A \varphi \vartheta, n+1} \frac{\partial \mathfrak{f}_{1, H A \varphi \vartheta}}{\partial \boldsymbol{\sigma}_{H A \varphi \vartheta, n+1}}+\Delta \lambda_{2, H A \varphi \vartheta, n+1} \frac{\partial \mathfrak{f}_{2, H A \varphi \vartheta}}{\partial \boldsymbol{\sigma}_{H A \varphi \vartheta, n+1}}
$$


with $\mathfrak{f}_{1, H A \varphi \vartheta}=\mathfrak{f}_{H A \varphi \vartheta}=0$ from Eq. (22). This leads to plastic multipliers reading as

$$
\begin{aligned}
& \Delta \lambda_{1, H A \varphi \vartheta, n+1}=\operatorname{sgn}\left(\sigma_{H A}^{N n}\right) \frac{\bar{\varepsilon}_{13}}{\beta} \\
& \Delta \lambda_{2, H A \varphi \vartheta, n+1}= \\
& \frac{\left(3 k_{H A}-2 \mu_{H A}\right) \beta \bar{\varepsilon}_{11}+\left(3 k_{H A}-2 \mu_{H A}\right) \beta \bar{\varepsilon}_{22}+\left(3 k_{H A}+4 \mu_{H A}\right) \beta \bar{\varepsilon}_{33}+}{\left(3 k_{H A}+4 \mu_{H A}\right) \beta}+ \\
& +\frac{\operatorname{sgn}\left(\sigma_{H A}^{N n}\right)\left(3 k_{H A}+4 \mu_{H A}\right) \bar{\varepsilon}_{13}-3 \beta \sigma_{H A}^{u l t, t}}{\left(3 k_{H A}+4 \mu_{H A}\right) \beta}
\end{aligned}
$$

\section{Experimental validation of multiscale model for bone strength}

The mathematical model developed in Sections 4 and 5 is based on experimentally determined elasticity and strength properties of the elementary components hydroxyapatite, (molecular) collagen, and water. This model predicts,

for each set of tissue-specific volume fractions $\stackrel{\circ}{f o l}_{c o l}, \breve{f}_{\text {wetcol }}, \check{f}_{H A}, \bar{f}_{f i b}, \tilde{f}_{\text {excel }}$, and $f_{\text {exvas }}$ (see Figure 3), the corresponding tissue-specific elasticity and strength properties at all observation scales of Figure 3. Thus, a strict experimental validation of the mathematical model is realized as follows: (i) different sets of volume fractions are determined from composition experiments on different bone samples with different ages, from different species and different anatomical locations (micrographs, weighing tests on demineralized/dehydrated tissues, neutron diffraction tests; see Subsection 6.1); (ii) these volume fractions are used as model input, and (iii) corresponding model-predicted strength values (model output) are compared to results from strength experiments on the same or very similar bone samples. We here refrain from validation of modelpredicted elastic values, since these are reported, in great detail, in [Fritsch and Hellmich, 2007]. 


\subsection{Experimental set providing tissue-specific volume fractions as model input}

Experimental validation of the six-step upscaling procedure [Eqs. (22) to (39)] requires determination of the phase volume fractions within the six considered RVEs (Figure 3).

Within an RVE of cortical bone [Figure 3(f)], the extravascular volume fraction $f_{\text {exvas }}$ is primarily driven by the interplay of osteoblastic and osteoclastic action in the vascular pore space. We here have access to typical mammalian cortical bone under physiological conditions, for which $f_{\text {exvas }}$ does not exceed $5 \%$ [Sietsema, 1995], and the microradiographs of bovine tibia provided by Lees et al. [1979a] yield $f_{\text {exvas }}=3 \%$ (see [Fritsch and Hellmich, 2007] for details); we will adopt this value throughout this validation section.

Within an RVE of extravascular bone material [Figure 3(e)], the lacunar volume fraction $\tilde{f}_{\text {lac }}$ relates to the way osteoblasts work: when laying down osteoid, a typical fraction of osteoblasts become buried in this newly formed ultrastructure, leading to the formation of lacunae. Hence, $\tilde{f}_{l a c}$ always lies in a narrow range of values, around $\tilde{f}_{l a c}=2 \%$ (see [Fritsch and Hellmich, 2007] for details); we will adopt this value for the remainder of this validation section.

As regards hydroxyapatite and collagen contents, Lees [1987] has provided the weight fractions of mineral and organic components within cortical bone samples, $W F_{H A}^{c o r t}$ and $W F_{\text {org }}^{\text {cort }}$, for several mammalian species and organs, including human and bovine bone samples, together with their mass densities $\rho_{\text {cort }}$ (see Table 3). These values give access to the weight fractions at the extracellular (ultrastructural) scale [Figure 3(d)], through 


$$
\begin{aligned}
W F_{H A}^{\text {excel }} & =\frac{W F_{H A}^{c o r t}}{1-\frac{\rho_{H_{2} O} \times\left[f_{\text {vas }}+\left(1-f_{\text {vas }}\right) \tilde{f}_{\text {lac }}\right]}{\rho_{\text {cort }}}} \\
W F_{\text {org }}^{\text {excel }} & =\frac{W F_{\text {org }}^{\text {cort }}}{1-\frac{\rho_{H_{2} O} \times\left[f_{\text {vas }}+\left(1-f_{\text {vas }}\right) \tilde{f}_{\text {lac }}\right]}{\rho_{\text {cort }}}}
\end{aligned}
$$

with $\rho_{\mathrm{H}_{2} \mathrm{O}}=1 \mathrm{~kg} / \mathrm{dm}^{3}$ as the mass density of water filling the vascular and lacunar pores spaces. Since $90 \%$ of mass of organic matter in bone is collagen [Urist et al., 1983, Lees, 1987, Weiner and Wagner, 1998], the weight fraction of collagen within the extracellular matrix follows to be

$$
W F_{\text {col }}^{\text {excel }}=0.9 \times W F_{\text {org }}^{\text {excel }}
$$

These weight fractions, together with the tissue mass density at the extracellular scale (the pores of specimens discussed in Table 3 are filled with water, see [Fritsch and Hellmich, 2007] for details),

$$
\rho_{\text {excel }}=\frac{\rho_{\text {cort }}-\rho_{\mathrm{H}_{2} \mathrm{O}}\left[f_{\text {vas }}+\left(1-f_{\text {vas }}\right) \tilde{f}_{\text {lac }}\right]}{1-f_{\text {vas }}-\left(1-f_{\text {vas }}\right) \tilde{f}_{\text {lac }}}
$$

give access to the mineral and collagen volume fractions at the extracellular observation scale,

$$
\begin{gathered}
\bar{f}_{H A}=\frac{\rho_{\text {excel }}}{\rho_{H A}} \times W F_{H A}^{\text {excel }} \\
\bar{f}_{\text {col }}=\frac{\rho_{\text {excel }}}{\rho_{\text {col }}} \times W F_{\text {col }}^{\text {excel }}
\end{gathered}
$$

where $\rho_{H A}=3.00 \mathrm{~kg} / \mathrm{dm}^{3}$ [Lees, 1987 , Hellmich, 2004] and $\rho_{\text {col }}=1.41 \mathrm{~kg} / \mathrm{dm}^{3}$ [Katz and Li, 1973, Lees, 1987] (see Table 3 for values of $\bar{f}_{H A}$ and $\bar{f}_{\text {col }}$ used for the validation of the herein proposed strength model).

The dehydration-demineralization tests of Lees et al. [1979b], Lees [1987], Lees et al. [1995] show that, throughout samples from the entire vertebrate animal kingdom, the extracellular volume fraction $\bar{f}_{H A}$ depends linearly on the extracellular mass density $\rho_{\text {excel }}$,

$$
\mathcal{F}_{\bar{f}_{H A}}=\mathcal{A} \times \rho_{\text {excel }}+\mathcal{B}
$$


with $\mathcal{A}=0.59 \mathrm{ml} / \mathrm{g}$ and $\mathcal{B}=-0.75$, see [Fritsch and Hellmich, 2007] for details. Combination of (46) with

$$
\rho_{\text {excel }}=\bar{f}_{\mathrm{H}_{2} \mathrm{O}} \rho_{\mathrm{H}_{2} \mathrm{O}}+\bar{f}_{\text {org }} \rho_{\text {org }}+\bar{f}_{H A} \rho_{H A}
$$

with $\rho_{\text {org }} \approx \rho_{\text {col }}$, with $1=\bar{f}_{\text {org }}+\bar{f}_{H_{2} O}+\bar{f}_{H A}$, and with $\bar{f}_{\text {col }}=0.9 \times \bar{f}_{\text {org }}$, yields the collagen content as a function of the extracellular mass density,

$$
\begin{aligned}
& \mathcal{F}_{\bar{f}_{\text {col }}}\left(\rho_{\text {excel }}\right)=\frac{0.9}{\rho_{\mathrm{H}_{2} \mathrm{O}}-\rho_{\text {org }}} \times \\
& \left\{\mathcal{F}_{\bar{f}_{H A}}\left(\rho_{\text {excel }}\right) \times\left[\rho_{H A}-\rho_{H_{2} O}\right]-\rho_{\text {excel }}+\rho_{H_{2} O}\right\}
\end{aligned}
$$

see Table 3 for values based on these functions, used for the validation of the herein proposed strength model.

The extracellular volume fractions of the fibrils and the extracellular space, $\bar{f}_{f i b}$ and $\bar{f}_{\text {ef }}$ [Figure $\left.3(\mathrm{~d})\right]$, can be quantified on the basis of the generalized packing model of Lees et al. [1984b], Lees [1987], through

$$
\bar{f}_{f i b}=\bar{f}_{c o l} \times \frac{v_{f i b}}{v_{c o l}}, \quad v_{f i b}=b d_{s} 5 D
$$

where $\bar{f}_{\text {col }}$ is determined according to (45) and (42), or according to (48) and (46), respectively. $v_{\mathrm{col}}=335.6 \mathrm{~nm}^{3}$ is the volume of a single collagen molecule [Lees, 1987]. $v_{f i b}$ is the volume of one rhomboidal fibrillar unit with length $5 D$, width $b$, and height $d_{s} . b=1.47 \mathrm{~nm}$ is an average (rigid) collagen crosslink length valid for all mineralized tissues [Lees et al., 1984b], $D \approx 64 \mathrm{~nm}$ is the axial macroperiod of staggered assemblies of type I collagen, and $d_{s}$ is the tissue-specific neutron diffraction spacing between collagen molecules, which depends on the mineralization and the hydration state of the tissue [Lees et al., 1984a, Bonar et al., 1985, Lees et al., 1994]. For wet tissues, $d_{s}$ can be given in a dimensionless form [Hellmich and Ulm, 2003], as a function of $\rho_{\text {excel }}$ only. For the rather narrow range of tissue mass densities considered here, this function 
can be linearly approximated through

$$
d_{s}=\mathcal{C} \times \rho_{\text {excel }}+\mathcal{D}
$$

where $\mathcal{C}=-0.2000 \mathrm{~nm} /\left(\mathrm{g} \mathrm{cm}^{-3}\right)$ and $\mathcal{D}=1.6580 \mathrm{~nm}$.

The volume fractions for scales below the extracellular bone matrix can be derived directly from $\bar{f}_{f i b}$ and $\bar{f}_{\text {col }}$, on the basis of the finding of Hellmich and Ulm [2001, 2003] that the average hydroxyapatite concentration in the extracollagenous space of the extracellular bone matrix of wet mineralized tissues is the same inside and outside the fibrils. Accordingly, the relative amount of hydroxyapatite in the extrafibrillar space reads as [Hellmich and Ulm, 2001, 2003]

$$
\phi_{H A, e f}=\frac{1-\bar{f}_{f i b}}{1-\bar{f}_{c o l}}
$$

With this value at hand, the mineral volume fractions in the fibrillar [Figure $3(\mathrm{~b})]$ and the extrafibrillar space [Figure 3(c)] are,

$$
\begin{aligned}
\breve{f}_{H A} & =\frac{\bar{f}_{H A}\left(1-\phi_{H A, e f}\right)}{\bar{f}_{f i b}} \\
\check{f}_{H A} & =\frac{\phi_{H A, e f} \bar{f}_{H A}}{\bar{f}_{e f}}
\end{aligned}
$$

see Table 3 for values used to validate the herein proposed strength model.

Within the fibril, comprising the phases hydroxyapatite and wet collagen, the volume fraction of the latter reads as

$$
\breve{f}_{\text {wetcol }}=1-\breve{f}_{H A}
$$

Finally, the volume fraction of (molecular) collagen at the wet collagen level [Figure $3(\mathrm{a})$ ] can be calculated from $\bar{f}_{\text {col }}$, through

$$
\stackrel{\circ}{\text { col }}_{\text {cotcol }}=\frac{\bar{f}_{\text {col }}}{\breve{f}_{\text {wet }}}
$$

see Table 3 for values used for validating the proposed strength model. 


\subsection{Experimental set providing tissue-specific strength values for model test- ing}

In most cases, strength of bone is quantified in terms of uniaxial, compressive or tensile mechanical tests, under quasi-static conditions (i.e. with a strain rate well below one). To show the relevance of our model approach, we consider various experimental results from various laboratories and various test setups, on various different bone samples (see Table 4 for specimen geometries, employed machines, and strain rates, and Table 5 for tissue-specific experimental results).

\subsection{Comparison between tissue-specific strength predictions and correspond- ing experiments}

The strength values predicted by the six-step homogenization scheme (Figure 3) for tissue-specific volume fractions (experimental set of Subsection 6.1) on the basis of tissue-independent 'universal' phase stiffness and strength properties (experimental set of Tables 1 and 2) are compared to corresponding experimentally determined tissue-specific uniaxial tensile and compressive strength values from the experimental set of Subsection 6.2. The experimental strength values of Subsection 6.2 are grouped into types of tissues (e.g. human tibia), and their corresponding weighted mean and standard deviation is considered (see Tables 6 and 7 as well as Figure 6).

To quantify the model's predictive capabilities, we consider the mean and the standard deviation of the relative error between strength predictions and experiments,

$$
\begin{aligned}
\bar{e} & =\frac{1}{n} \sum e_{i}=\frac{1}{n} \sum \frac{\Sigma_{c o r t}^{u l t}-\sum_{\text {exp }}^{u l t}}{\sum_{\text {cort }}^{u l t}} \\
e_{S} & =\left[\frac{1}{n-1} \sum\left(e_{i}-\bar{e}\right)^{2}\right]^{\frac{1}{2}}
\end{aligned}
$$


The satisfactory agreement between model predictions and experiments is quantified by prediction errors of $+2.61 \pm 24.7 \%$ for uniaxial tensile strength, and of $-4.00 \pm 8.42 \%$ for uniaxial compressive strength $\left[\bar{e} \pm e_{S}\right.$ according to Eqs. (56) and (57)].

\section{Discussion of model characteristics}

\subsection{Sliding events in the extrafibrillar space}

Having successfully shown the predictive capabilities of the proposed model for various cortical bone tissues tested in uniaxial tension and compression, it is interesting to study the sequence of plastic (interfacial) events in the extrafibrillar space, in terms of the orientations of involved hydroxyapatite crystals.

Under uniaxial tensile loading of cortical bone in axial (longitudinal) direction $\left(\vartheta=0^{\circ}\right)$, longitudinally oriented crystals are the first to undergo inelastic deformation. In the course of further loading, inelastic deformations spread relatively quickly over the range defined by orientation angles $\vartheta$ between zero and 30 degrees [see Figure 7(c)-(e) for $E_{\text {cort }, 33}$ below 0.1\%]. Afterwards, the spreading of plasticity slows off, and stops at an orientation angle of about 65 degrees, see Figure 7(d)-(e) for plastic strains, and Figure 7(c) for orientation $\vartheta=74.25^{\circ}$ remaining in the elastic regime. Thereby, crystals with longitudinal orientation carry tensile normal stresses at a constant level throughout the plastic loading stage, whereas the normal stresses in inclined crystals are declining, while increasing shear stresses build up [see Figure 7(a)-(b)].

Under uniaxial compressive loading of cortical bone material in axial (longi-

tudinal) direction $\left(\vartheta=0^{\circ}\right)$, transversely oriented crystals (i.e. such oriented perpendicular to the longitudinal direction) are the first to undergo inelastic 
deformation. In the course of further loading, inelastic deformations spread relatively quickly over the range defined by orientation angles between 90 and 70 degrees [see Figure 8(c)-(e) for $E_{\text {cort }, 33}$ below 0.1\%]. Afterwards, the spreading of plasticity slows off, and stops at an orientation angle of about 60 degrees, see Figure 8(d)-(e) for plastic strains, and Figure 8(c) for orientation $\vartheta<60^{\circ}$ remaining in the elastic regime. Thereby, transversely oriented crystals and crystals with slight inclination from the transverse directions (which are first associated with plasticity) carry normal tensile stresses, while more inclined crystals are loaded in normal compression. Throughout the plastic loading stage, all these crystals, whether loaded normally in tension or in compression, carry increasing shear stresses [see Figure 8(a)-(b)].

This sequence of plastic events leads to distinctive stress-strain relationships at the level of cortical bone (see Figure 9): Elastoplastic behavior associated to longitudinal extrafibrillar crystals under tensile loading provokes a decrease of slope in the stress-strain curve, which is more pronounced than that related to elastoplastic behavior in transverse crystal clusters under compression. Thereby, Figure 9 illustrates the stress-strain curves until the failure stress in the collagen according to (24) is reached - this agrees well with the investigations of Pidaparti et al. [1997], Morgan et al. [2005], showing a rather (quasi-)brittle behavior of cortical bone under uniaxial loading. On the other hand, several investigators [Currey, 1959, Reilly and Burstein, 1974b, Kotha and Guzelsu, 2002] report increasing cortical strains at a constant cortical stress level close to the ultimate strength level, i.e. the occurrence of (macroscopically apparent) 'plastic' events also beyond the point when the collagen failure criterion (24) is reached in the framework of our model. The micromechanical consideration of respective plastic or microcracking/crack bridging events (as dealt with by various researchers [Burr et al., 1998, Reilly and Currey, 2000, Akkus and Rimnac, 2001, Okumura and Gennes, 2001, Taylor, 2003, Ballarini et al., 2005, O'Brien et al., 2007, Koester et al., 2008]) is beyond the 
scope of this manuscript, where we focus on a model which can predict, as function of the bone sample's composition, the ultimate stress which is bearable by that sample.

Finally, there could seem to be a contradiction between the ductile behavior of interfaces between the hydroxyapatite crystals as part of natural collagenous bone tissue considered in this paper, and the brittle behavior of the interfaces between crystals of man-made hydroxyapatite biomaterials [Akao et al., 1981, Fritsch et al., 2009]. The reason for the different behaviors may well lie in the characteristic size of the crystals, and hence of the nature of their contact surfaces, the crystals in collagenous bone tissue being much smaller than the biomaterial crystals. In the same sense, in low or non-collagenous tissues, such as specific whale bones [Zioupos et al., 1997], the minerals grow larger, and also these tissues exhibit a brittle failure behavior. The idea of increased ductility due to increased activity of layered water films is also supported by the fact [Nyman et al., 2008] that bound water content is correlated to bone toughness; and this idea fits well with the suggestions of Boskey [2003], that larger crystals (implying less layered water films per crystal content) would lead to a more brittle behavior of bone materials.

\subsection{Effects of porosity and mineralization}

It is also interesting to study the effect of species, individual, and organspecific bone microstructures, on the cortical strength of corresponding bone materials: In healthy mammalian cortical bone, the vascular porosity varies typically between 2 and $8 \%$, while osteoporosis may lead to porosities up to $27 \%$ [Bousson et al., 2000]. Influence of vascular porosity increase on cortical strength is illustrated in Figures 10 and 11, it is of linear nature.

Within the extravascular matrix of a specific organ of an adult mammal, the average chemical composition is constant in space and time [Hellmich et al., 
2008], as can be seen from experimental results from computerized contact microradiography [Boivin and Meunier, 2002], quantitative backscattered electron imaging [Roschger et al., 2003], Raman microscopy [Akkus et al., 2003], and Synchrotron Micro Computer Tomography [Bossy et al., 2004]. Therefore, effects of (varying) extravascular mineral content [while the collagen content follows (48)] on different resulting cortical strength values (see Figure 11), reflect inter-organ and inter-species variations from one bone sample to another, with mineral contents between 30\% (typical for deer antler) and $70 \%$ (typical for equine metacarpus): the mineralization varying by a factor of two, implies a strength variation by a factor of two in tension, and by a factor of three in compression (Figure 11). In contrast to the extravascular porosity, the mineral content has a nonlinear influence on cortical strength - this qualitative model feature is in perfect agreement with a wealth of experimental data [Currey, 1984, 1988, Hernandez et al., 2001].

\subsection{Concentration relation and X-ray measurements}

A KEY FEATURE OF OUR MODEL ARE THE CONCENTRATION TENSORS INtroduced in Section 3.2 and Given in detail in Section 3.3, which ASSIGN MACROSCOPIC STRAINS TO STRAINS AND STRESSES AT THE SCALE OF INDIVIDUAL MINERAL CRYSTALS, WHICH ARE RELEVANT FOR MATERIAL FAILURE THROUGH DUCTILE SLIDING PROCESSES. WHILE A DIRECT EXPERIMENTAL DETERMINATION OF ALL COMPONENTS OF THE FOURTH-ORDER STRAIN CONCENTRATION TENSOR SEEMS TO BE OUT OF SIGHT FOR THE MOMENT, WE MAY REMEMBER THAT EXPERIMENTAL DETERMINATION OF CONCENTRATION RELATIONS IN BONE HAS BEEN DISCUSSED IN THE BONE BIOMECHANICAL AND STRUCTURAL BIOLOGY COMMUNITIES FOR A WHILE: THEREBY, EXPERIMENTALISTS FOCUSSED ON RELATING ONE MACROSCOPIC STRESS OR STRAIN COMPONENT (TYPICALLY AT THE TISSUE SCALE AND DERIVED FROM A CLASSICAL MECHANICAL TEST) TO ONE STRESS OR STRAIN 
COMPONENT IN THE MINERAL OR COLLAGEN PHASES (ESTIMATED FROM X-RAY DIFFRACTION PATTERN CHANGES DUE TO EXTERNAL FORCES ACTING ON THE PIECE OF BONE). While EQ. (5) DIRECTly SHOWs That, RIGOROUSLY SPEAKING, SUCH A RATIO RELATES TO NONE OF THE COMPONENTS OF THE CONCENTRATION TENSOR, IT SEEMS INTERESTING TO COMPARE THE X-RAY-ESTIMATED STRAins TO PREDICTIONS FROM OUR MiCROMEChaniCAL MODEL. More SPeCifiCAlly, We Will CONSIDER The TISSUE-TO-(INTRAFIBRILLAR) MINERAL STRAIN RATIO OF 0.16 (REPORTED By Gupta ET AL. [2006]) TO THE RATIO PREDICTED BY OUR MODEL FOR A UNIAXIAL STRESS EXPERIMENT $\Sigma^{e x p}=\Sigma_{33} \underline{e}_{3} \otimes \underline{e}_{3}$, NAMELY $\breve{\varepsilon}_{H A, 33} / E_{\text {cort }, 33}$, WITH $\boldsymbol{E}_{\text {cort }}=\mathbb{C}_{\text {cort }}^{M T I V}: \boldsymbol{\Sigma}_{\text {cort }}=E_{\text {cort }, 11 \underline{e}_{1}} \otimes \underline{e}_{1}+E_{\text {cort }, 22 \underline{e}_{2}} \otimes \underline{e}_{2}+E_{\text {cort }, 33 \underline{e}_{3}} \otimes \underline{e}_{3}$ $\operatorname{AND} \breve{\varepsilon}_{H A}=\mathbb{A}_{H A, f i b}: \mathbb{A}_{f i b}: \mathbb{A}_{\text {excel }}: \mathbb{A}_{\text {exvas }}: \boldsymbol{E}_{\text {cort }}=\breve{\varepsilon}_{H A, 11} \underline{e}_{1} \otimes \underline{e}_{1}+\breve{\varepsilon}_{H A, 22} \underline{e}_{2} \otimes$ $\underline{e}_{2}+\breve{\varepsilon}_{H A, 33 \underline{e}_{3}} \otimes \underline{e}_{3} ;$ The PREDiCTED RAtio AMOUnts To 0.20. The High SCATTER OF SUCH X-RAY EXPERIMENTS (STRAIN CONCENTRATION FACTORS VARY BETWEEN 0.16 AND 0.7 [GUPTA ET AL., 2006, FUJISAKI AND TADANO, 2006]; AND STRESS CONCENTRATION FACTORS VARY BETWEEN 1.5 And 2.8 [Borsato And SAsAKi, 1997, Almer And Stock, 2005, Gupta ET AL., 2006]) AND THE FACT THAT The VAlues of Gupta ET AL. LIE AT THE LOWER END OF THE RANGE OF EXPERIMENTALLY ESTIMATED CONCENTRATION VALUES, SUPPORT THE STATEMENT THAT OUR MODEL IS IN VERY GOOD AGREEMENT WITH X-RAY DIFFRACTION-BASED CONCENTRATION ESTIMATES.

7.4 Experimental sources for 'universal' mechanical properties of bone's elementary components: hydroxyapatite and molecular collagen

The QUestion Might ARISE Why We PREFER TO TAKE KATZ AND UKRAinCIK'S directly measured ISOTROPIC ELASTICITY VALUES FOR HYDROXYAPATITE RATHER THAN THE ANISOTROPIC VALUES GIVEN IN THAT PAPER, WHICH WERE RECENTLY RETRIEVED THROUGH MOLECULAR DYNAMICS SIM- 
ulations of Mostafa And Brown [2007]. The REAson for that IS THREEFold: (I) THE ANISOTROPIC PROPERTIES OF STOICHIOMETRIC HYDROXYAPATITE HAVE NOT BEEN DIRECTLY MEASURED, BUT INFERRED FROM THOSE MEASURED ON FLUORAPATITE AND FROM THE SIMILARITIES IN THE CRYSTAL STRUCTURES OF FLUORAPATITE AND STOICHIOMETRIC HYDROXAYAPATITE (SEE [KATZ AND UKRAINCIK, 1971] FOR DETAILS); (II) BONE MINERAL IS NOT STOICHIOMETRIC HYDROXYAPATITE, BUT CHARACTERIZED BY IMPURITIES AND LOWER CRYSTALLINITY [EPPLE, 2001] - HENCE, BY A MORE ISOTROPIC MATERIAL BEHAVIOR THAN THAT OF STOICHIOMETRIC HYDROXYAPATITE; (III) THE EXTENT OF ANISOTROPY OF HYDROXYAPATITE (SOMEWHERE BETWEEN THE ISOTROPIC AND THE FLUORAPATITE-DERIVED ANISOTROPIC LIMIT CASES) DOES VIRTUALLY NOT AFFECT THE OVERALL HOMOGENIZED ELASTIC BEHAVIOR OF THE EXTRAFIBRILLAR POROUS POLYCRYSTAL (WITH LARGELY DISORDERED MINERAL ORIENtations) of Figure 3(c), AS WE HAVE SHOWN IN [Fritsch ET AL., 2006].

WHILE NUMEROUS STEERED MOLECULAR DYNAMICS SIMULATIONS AIMED AT ESTIMATION OF THE STIFFNESS OF one single collagen molecule - or more precisely, of a somehow characteristic portion of such a very long molecule with an aspect ratio of 1:300 [LoREnzo AND CAFFARENA, 2005, VESENTini ET AL., 2005A, Buehler, 2006B, 2007, Gautieri et Al., 2008, Buehler, 2008, Gautieri et Al., 2009], the 'MOlecular COllagen' PHASE intRoducEd in THE RVE OF WET COLLAGEN [Figure 3(A)] DOES NEITHER RELATE TO A SINGLE COLLAGEN MOLECULE (NOR TO PORTIONS OF SUCH A MOLECUle), BUt TO THE MATERIAL BUILDING UP THE COLLAGEN NETWORKS IN THE MICROFIBRIL [WHICH ARE BEAUTIFULLY DEPICTED IN THE ELECTRON DENSITy MAPS OF ORGEL ET AL. [2006], SEE Figure 1(A)]. AcCordingly, We need experimental access to the STIFFNESS OF THE ENTITY OF COLLAGEN MOLECULES INCLUSIVE OF THE 
CROSSLINKS BINDING THEM TOGETHER, BUT EXCLUSIVE OF THE INTERMOLECULAR SPACE (WHICH IS MODELLED AS SEPARATE MATERIAL PHASE). Therefore, We Remember LeEs's Result [LEes et AL., 1984A, Bonar ET AL., 1985, LEES, 1987], THAT DRIED COLlAGEN IS VERY DENSELY PACKED, REDUCING THE INTERMOLECULAR SPACE TO A NEGLIGIBLE SIZE. ACCORdingly, DRIEd COllageneous tissues ARE The PRime CANDiDATES FOR DELIVERING THE ELASTICITY OF THE MATERIAL PHASE 'MOLECULAR COLlagen'. SuCH TISSUES (NAMELY DRIED RAT TAIL TENDON) WERE Tested in 3D By Cusack And Miller [1979]: They sent Waves WITh WAVE LENGTHS OF SEVERAL HUNDRED NANOMETERS THROUGH THE TISSUES, AND THEREFORE MEASURED CONTINUUM PROPERTIES AT A SCALE OF SEVERAL TENS OF NANOMETERS (RATHER THAN PROPERTIES OF ONE SINGle Collagen molecule). These experiments come the Closest to OUR MODELING APPROACH, SO THAT THEIR RESUlTS (GIVEN IN TABLE 1) ARE THE BASIS FOR OUR MICROMECHANICAL MODEL, AS THEY WERE FOR its PURELY (PORO-)ELASTiC PREDECESSORS [Hellmich ET AL., 2004B,A, Hellmich And Ulm, 2005, Fritsch AND Hellmich, 2007, Hellmich ET AL., 2009].

\subsection{Model limitations and potential model extensions}

IT IS ALSO APPROPRIATE TO STATE THE LIMITATIONS OF THE PROPOSED MODEL: WHILE IT SATISFACTORY PREDICTS BONE STRENGTH VALUES FROM TISSUE-SPECIFIC COMPOSITION, IT MAKES NO PREDICTIONS FOR TOUGHNess. Consequently, it MAY BeCOME A WELL-Suited TOOL FOR SAFETy ASSESSMENT OF SKELETAL STRUCTURES IN HEALTH AND DisEASE (CONTRIBUTING TO ANSWER QUESTIONS SUCH AS 'HOW FAR IS THE BONE MATERIAL FROM FAILURE?' OR 'DO THE APPLIED LOADS INDUCE DANGEROUS FAILURE RISK?'), WHEREAS, IN ITS PRESENT FORM, IT DOES NOT CONTRIBUte TO ANSWER QUESTIONS LIKE 'How LONG DOES THE MATE- 
RIAL SUSTAin LOADS IN The POST PEAK REGIME?'. Possible EXtensions OF THE MODEL IN THIS DIRECTION WOULD PROBABLY NEED TO EXPLICITLY CONSIDER 'SLIDING-TYPE' MECHANISMS RELATIVE TO THE MOLECULAR COLLAGEN PHASE. IN A RATHER QUALITATIVE THAN STRICTLY QUANTITATIVE WAY, A SIMILAR 'SLIPPING AT THE INTERFACE BETWEEN HYDROXYAPATITE AND TROPOCOLLAGEN' HAS RECENTLY BEEN SUGGESTED AS TOUGHNESS-GOVERNING FEATURE IN MINERALIZED COLLAGEN FIBRILS [Buehler, 2007]. Corresponding Simulations Were Performed FOR SOLVATED COLLAGEN MOLECULES, WHICH SEEMS TO UNDERLINE THE ROLE OF WATER IN SUCH SLIPPING/GLIDING MECHANISMS, WHICH WAS KEY TO THE PERFORMANCE OF THE MICROMECHANICS MODEL PRESENTED HEREIN. TOUGHNESS-INCREASING GLIDING MECHANISMS HAVE BEEN ALSO SUGGESTED IN THE FORM OF 'SACRIFICIAL BONDS' BETWEEN OR WITHIN COLLAGEN molecules [Thompson et Al., 2001, FAntner ET AL., 2006, Hansma ET AL., 2007].

Potential Future MOdeling of inelastic Behavior of the MOLECULAR COLLAGEN PHASE ALSO EVOKES THE QUESTION ON THE BRITTLENESS OF THIS PHASE (QUASI-BRITTLE EXPERIMENTAL RESULTS WERE REFERRED TO IN SECTION 4.2): IT WAS SHOWN EXPERIMENTALLY [TORP ET AL., 1975, BAiley ET AL., 1998] AND COMPUTATIONALly [BuEhleR, 2008] THAT COLLAGEN BRITTLENESS INCREASES WITH CROSSLINK DENSITY, WITH A SOFT AND DUCTILE GEL AT THE LOWER CROSSLINK DENSITY LIMIT. AN EVEN MORE DETAILLED MODEL FOR BONE'S POST-PEAK BEHAVIOR COULD ALSO DISTINGUISH BETWEEN INTERMOLECULAR CROSSLINKS (BETWEEN DIFFERENT COLLAGEN MOLECULES) AND CROSSLINKS BETWEEN DIFFERENT FIBRILS. 


\section{Conclusion and Perspectives}

We have proposed a first multiscale micromechanics model for bone strength, extending earlier developments in the realm of elasticity [Hellmich et al., 2004a, Fritsch and Hellmich, 2007]. Thereby, the explanation of bone strength across different species and ages required resolution of the mineral phase into an infinite amount of non-spherical phases, and definition of an elastoplastic failure criterion for the mineral crystals, reflecting layered water-induced ductile sliding between these mineral crystals. The multiscale material model was validated through independent experimental results: Tissue-specific strength values predicted by the micromechanical model on the basis of tissue-independent ('universal') stiffnesses and strengths of the elementary components (mineral, collagen, water), for tissue-specific composition data (volume fractions) were compared to corresponding experimentally determined tissue-specific strength values. Mean relative errors between stiffness experiments and model estimates were well below $10 \%$, which, given remarkable experimental scattering, is considered satisfactory.

This renders the model ready for supporting various future scientific as well as application-oriented activities:

(1) As was already shown for elasticity [Hellmich et al., 2008], the model is expected to be combined with computer tomographic images: Based on average relations from X-ray physics, the voxel-specific X-ray attenuation information would be translated to voxel-specific material composition; and the latter would serve as input for the micromechanical model, which would then deliver voxel-specific (anisotropic and inhomogeneous) stiffness and strength values. In this way, the current activities concerning the virtual physiological human [Taylor et al., 2002, Yosibash et al., 2007, Viceconti et al., 2008], could be extended from the realm of elasticity to that of full elastoplasticity, resulting in patient-specific fracture risk as- 
sessment of whole organs in both healthy and pathological conditions.

(2) The proposed model could also support the design of tissue engineering scaffolds, through predictions of the failure properties of bone tissueengineering scaffolds with tissue-engineered bone, by feeding recently developed multiscale representations [Bertrand and Hellmich, 2009] not only with an elastic, but with the present elastoplastic micromechanical representation of the extracellular bone material.

(3) Since the proposed model is linked to the hierarchical organization of bone and to its elementary components, it is ready to be combined with most recent developments in theoretical and computational biochemistry and biology, which quantify the well-tuned interplay of biological cells via biochemical signaling pathways [Lemaire et al., 2004, Pivonka et al., 2008] - giving as output the volume fraction of newly deposited or resorbed extravascular bone, which may serve as input for the proposed multiscale strength model. That is expected to open the way to translation of biochemical remodeling events to associated changes in mechanical competence. 


\section{Appendices}

\section{A Hill tensors $\mathbb{P}$}

\section{A.1 Hill tensor for homogenization over wet collagen}

$\mathbb{P}_{c y l}^{c o l}$ refers to a cylindrical inclusion in a transversely isotropic matrix with stiffness $\mathbb{C}_{c o l}$, where the plane of isotropy is oriented perpendicular to the long axis of the cylinder. The non-zero components of the symmetric tensor $\mathbb{P}_{c y l}^{c o l}$ read as follows [Hellmich et al., 2004a, Levin et al., 2000]:

$$
\begin{aligned}
& P_{c y l, 1111}^{c o l}=P_{c y l, 2222}^{c o l}=1 / 8\left(5 c_{c o l, 1111}-3 c_{c o l, 1122}\right) / c_{c o l, 1111} / \mathcal{D}_{2}, \\
& P_{c y l, 1122}^{c o l}=P_{c y l, 2211}^{c o l}=-1 / 8\left(c_{c o l, 1111}+c_{c o l, 1122}\right) / c_{c o l, 1111} / \mathcal{D}_{2}, \\
& P_{c y l, 2323}^{c o l}=P_{c y l, 1313}^{c o l}=1 /\left(8 c_{c o l, 2323}\right), \\
& P_{c y l, 1212}^{c o l}=1 / 8\left(3 c_{c o l, 1111}-c_{c o l, 1122}\right) / c_{c o l, 1111} / \mathcal{D}_{2},
\end{aligned}
$$

whereby

$$
\mathcal{D}_{2}=c_{c o l}, 1111-c_{c o l, 1122}
$$

\section{A.2 Hill tensors for homogenization over mineralized collagen fibril}

The non-zero components of $\mathbb{P}_{c y l}^{f i b}$ follow from substitution of ' $c_{c o l, i j k l}$ ' by ' $C_{f i b, i j k l}^{S C S}$ ' in (A.1)-(A.5). The non-zero components of $\mathbb{P}_{s p h}^{f i b}$ for spherical inclusions in a transversely isotropic matrix follow from substitution of ' $C_{i j k l}^{0}$ ' by ' $C_{f i b, i j k l}^{S C S}$ ' in the following equations:

$$
\begin{aligned}
& P_{s p h, 1111}^{0}=\frac{1}{16} \int_{-1}^{1}-\left(-5 C_{1111}^{0} x^{4} C_{3333}^{0}-3 C_{1122}^{0} x^{2} C_{3333}^{0}-3 C_{1122}^{0} x^{4} C_{2323}^{0}\right. \\
& +3 C_{1122}^{0} x^{4} C_{3333}^{0}+5 C_{1111}^{0} x^{4} C_{2323}^{0}-10 C_{1111}^{0} C_{2323}^{0} x^{2}+2 x^{4} C_{1133}^{0,2} \\
& +8 C_{2323}^{0} x^{4} C_{3333}^{0}-6 C_{2323}^{0,2} x^{4}+4 C_{2323}^{0} x^{4} C_{1133}^{0}+6 C_{1122}^{0} C_{2323}^{0} x^{2} \\
& +5 C_{1111}^{0} C_{2323}^{0}+5 C_{1111}^{0} x^{2} C_{3333}^{0}-4 C_{2323}^{0} x^{2} C_{1133}^{0}+6 C_{2323}^{0,2} x^{2} \\
& \left.-2 x^{2} C_{1133}^{0,2}-3 C_{1122}^{0} C_{2323}^{0}\right)\left(-1+x^{2}\right) / \mathcal{D}_{1} d x
\end{aligned}
$$




$$
\begin{aligned}
& P_{s p h, 1122}^{0}=P_{s p h, 2211}^{0}=\frac{1}{16} \int_{-1}^{1}\left(C_{1111}^{0} C_{2323}^{0}-2 C_{1111}^{0} C_{2323}^{0} x^{2}+C_{1111}^{0} x^{2} C_{3333}^{0}\right. \\
& +C_{1122}^{0} C_{2323}^{0}-2 C_{1122}^{0} C_{2323}^{0} x^{2}+C_{1122}^{0} x^{2} C_{3333}^{0}+C_{1111}^{0} x^{4} C_{2323}^{0}-C_{1111}^{0} x^{4} C_{3333}^{0} \\
& +C_{1122}^{0} x^{4} C_{2323}^{0}-C_{1122}^{0} x^{4} C_{3333}^{0}-2 C_{2323}^{0,2} x^{2}+2 C_{2323}^{0,2} x^{4}-4 C_{2323}^{0} x^{2} C_{1133}^{0} \\
& \left.+4 C_{2323}^{0} x^{4} C_{1133}^{0}-2 x^{2} C_{1133}^{0,2}+2 x^{4} C_{1133}^{0,2}\right)\left(-1+x^{2}\right) / \mathcal{D}_{1} d x \\
& P_{s p h, 1133}^{0}=P_{s p h, 3311}^{0}=\frac{1}{4} \int_{-1}^{1}\left(-1+x^{2}\right) x^{2}\left(C_{2323}^{0}+C_{1133}^{0}\right) / \mathcal{D}_{2} d x \\
& P_{s p h, 2323}^{0}=\frac{1}{16} \int_{-1}^{1}\left(4 C_{1111}^{0} C_{2323}^{0} x^{2}-8 C_{2323}^{0} x^{4} C_{1133}^{0}-2 x^{4} C_{1133}^{0,2}-C_{1122}^{0} x^{4} C_{3333}^{0}\right. \\
& -8 C_{1111}^{0} x^{4} C_{2323}^{0}+3 C_{1111}^{0} x^{4} C_{3333}^{0}+4 C_{1111}^{0} x^{4} C_{1133}^{0}-4 C_{1122}^{0} x^{4} C_{1133}^{0} \\
& +2 C_{1122}^{0} x^{6} C_{1133}^{0}-2 C_{1111}^{0} x^{6} C_{1133}^{0}+C_{1122}^{0} x^{6} C_{1111}^{0}-3 C_{1122}^{0} x^{4} C_{1111}^{0} \\
& +3 C_{1122}^{0} C_{1111}^{0} x^{2}-2 C_{1111}^{0} x^{2} C_{1133}^{0}+2 C_{1122}^{0} x^{2} C_{1133}^{0}+8 x^{6} C_{2323}^{0} C_{1133}^{0} \\
& -3 x^{6} C_{1111}^{0} C_{3333}^{0}+4 x^{6} C_{2323}^{0} C_{3333}^{0}+4 C_{1111}^{0} x^{6} C_{2323}^{0}+C_{1122}^{0} x^{6} C_{3333}^{0}+3 C_{1111}^{0,2} x^{4} \\
& \left.-C_{1111}^{0,2} x^{6}+2 C_{1133}^{0,2} x^{6}-3 C_{1111}^{0,2} x^{2}+C_{1111}^{0,2}-C_{1122}^{0} C_{1111}^{0}\right) / \mathcal{D}_{1} d x \\
& P_{s p h, 3333}^{0}=\frac{1}{2} \int_{-1}^{1} x^{2}\left(x^{2} C_{2323}^{0}-C_{1111}^{0} x^{2}+C_{1111}^{0}\right) / \mathcal{D}_{2} d x
\end{aligned}
$$

whereby

$$
\begin{aligned}
& \mathcal{D}_{1}=-2 C_{1111}^{0,2} x^{4} C_{3333}^{0}+2 C_{2323}^{0,2} x^{6} C_{3333}^{0}-4 C_{1111}^{0} C_{2323}^{0,2} x^{4}-3 C_{1111}^{0,2} C_{2323}^{0} x^{2}+C_{1111}^{0,2} x^{2} C_{3333}^{0}+ \\
& 2 C_{1111}^{0} C_{2323}^{0,2} x^{2}-2 C_{2323}^{0} x^{4} C_{1133}^{0,2}-C_{1111}^{0} C_{1133}^{0,2} x^{6}+2 C_{1111}^{0} C_{1133}^{0,2} x^{4}+4 C_{2323}^{0,2} x^{6} C_{1133}^{0} \\
& -2 C_{1122}^{0} C_{1133}^{0,2} x^{4}+2 C_{2323}^{0} x^{6} C_{1133}^{0,2}+3 C_{1111}^{0,2} x^{4} C_{2323}^{0}+C_{1122}^{0} C_{1133}^{0,2} x^{6}-C_{1111}^{0,2} x^{6} C_{2323}^{0} \\
& +2 C_{1111}^{0} x^{6} C_{2323}^{0,2}+C_{1111}^{0,2} x^{6} C_{3333}^{0}-C_{1111}^{0} C_{1133}^{0,2} x^{2}-4 C_{2323}^{0,2} x^{4} C_{1133}^{0}+C_{1122}^{0} C_{1133}^{0,2} x^{2} \\
& +C_{1111}^{0,2} C_{2323}^{0}-C_{1122}^{0} C_{1111}^{0} C_{2323}^{0}-C_{1122}^{0} x^{6} C_{1111}^{0} C_{3333}^{0}+4 C_{1111}^{0} x^{4} C_{2323}^{0} C_{1133}^{0}-2 C_{1111}^{0} x^{2} C_{2323}^{0} C_{1133}^{0} \\
& -4 C_{1122}^{0} x^{4} C_{2323}^{0} C_{1133}^{0}+2 C_{1122}^{0} x^{2} C_{2323}^{0} C_{1133}^{0}+2 C_{1122}^{0} x^{6} C_{2323}^{0} C_{1133}^{0}-2 C_{1111}^{0} x^{6} C_{2323}^{0} C_{1133}^{0} \\
& -3 C_{1111}^{0} x^{6} C_{2323}^{0} C_{3333}^{0}+2 C_{1122}^{0} C_{1111}^{0} x^{4} C_{3333}^{0}-C_{1122}^{0} C_{2323}^{0} x^{4} C_{3333}^{0}-3 C_{1122}^{0} C_{1111}^{0} x^{4} C_{2323}^{0} \\
& -C_{1122}^{0} C_{1111}^{0} x^{2} C_{3333}^{0}+3 C_{1122}^{0} C_{1111}^{0} C_{2323}^{0} x^{2}+3 C_{1111}^{0} C_{2323}^{0} x^{4} C_{3333}^{0}+C_{1122}^{0} x^{6} C_{1111}^{0} C_{2323}^{0} \\
& +C_{1122}^{0} x^{6} C_{2323}^{0} C_{3333}^{0}
\end{aligned}
$$

and

$$
\begin{aligned}
& \mathcal{D}_{2}=2 C_{2323}^{0} x^{4} C_{1133}^{0}+C_{2323}^{0} x^{4} C_{3333}^{0}+C_{1111}^{0} x^{4} C_{2323}^{0}-2 C_{2323}^{0} x^{2} C_{1133}^{0}-2 C_{1111}^{0} C_{2323}^{0} x^{2} \\
& +C_{1111}^{0} C_{2323}^{0}+x^{4} C_{1133}^{0,2}-C_{1111}^{0} x^{4} C_{3333}^{0}-x^{2} C_{1133}^{0,2}+C_{1111}^{0} x^{2} C_{3333}^{0}
\end{aligned}
$$




\section{A.3 Hill tensors for homogenization over extrafibrillar space}

$\mathbb{P}_{s p h}^{e f}$, the Hill tensor for a spherical inclusion in an isotropic matrix of stiffness $\mathbb{C}_{e f}^{S C S I I}$, is of the form [Eshelby, 1957, Zaoui, 1997]

$$
\begin{gathered}
\mathbb{P}_{s p h}^{e f}=\mathbb{S}_{s p h}^{e s h, e f}: \mathbb{C}_{e f}^{S C S I I,-1}, \\
\mathbb{S}_{s p h}^{e s h, e f}=\alpha_{e f}^{S C S I I} \mathbb{J}+\beta_{e f}^{S C S I I} \mathbb{K}
\end{gathered}
$$

with

$$
\begin{aligned}
\alpha_{e f}^{S C S I I} & =\frac{3 k_{e f}^{S C S I I}}{3 k_{e f}^{S C S I I}+4 \mu_{e f}^{S C S I I}} \\
\beta_{e f}^{S C S I I} & =\frac{6\left(k_{e f}^{S C S I I}+2 \mu_{e f}^{S C S I I}\right)}{5\left(3 k_{e f}^{S C S I I}+4 \mu_{e f}^{S C S I I}\right)}
\end{aligned}
$$

$\mathbb{P}_{c y l}^{e f}$, the Hill tensor for a cylindrical inclusion in an isotropic matrix, is of the form

$$
\mathbb{P}_{c y l}^{e f}=\mathbb{S}_{c y l}^{e s h}: \mathbb{C}_{e f}^{S C S I I,-1}
$$

The non-zero components of the Eshelby tensor $\mathbb{S}_{c y l}^{e s h}$ corresponding to cylindrical inclusions read as

$$
\begin{array}{r}
S_{c y l, 1111}^{e s h}=S_{c y l, 2222}^{e s h}=\frac{5-4 \nu_{e f}^{S C S I I}}{8\left(1-\nu_{e f}^{S C S I I}\right)} \\
S_{c y l, 1122}^{e s h}=S_{c y l, 2211}^{e s h}=\frac{-1+4 \nu_{e f}^{S C S I I}}{8\left(1-\nu_{e f}^{S C S I I}\right)} \\
S_{c y l, 1133}^{e s h}=S_{c y l, 2233}^{e s h}=\frac{\nu_{e f}^{S C S I I}}{2\left(1-\nu_{e f}^{S C S I I}\right)} \\
S_{c y l, 2323}^{e s h}=S_{c y l, 3232}^{e s h}=S_{c y l, 3223}^{e s h}=S_{c y l, 2332}^{e s h}= \\
=S_{c y l, 3131}^{e s h}=S_{c y l, 1313}^{e s h}=S_{c y l, 1331}^{e s h}=S_{c y l, 3113}^{e s h}=\frac{1}{4} \\
S_{c y l, 1212}^{e s h}=S_{c y l, 2121}^{e s h}=S_{c y l, 2112}^{e s h}=S_{c y l, 1221}^{e s h}=\frac{3-4 \nu_{e f}^{S C S I I}}{8\left(1-\nu_{e f}^{S C S I I}\right)}
\end{array}
$$


where principal directions 1, 2, and 3 follow Figure 3, and with $\nu_{e f}^{S C S I I}$ as Poisson's ratio of the extrafibrillar space,

$$
\nu_{e f}=\frac{3 k_{e f}^{S C S I I}-2 \mu_{e f}^{S C S I I}}{6 k_{e f}^{S C S I I}+2 \mu_{e f}^{S C S I I}}
$$

Following standard tensor calculus [Salencon, 2001], the tensor components of $\mathbb{P}_{c y l}^{e f}(\vartheta, \varphi)$, being related to differently oriented inclusions, are transformed into one, single base frame $\left(\underline{e}_{1}, \underline{e}_{2}, \underline{e}_{3}\right)$, in order to evaluate the integrals in Eq. (27).

A.4 Hill tensor for homogenization over extracellular bone matrix

$\mathbb{P}_{c y l}^{e f}$, the Hill tensor for a cylindrical inclusion in an isotropic matrix, is given in Eq. A.16.

\section{A.5 Hill tensor for homogenization over extravascular bone material}

The non-zero components of $\underset{s p h}{\text { excel }}$ for spherical inclusions in a transversely isotropic matrix follow from substitution of ' $c_{i j k l}^{0}$ ' by ' $C_{e x c e l, i j k l}^{M T I I}$ ' in Eqs (A.6)(A.12).

\section{A.6 Hill tensor for homogenization over cortical bone material}

The non-zero components of $\mathbb{P}_{c y l}^{\text {exvas }}$ for cylindrical inclusions in a transversely isotropic matrix follow from substitution of ' $c_{c o l, i j k l}$ ' by ' $C_{\text {exvas,ijkl }}^{\text {MTIII }}$ in Eqs (A.1)(A.5). 


\section{Nomenclature}

\begin{tabular}{|c|c|}
\hline$a_{c s}$ & side length of reduced cross section of a bone specimen \\
\hline $\mathbb{a}_{r s}$ & fourth-order influence tensor \\
\hline $\mathcal{A}$ & constant in the linear relationship between $\rho_{\text {excel }}$ and $\bar{f}_{H A}$ \\
\hline $\mathbb{A}_{r}$ & fourth-order strain concentration tensor of phase $r$ \\
\hline$b$ & width of a volume of one rhomboidal fibrillar unit \\
\hline $\mathcal{B}$ & constant in the linear relationship between $\rho_{\text {excel }}$ and $\bar{f}_{H A}$ \\
\hline $\mathbb{C}_{c o l}$ & fourth-order stiffness tensor of molecular collagen \\
\hline$c_{c o l, i j k l}$ & component of fourth-order stiffness tensor of molecular collagen \\
\hline $\mathcal{C}$ & constant in the linear relationship between $\rho_{\text {excel }}$ and $d_{s}$ \\
\hline $\mathbb{C}_{\text {cort }}^{M T I V}$ & homogenized fourth-order stiffness tensor of cortical bone material \\
\hline $\mathbb{C}_{e f}^{S C S I I}$ & homogenized fourth-order stiffness tensor of extrafibrillar space \\
\hline $\mathbb{C}_{\text {excel }}^{M T I I}$ & homogenized fourth-order stiffness tensor of extracellular bone matrix \\
\hline $\mathbb{C}_{\text {exvas }}^{M T I I I}$ & homogenized fourth-order stiffness tensor of extravascular bone material \\
\hline $\mathbb{C}_{f i b}^{S C S}$ & homogenized fourth-order stiffness tensor of mineralized collagen fibril \\
\hline $\mathbb{C}_{H A}$ & fourth-order stiffness tensor of hydroxyapatite \\
\hline $\mathbb{C}_{i c}$ & fourth-order stiffness tensor of intercrystalline space \\
\hline $\mathbb{C}_{i m}$ & fourth-order stiffness tensor of intermolecular water \\
\hline $\mathbb{C}_{i n c}$ & $\begin{array}{l}\text { fourth-order stiffness tensor of an inclusion embedded in a matrix } \\
\text { with stiffness } \mathbb{C}^{0}\end{array}$ \\
\hline $\mathbb{C}_{l a c}$ & fourth-order stiffness tensor of lacunae \\
\hline $\mathbb{C}_{M}$ & fourth-order stiffness tensor of the matrix phase \\
\hline $\mathbb{C}_{r}$ & fourth-order stiffness tensor of phase $r$ \\
\hline $\mathbb{C}_{\text {vas }}$ & fourth-order stiffness tensor of Haversian canals \\
\hline $\mathbb{C}_{\text {wetcol }}^{M T}$ & homogenized fourth-order stiffness tensor of wet collagen \\
\hline $\mathbb{C}^{h o m}$ & homogenized fourth-order stiffness tensor \\
\hline $\mathbb{C}^{0}$ & $\begin{array}{l}\text { fourth-order stiffness tensor of an infinite matrix surrounding an } \\
\text { ellipsoidal inclusion }\end{array}$ \\
\hline$d$ & characteristic length of the inhomogeneities within an RVE \\
\hline
\end{tabular}




\begin{tabular}{|c|c|}
\hline$d_{c s}$ & diameter of reduced cross section of a bone specimen \\
\hline$d_{s}$ & neutron diffraction spacing between collagen molecules \\
\hline$d_{S}$ & diameter of a bone specimen \\
\hline$D$ & $1 / 5$ of length of a volume of one rhomboidal fibrillar unit \\
\hline $\mathcal{D}$ & constant in the linear relationship between $\rho_{\text {excel }}$ and $d_{s}$ \\
\hline $\boldsymbol{E}$ & second-order 'macroscopic' strain tensor \\
\hline $\boldsymbol{E}_{r}$ & second-order 'macroscopic' strain tensor of phase $r$ \\
\hline $\boldsymbol{E}_{r, n}, \boldsymbol{E}_{r, n+1}$ & $\begin{array}{l}\text { second-order 'macroscopic' strain tensors of phase } r \text { for load steps } n \\
\text { and } n+1 \text {, respectively }\end{array}$ \\
\hline $\boldsymbol{E}_{r, n}^{p}, \boldsymbol{E}_{r, n+1}^{p}$ & $\begin{array}{l}\text { second-order 'macroscopic' plastic strain tensors of phase } r \text { for load } \\
\text { steps } n \text { and } n+1 \text {, respectively }\end{array}$ \\
\hline $\boldsymbol{E}_{r, n+1}^{p(k)}$ & $\begin{array}{l}k \text {-th approximation of second-order 'macroscopic' plastic strain tensor } \\
\text { of phase } r \text { for load step } n+1\end{array}$ \\
\hline $\boldsymbol{E}_{r, n+1}^{t r i a l}$ & $\begin{array}{l}\text { second-order 'macroscopic' trial strain tensor of phase } r \text { for load } \\
\text { step } n+1\end{array}$ \\
\hline $\boldsymbol{E}^{p}$ & second-order 'macroscopic' plastic strain tensor \\
\hline $\boldsymbol{E}^{0, p}$ & uniform 'macroscopic' plastic strain in matrix of a matrix-inclusion problem \\
\hline $\boldsymbol{E}^{\infty}$ & uniform 'macroscopic' strain at infinity of a matrix-inclusion problem \\
\hline$\underline{e}_{1}, \underline{e}_{2}, \underline{e}_{3}$ & unit base vectors of Cartesian reference base frame \\
\hline$\underline{e}_{\vartheta}, \underline{e}_{\varphi}, \underline{e}_{r}$ & $\begin{array}{l}\text { unit base vectors of Cartesian local base frame of a single crystal of } \\
\text { hydroxyapatite within extrafibrillar space }\end{array}$ \\
\hline $\mathfrak{f}_{r}\left(\boldsymbol{\sigma}_{r}\right)$ & boundary $r$ of elastic domain of phase $r$ in space of microstresses \\
\hline $\bar{f}_{c o l}$ & volume fraction of collagen within an RVE $\bar{V}_{e x c e l}$ \\
\hline$\stackrel{\circ}{f}_{c o l}$ & volume fraction of molecular collagen within an RVE $\stackrel{\circ}{V}_{\text {wetcol }}$ \\
\hline $\bar{f}_{e f}$ & volume fraction of extrafibrillar space within an RVE $\bar{V}_{\text {excel }}$ \\
\hline$\tilde{f}_{\text {excel }}$ & volume fraction of extracellular bone matrix within an RVE $\tilde{V}_{\text {exvas }}$ \\
\hline$f_{\text {exvas }}$ & volume fraction of extravascular bone material within an $\mathrm{RVE} V_{\text {cort }}$ \\
\hline $\bar{f}_{f i b}$ & volume fraction of mineralized collagen fibril within an $\operatorname{RVE} \bar{V}_{\text {excel }}$ \\
\hline $\bar{f}_{H A}$ & volume fraction of hydroxyapatite within an RVE $\bar{V}_{\text {excel }}$ \\
\hline$\breve{f}_{H A}$ & volume fraction of hydroxyapatite within an RVE $\breve{V}_{f i b}$ \\
\hline
\end{tabular}


$\check{f}_{H A} \quad$ volume fraction of hydroxyapatite within an RVE $\check{V}_{e f}$

$\bar{f}_{\mathrm{H}_{2} \mathrm{O}} \quad$ volume fraction of water within an RVE $\bar{V}_{\text {excel }}$

$\check{f}_{i c} \quad$ volume fraction of intercrystalline space within an RVE $\check{V}_{e f}$

$\stackrel{\circ}{f m}_{i m}$ volume fraction of intermolecular water within an RVE $\stackrel{\circ}{V}_{\text {wetcol }}$

$\tilde{f}_{l a c} \quad$ volume fraction of lacunae within an RVE $\tilde{V}_{\text {exvas }}$

$\bar{f}_{\text {org }} \quad$ volume fraction of organic matter within an RVE $\bar{V}_{\text {excel }}$

$f_{r} \quad$ volume fraction of phase $r$

$f_{\text {vas }} \quad$ volume fraction of Haversian canals within an RVE $V_{\text {cort }}$

$\breve{f}_{\text {wetcol }}$ volume fraction of wet collagen within an RVE $\breve{V}_{f i b}$

HA hydroxyapatite

1 fourth-order identity tensor

$\sqrt{ } \quad$ volumetric part of fourth-order identity tensor 『

$\mathbb{K} \quad$ deviatoric part of fourth-order identity tensor $\mathbb{}$

$k_{H A} \quad$ bulk modulus of hydroxyapatite

$k_{\mathrm{H}_{2} \mathrm{O}} \quad$ bulk modulus of water

$\mathcal{L} \quad$ characteristic lengths of geometry or loading of a structure built up by the material defined on the RVE

$l_{S} \quad$ length of a bone specimen

$\ell \quad$ characteristic length of an RVE

$\ell_{\text {cort }} \quad$ characteristic length of an RVE $V_{\text {cort }}$ of cortical bone material

$\ell_{e f} \quad$ characteristic length of an RVE $\check{V}_{e f}$ of extrafibrillar space

$\ell_{\text {excel }}$ characteristic length of an RVE $\bar{V}_{\text {excel }}$ of extracellular bone matrix

$\ell_{\text {exvas }}$ characteristic length of an RVE $\tilde{V}_{\text {exvas }}$ of extravascular bone material

$\ell_{f i b} \quad$ characteristic length of an RVE $\breve{V}_{f i b}$ of mineralized collagen fibril

$\ell_{\text {wetcol }}$ characteristic length of an RVE $\stackrel{\circ}{V}_{c o l}$ of wet collagen

$M \quad$ index denoting a material phase being the matrix

$\underline{N} \quad$ orientation vector aligned with longitudinal axis of hydroxyapatite needle

$n_{r} \quad$ number of material phases within an RVE

$\underline{n} \quad$ orientation vector perpendicular to $\underline{N}$

RVE representative volume element 


\begin{tabular}{|c|c|}
\hline$r$ & index denoting a material phase \\
\hline $\mathbb{P}_{i n c}^{0}$ & $\begin{array}{l}\text { fourth-order Hill tensor characterizing the interaction between the inclusion } \\
\text { inc and the matrix } \mathbb{C}^{0}\end{array}$ \\
\hline $\mathbb{P}_{r}^{0}$ & $\begin{array}{l}\text { fourth-order Hill tensor characterizing the interaction between the phase } r \\
\text { and the matrix } \mathbb{C}^{0}\end{array}$ \\
\hline $\operatorname{sgn}()$. & signum function of quantity (.) \\
\hline $\mathbb{S}$ & fourth-order Eshelby tensor for spherical inclusions \\
\hline$v_{c o l}$ & volume of a single collagen molecule \\
\hline$v_{f i b}$ & volume of one rhomboidal fibrillar unit \\
\hline$\stackrel{\circ}{V}_{c o l}$ & volume of molecular collagen within an RVE $\stackrel{\circ}{V}_{\text {wetcol }}$ \\
\hline$V_{\text {cort }}$ & volume of RVE 'cortical bone material' \\
\hline$\check{V}_{e f}$ & volume of RVE 'extrafibrillar space' \\
\hline $\bar{V}_{e f}$ & volume of extrafibrillar space within an RVE $\bar{V}_{\text {excel }}$ \\
\hline $\bar{V}_{\text {excel }}$ & volume of RVE 'extracellular bone matrix' \\
\hline$\tilde{V}_{\text {excel }}$ & volume of extracellular bone matrix within an RVE $\tilde{V}_{\text {exvas }}$ \\
\hline$\tilde{V}_{\text {exvas }}$ & volume of RVE 'extravascular bone material' \\
\hline$V_{\text {exvas }}$ & volume of extravascular bone material within an RVE $V_{\text {cort }}$ \\
\hline$\breve{V}_{f i b}$ & volume of RVE 'mineralized collagen fibril' \\
\hline $\bar{V}_{f i b}$ & volume of mineralized collagen fibril within an $\operatorname{RVE} \bar{V}_{\text {excel }}$ \\
\hline$\breve{V}_{H A}$ & volume of hydroxyapatite within an RVE $\breve{V}_{f i b}$ \\
\hline$\check{V}_{H A}$ & volume of hydroxyapatite within an RVE $\check{V}_{e f}$ \\
\hline$\check{V}_{i c}$ & volume of intercrystalline space within an RVE $\check{V}_{e f}$ \\
\hline$\stackrel{\circ}{V}_{i m}$ & volume of intermolecular water within an RVE $\stackrel{\circ}{V}_{\text {wetcol }}$ \\
\hline$\tilde{V}_{l a c}$ & volume of lacunae within an RVE $\tilde{V}_{\text {exvas }}$ \\
\hline$V_{\text {vas }}$ & volume of Haversian canals within an RVE $V_{\text {cort }}$ \\
\hline$\stackrel{\circ}{V}_{\text {wetcol }}$ & volume of RVE 'wet collagen' \\
\hline$\breve{V}_{\text {wetcol }}$ & volume of wet collagen within an RVE $\breve{V}_{f i b}$ \\
\hline$W F_{H A}^{c o r t}$ & weight fraction of hydroxyapatite at the scale of cortical bone material \\
\hline$W F_{H A}^{e x c e l}$ & weight fraction of hydroxyapatite at the extracellular scale \\
\hline$W F_{\text {org }}^{c o r t}$ & weight fraction of organic matter at the scale o \\
\hline
\end{tabular}




\begin{tabular}{|c|c|}
\hline$W F_{\text {org }}^{\text {excel }}$ & weight fraction of organic matter at the extracellular scale \\
\hline$\beta$ & ratio between uniaxial tensile strength and shear strength of pure HA \\
\hline$\Delta \boldsymbol{E}_{r, n+1}$ & $\begin{array}{l}\text { incremental second-order 'macroscopic' strain tensor of phase } r \text { for load } \\
\text { step } n+1\end{array}$ \\
\hline$\Delta \boldsymbol{E}_{r, n+1}^{p}$ & $\begin{array}{l}\text { incremental second-order 'macroscopic' plastic strain tensor of phase } r \\
\text { for load step } n+1\end{array}$ \\
\hline$\Delta \boldsymbol{E}_{r, n+1}^{p(k)}$ & $\begin{array}{l}k \text {-th approximation of incremental second-order 'macroscopic' plastic } \\
\text { strain tensor of phase } r \text { for load step } n+1\end{array}$ \\
\hline$\Delta \varepsilon_{n+1}^{p}$ & incrmental plastic strain of $n+1$-st load increment \\
\hline$\Delta \lambda_{H A, n+1}$ & incrmental plastic multiplier of $n+1$-st load increment \\
\hline$\varepsilon_{c o l}$ & second-order strain tensor field within molecular collagen \\
\hline$\varepsilon_{e f}$ & second-order strain tensor field within an RVE $\check{V}_{e f}$ of extrafibrillar space \\
\hline$\varepsilon_{\text {excel }}$ & $\begin{array}{l}\text { second-order strain tensor field within an RVE } \bar{V}_{\text {excel }} \text { of extracellular } \\
\text { bone matrix }\end{array}$ \\
\hline$\varepsilon_{\text {exvas }}$ & $\begin{array}{l}\text { second-order strain tensor field within an RVE } \tilde{V}_{\text {exvas }} \text { of extravascular } \\
\text { bone material }\end{array}$ \\
\hline$\varepsilon_{f i b}$ & $\begin{array}{l}\text { second-order strain tensor field within an RVE } \breve{V}_{f i b} \text { of mineralized } \\
\text { collagen fibril }\end{array}$ \\
\hline$\varepsilon_{H A \vartheta \varphi}$ & $\begin{array}{l}\text { second-order strain tensor field within oriented hydroxyapatite } \\
\text { needles in extrafibrillar space }\end{array}$ \\
\hline$\varepsilon_{i n c}$ & second-order strain tensor field within an inclusion embedded in matrix $\mathbb{C}^{0}$ \\
\hline$\varepsilon_{i n c}^{p}$ & $\begin{array}{l}\text { second-order plastic strain tensor field within an inclusion embedded } \\
\text { in matrix } \mathbb{C}^{0}\end{array}$ \\
\hline $\bar{\varepsilon}_{i j}$ & $\begin{array}{l}\text { tensor component of difference }\left(\varepsilon_{H A \varphi \vartheta, n+1}-\varepsilon_{H A \varphi \vartheta, n}^{p}\right) \text {, given } \\
\text { in a local base frame }\end{array}$ \\
\hline$\varepsilon_{M}^{p}$ & second-order plastic strain tensor field within the matrix phase \\
\hline$\varepsilon_{n}^{p}, \varepsilon_{n+1}^{p}$ & second-order strain tensor fields for load steps $n$ and $n+1$, respectively \\
\hline$\varepsilon_{r}$ & second-order 'microscopic' strain tensor field within phase $r$ \\
\hline$\dot{\theta}_{r}$ & incremental 'microscopic' second-order strain tensor field within phase $r$ \\
\hline
\end{tabular}




\begin{tabular}{|c|c|}
\hline$\varepsilon_{r}^{p}$ & second-order 'microscopic' plastic strain tensor field within phase $r$ \\
\hline$\varepsilon_{r}^{\text {trial }}$ & second-order 'microscopic' trial strain tensor field within phase $r$ \\
\hline$\varepsilon_{\text {wetcol }}$ & second-order strain tensor field within an RVE $\stackrel{\circ}{\text { col }}_{\text {of wet collagen }}$ \\
\hline$\dot{\lambda}_{r}$ & incremental plastic multiplier \\
\hline$\vartheta$ & latitudinal coordinate of spherical coordinate system \\
\hline$\theta$ & integration variable, $\theta=0 \ldots \pi$ \\
\hline$\mu_{H A}$ & shear modulus of hydroxyapatite \\
\hline$\mu_{H_{2} \mathrm{O}}$ & shear modulus of water \\
\hline$\rho_{\text {col }}$ & mass density of molecular collagen \\
\hline$\rho_{\text {cort }}$ & mass density of cortical bone material \\
\hline$\rho_{\text {excel }}$ & mass density of the extracellular bone matrix \\
\hline$\rho_{H A}$ & mass density of hydroxyapatite \\
\hline$\rho_{\mathrm{H}_{2} \mathrm{O}}$ & mass density of water \\
\hline$\rho_{\text {org }}$ & mass density of organic matter \\
\hline $\boldsymbol{\sigma}_{c o l}$ & second-order stress tensor field within molecular collagen \\
\hline$\sigma_{\text {col }}^{u l t}$ & uniaxial tensile or compressive strength of molecular collagen \\
\hline $\boldsymbol{\sigma}_{e f}$ & second-order stress tensor field within an RVE $\check{V}_{e f}$ of extrafibrillar space \\
\hline $\boldsymbol{\sigma}_{\text {excel }}$ & $\begin{array}{l}\text { second-order stress tensor field within an RVE } \bar{V}_{\text {excel }} \text { of extracellular } \\
\text { bone matrix }\end{array}$ \\
\hline $\boldsymbol{\sigma}_{\text {exvas }}$ & $\begin{array}{l}\text { second-order stress tensor field within an RVE } \tilde{V}_{\text {exvas }} \text { of extravascular } \\
\text { bone material }\end{array}$ \\
\hline $\boldsymbol{\sigma}_{f i b}$ & $\begin{array}{l}\text { second-order stress tensor field within an RVE } \breve{V}_{f i b} \text { of mineralized } \\
\text { collagen fibril }\end{array}$ \\
\hline $\boldsymbol{\sigma}_{H A \vartheta, \varphi}$ & $\begin{array}{l}\text { second-order stress tensor field within oriented hydroxyapatite needle } \\
\text { in extrafibrillar space }\end{array}$ \\
\hline$\sigma_{H A}^{N N}$ & normal component of stress tensor $\boldsymbol{\sigma}_{H A \vartheta \varphi}$ in needle direction \\
\hline$\sigma_{H A}^{N n}$ & $\begin{array}{l}\text { shear component of stress tensor } \boldsymbol{\sigma}_{H A \vartheta \varphi} \text { in planes orthogonal to the } \\
\text { needle direction }\end{array}$ \\
\hline $\boldsymbol{\sigma}_{H A \vartheta \varphi, n+1}^{\text {trial }}$ & second-order trial stress tensor field within oriented HA needle for \\
\hline
\end{tabular}




\begin{tabular}{|c|c|}
\hline & load step $n+1$ \\
\hline$\sigma_{H A}^{u l t, s}$ & uniaxial shear strength of pure HA \\
\hline$\sigma_{H A}^{u l t, t}$ & uniaxial tensile strength of pure HA \\
\hline $\boldsymbol{\sigma}_{r}$ & second-order stress tensor field within phase $r$ \\
\hline $\boldsymbol{\sigma}_{r}^{(k)}$ & $k$-th approximation of stress field within phase $r$ \\
\hline $\boldsymbol{\sigma}_{\text {wetcol }}$ & second-order stress tensor field within an RVE $\stackrel{\circ}{\text { col }}_{\text {of wet collagen }}$ \\
\hline$\Sigma$ & second-order 'macroscopic' stress tensor \\
\hline$\Sigma_{\text {cort }}$ & second-order stress tensor within an RVE $V_{\text {cort }}$ of cortical bone material \\
\hline$\Sigma_{\text {cort }}^{u l t}$ & model-predicted uniaxial strength of cortical bone material \\
\hline$\Sigma_{e x p}^{u l t}$ & experimental uniaxial strength of cortical bone material \\
\hline$\varphi$ & longitudinal coordinate of spherical coordinate system \\
\hline$\phi$ & integration variable, $\phi=0 . .2 \pi$ \\
\hline$\phi_{H A, e f}$ & relative amount of hydroxyapatite in the extrafibrillar space \\
\hline$\psi$ & longitudinal coordinate of vector $\underline{n}$ \\
\hline . & first-order tensor contraction \\
\hline : & second-order tensor contractior \\
\hline$\otimes$ & dyadic product of tensors \\
\hline
\end{tabular}




\section{References}

M. Akao, H. Aoki, and K. Kato. Mechanical properties of sintered hydroxyapatite for prosthetic applications. Journal of Materials Science, 16:809812, 1981.

O. Akkus and C.M. Rimnac. Cortical bone tissue resists fatigue fracture by deceleration and arrest of microcrack growth. Journal of Biomechanics, 34: $757-764,2001$.

O. Akkus, A. Polyakova-Akkus, F. Adar, and M.B. Schaffler. Aging of microstructural compartments in human compact bone. Journal of Bone and Mineral Research, 18(6):1012 - 1019, 2003.

J.D. Almer and S.R. Stock. Internal strains and stresses measured in cortical bone via high-energy X-ray diffraction. Journal of Structural Biology, 152: $14-27,2005$.

R.B. Ashman, S.C. Cowin, W.C. van Buskirk, and J.C. Rice. A continuous wave technique for the measurement of the elastic properties of cortical bone. Journal of Biomechanics, 17(5):349-361, 1984.

A.J. Bailey, R.G. Paul, and L. Knott. Mechanisms of maturation and ageing of collagen. Mechanisms of Ageing and Development, 106:1 - 56, 1998.

R. Ballarini, R. Kayacan, F.J. Ulm, T. Belytschko, and A.H. Heuer. Biological structures mitigate catastrophic fracture through various strategies. International Journal of Fracture, 135:187 - 197, 2005.

M. Balooch, S. Habelitz, J.H. Kinney, S.J. Marshall, and G.W. Marshall. Mechanical properties of mineralized collagen fibrils as influenced by demineralization. Journal of Structural Biology, 162:404 - 410, 2008.

V. Benezra Rosen, L.W. Hobbs, and M. Spector. The ultrastructure of anorganic bovine bone and selected synthetic hydroxyapatites used as bone graft substitute material. Biomaterials, 23:921 - 928, 2002.

Y. Benveniste. A new approach to the application of Mori-Tanaka's theory in composite materials. Mechanics of Materials, 6:147 - 157, 1987. 
E. Bertrand and Ch. Hellmich. Multiscale elasticity of tissue engineering scaffolds with tissue-engineered bone: a continuum micromechanics approach. Journal of Engineering Mechanics, 135:395 - 412, 2009.

R. Bhowmik, K.S. Katti, and D.R. Katti. Mechanics of molecular collagen is influenced by hydroxyapatite in natural bone. Journal of Materials Science, 42:8795-8803, 2007.

R. Bhowmik, K.S. Katti, and D.R. Katti. Mechanisms of load-deformation behavior of molecular collagen in hydroxyapatite-tropocollagen molecular system: Steered molecular dynamics study. Journal of Engineering Mechanics, 135(5):413 - 421, 2009.

G. Boivin and P.J. Meunier. The degree of mineralization of bone tissue measured by computerized quantitative contact microradiography. Calcified Tissue International, 70:503 - 511, 2002.

L.C. Bonar, S. Lees, and H.A. Mook. Neutron diffraction studies of collagen in fully mineralized bone. Journal of Molecular Biology, 181:265 - 270, 1985.

K.S. Borsato and N. Sasaki. Measurement of partition of stress between mineral and collagen phases in bone using X-ray diffraction techniques. Journal of Biomechanics, 30:955 - 957, 1997.

A. Boskey. Bone mineral crystal size. Osteoporosis International, 14(Suppl 5): S16 - S21, 2003.

E. Bossy, M. Talmant, F. Peyrin, L. Akrout, P. Cloetens, and P. Laugier. In in vitro study of the ultrasonic axial transmission technique at the radius: $1 \mathrm{MHz}$ velocity measurements are sensitive to both mineralization and introcortical porosity. Journal of Bone and Mineral Research, 19(9):1548 $1556,2004$.

V. Bousson, C. Bergot, A. Meunier, F. Barbot, C. Parlier-Cuau, A.-M. LavalJeantet, and J.-D. Laredo. CT of the middiaphyseal femur: Cortical bone mineral density and relation to porosity. Radiology, 217:179-187, 2000.

M.J. Buehler. Nature designs tough collagen: Explaining the nanostructure of collagen fibrils. Proceedings of the National Academy of Sciences of the 
United States of America (PNAS), 103(33):12285 - 12290, 2006a.

M.J. Buehler. Atomistic and continuum modeling of mechanical properties of collagen: Elasticity, fracture, and self-assembly. Journal of Materials Research, 21:1947 - 1961, 2006b.

M.J. Buehler. Molecular nanomechanics of nascent bone: fibrillar toughening by mineralization. Nanotechnology, 18(29):295102, 2007.

M.J. Buehler. Nanomechanics of collagen fibrils under varying cross-link densities: Atomistic and continuum studies. Journal of the Mechanical Behavior of Biomedical Materials, 1:59 - 67, 2008.

D.B. Burr, C.H. Turner, P. Naick, M.R. Forwood, W. Ambrosius, M.S. Hasan, and R. Pidaparti. Does microdamage accumulation affect the mechanical properties of bone. Journal of Biomechanics, 31:337 - 345, 1998.

J. Catanese, E.P. Iverson, R.K. Ng, and T.M. Keaveny. Heterogeneity of the mechanical properties of demineralized bone. Journal of Biomechanics, 32 : $1365-1369,1999$.

D.L. Christiansen, E.K. Huang, and F.H. Silver. Assembly of type I collagen: fusion of fibril subunits and the influence of fibril diameter on mechanical properties. Matrix Biology, 19:409-420, 2000.

J.D. Currey. Differences in the tensile strength of bone of different histological types. Journal of Anatomy, 93:87 - 95, 1959.

J.D. Currey. The relationship between the stiffness and the mineral content of bone. Journal of Biomechanics, 2:477 - 480, 1969.

J.D. Currey. Effects of differences in mineralization on the mechanical properties of bone. Philosophical Transactions of the Royal Society of London, Series B, 304:509 - 518, 1984.

J.D. Currey. Strain rate and mineral content in fracture models of bone. Journal of Orthopaedic Research, 6(1):32 - 38, 1988.

S. Cusack and A. Miller. Determination of the elastic constants of collagen by Brillouin light scattering. Journal of Molecular Biology, 135:39 - 51, 1979.

G.J. Dvorak. Transformation field analysis of inelastic composite materials. 
Proceedings of the Royal Society London, Series A, 437:311 - 327, 1992.

M. Epple. Solid-state chemical methods to investigate the nature of calcified deposits. Zeitschrift für Kardiologie, 90(Suppl. 3):III/64 - III/67, 2001.

J.D. Eshelby. The determination of the elastic field of an ellipsoidal inclusion, and related problems. Proceedings of the Royal Society London, Series A, $241: 376-396,1957$.

G.E. Fantner, E. Oroudjev, G. Schitter, L.S. Golde, P. Thurner, M.M. Finch, P. Turner, T. Gutsmann, D.E. Morse, H. Hansma, and P.K. Hansma. Sacrificial bonds and hidden length: Unraveling molecular mesostructures in tough materials. Biophysical Journal, 90:1411 - 1418, 2006.

P. Fratzl, S. Schreiber, and K. Klaushofer. Bone mineralization as studied by small-angle X-ray scattering. Connective Tissue Research, 34(4):247 - 254, 1996.

A. Fritsch and Ch. Hellmich. 'Universal' microstructural patterns in cortical and trabecular, extracellular and extravascular bone materials: Micromechanics-based prediction of anisotropic elasticity. Journal of Theoretical Biology, 244(4):597 - 620, 2007.

A. Fritsch, L. Dormieux, and Ch. Hellmich. Porous polycrystals built up by uniformly and axisymmetrically oriented needles: Homogenization of elastic properties. Comptes Rendus Mécanique, 334(3):151 - 157, 2006.

A. Fritsch, L. Dormieux, Ch. Hellmich, and J. Sanahuja. Mechanical behaviour of hydroxyapatite biomaterials: An experimentally validated micromechanical model for elasticity and strength. Journal of Biomedical Materials Research Part A, 88A:149 - 161, 2009.

K. Fujisaki and S. Tadano. Relationship between bone tissue strain and lattice strain of HAp crystals in bovine cortical bone under tensile loading. Journal of Biomechanics, 40:1832 - 1838, 2006.

Y.C. Fung. Celebrating the inauguration of the journal: Biomechanics and Modeling in Mechanobiology. Biomechanics and Modeling in Mechanobiology, $1: 3-4,2002$. 
A. Gautieri, S. Vesentini, F.M. Montevecchi, and A. Redaelli. Mechanical properties of physiological and pathological models of collagen peptides investigated via steered molecular dynamics simulations. Journal of Biomechanics, 41:3073 - 3077, 2008.

A. Gautieri, M.J. Buehler, and A. Redaelli. Deformation rate controls elasticity and unfolding pathway of single tropocollagen molecules. Journal of the Mechanical Behavior of Biomedical Materials, 2:130 - 137, 2009.

E. Gentleman, A.N. Lay, D.A. Dickerson, E.A. Nauman, G.A. Livesay, and K.C. Dee. Mechanical characterization of collagen fibers and scaffolds for tissue engineering. Biomaterials, 24:3805 - 3813, 2003.

L. Gibson. The mechanical behavior of cancellous bone. Journal of Biomechanics, 18:317-28, 1985.

L.J. Gibson and M.F. Ashby. Cellular Solids: Structure and Properties. Cambridge University Press, Cambridge, UK, 2 edition, 1997.

R.S. Gilmore and J.L. Katz. Elastic properties of apatites. Journal of Materials Science, 17:1131 - 1141, 1982.

H.S. Gupta, J. Seto, W. Wagermaier, P. Zaslansky, P. Boesecke, and P. Fratzl. Cooperative deformation of mineral and collagen in bone at the nanoscale. Proceedings of the National Academy of Sciences of the United States of America, 103(47):17741 - 17746, 2006.

P.K. Hansma, P.J. Turner, and R.S. Ruoff. Optimized adhesives for strong, lightweight, damage-resistant, nanocomposite materials: new insights from natural materials. Nanotechnology, 18(4):044026, 2007.

Ch. Hellmich. Microelasticity of bone. In L. Dormieux and F.-J. Ulm, editors, CISM Courses and Lectures, vol. 480. Applied Micromechanics of Porous Media, pages 289 - 332. Springer, Wien - New York, 2004.

Ch. Hellmich and F.-J. Ulm. Average hydroxyapatite concentration is uniform in extracollageneous ultrastructure of mineralized tissue. Biomechanics and Modeling in Mechanobiology, 2:21 - 36, 2003.

Ch. Hellmich and F.-J. Ulm. Are mineralized tissues open crystal foams rein- 
forced by crosslinked collagen? - some energy arguments. Journal of Biomechanics, 35:1199 - 1212, 2002a.

Ch. Hellmich and F.-J. Ulm. A micromechanical model for the ultrastructural stiffness of mineralized tissues. Journal of Engineering Mechanics (ASCE), 128(8):898 - 908, 2002b.

Ch. Hellmich and F.-J. Ulm. Hydroxyapatite is uniformly concentrated in the extracollagenous ultrastructure of mineralized tissue. In J. Middleton, N.G. Shrive, and M.L. Jones, editors, Proceedings of the Fifth International Symposium on Computer Methods in Biomechanics and Biomedical Engineering, Rome, Italy, 2001.

Ch. Hellmich and F.-J. Ulm. Drained and undrained poroelastic properties of healthy and pathological bone: a poro-micromechanical investigation. Transport in Porous Media, 58:243 - 268, 2005.

Ch. Hellmich, J.-F. Barthélémy, and L. Dormieux. Mineral-collagen interactions in elasticity of bone ultrastructure - a continuum micromechanics approach. European Journal of Mechanics A-Solids, 23:783 - 810, 2004a.

Ch. Hellmich, F.-J. Ulm, and L. Dormieux. Can the diverse elastic properties of trabecular and cortical bone be attributed to only a few tissueindependent phase properties and their interactions? - Arguments from a multiscale approach. Biomechanics and Modeling in Mechanobiology, 2:219 $-238,2004 b$.

Ch. Hellmich, C. Kober, and B. Erdmann. Micromechanics-based conversion of CT data into anisotropic elasticity tensors, applied to FE simulations of a mandible. Annals of Biomedical Engineering, 36:108 - 122, 2008.

Ch. Hellmich, D. Celundova, and F.-J. Ulm. Multiporoelasticity of hierarchically structured materials: Micromechanical foundations and application to bone. Journal of Engineering Mechanics, 135(5):382 - 394, 2009.

C.J. Hernandez, G.S. Beaupré, T.S. Keller, and D.R. Carter. The influence of bone volume fraction and ash fraction on bone strength and modulus. Bone, 29:74 - 78, 2001. 
A.V. Hershey. The elasticity of an isotropic aggregate of anisotropic cubic crystals. Journal of Applied Mechanics (ASME), 21:236 - 240, 1954.

R. Hill. Elastic properties of reinforced solids: some theoretical principles. Journal of the Mechanics and Physics of Solids, 11:357 - 362, 1963.

R. Hill. Continuum micro-mechanics of elastoplastic polycrystals. Journal of the Mechanics and Physics of Solids, 13:89 - 101, 1965.

I. Jäger and P. Fratzl. Mineralized collagen fibrils: a mechanical model with a staggered arrangement of mineral particles. Biophysical Journal, 79:1737 $-1746,2000$.

E.P. Katz and S.-T. Li. Structure and function of bone collagen fibrils. Journal of Molecular Biology, 80:1 - 15, 1973.

J.L. Katz. Anisotropy of Young's modulus of bone. Nature, 283:106 - 107, 1980.

J.L. Katz. Composite material models for cortical bone, pages 171 - 184 . American Society of Mechanical Engineers, New York, NY, USA, 1981.

J.L. Katz and K. Ukraincik. On the anisotropic elastic properties of hydroxyapatite. Journal of Biomechanics, 4:221 - 227, 1971.

T.M. Keaveny, R.E. Borchers, L.J. Gibson, and W.C. Hayes. Trabecular bone modulus and strength can depend on specimen geometry. Journal of Biomechanics, 26(8):991 - 1000, 1993.

K.J. Koester, J.W. Ager, and R.O. Ritchie. The true toughness of human cortical bone measured with realistically short cracks. Nature Materials, 7: $672-677,2008$.

W. Koiter. General theorems for elastic-plastic solids. In I. Sneddon and R. Hill, editors, Progress in solid mechanics, volume I, chapter IV, pages 167 - 218. North-Holland Publishing Company, Amsterdam, The Netherlands, 1960.

S.P. Kotha and N. Guzelsu. Modeling the tensile mechanical behavior of bone along the longitudinal direction. Journal of Theoretical Biology, 219:269 $279,2002$. 
S.P. Kotha and N. Guzelsu. Effect of bone mineral content on the tensile properties of cortical bone: Experiments and theory. Journal of Biomechanical Engineering, 125:785 - 793, 2003.

E. Kröner. Computation of the elastic constants of polycrystals from constants of single crystals. Zeitschrift für Physik, 151:504 - 518, 1958. In German.

W.J. Landis, M.J. Song, A. Leith, L. McEwen, and B.F. McEwen. Mineral and organic matrix interaction in normally calcifying tendon visualized in three dimensions by high-voltage electron microscopic tomography and graphic image reconstruction. Journal of Structural Biology, 110:39 - 54, 1993.

S. Lees. Considerations regarding the structure of the mammalian mineralized osteoid from viewpoint of the generalized packing model. Connective Tissue Research, 16:281 - 303, 1987.

S. Lees, P. Cleary, J.D. Heeley, and E.L. Gariepy. Distribution of sonic plesiovelocity in a compact bone sample. Journal of the Acoustical Society of America, 66(3):641-646, 1979a.

S. Lees, J.D. Heeley, and P.F. Cleary. A study of some properties of a sample of bovine cortical bone using ultrasound. Calcified Tissue International, 29: $107-117,1979 b$.

S. Lees, J.M. Ahern, and M. Leonard. Parameters influencing the sonic velocity in compact calcified tissues of various species. Journal of the Acoustical Society of America, 74(1):28 - 33, 1983.

S. Lees, L.C. Bonar, and H.A. Mook. A study of dense mineralized tissue by neutron diffraction. International Journal of Biological Macromolecules, 6: $321-326,1984 a$.

S. Lees, M. Pineri, and M. Escoubes. A generalized packing model for type I collagen. International Journal of Biological Macromolecules, 6:133 - 136, $1984 b$.

S. Lees, K.S. Prostak, V.K. Ingle, and K. Kjoller. The loci of mineral in turkey leg tendon as seen by atomic force microscope and electron microscopy. Calcified Tissue International, 55:180 - 189, 1994. 
S. Lees, D. Hanson, and E.A. Page. Some acoustical properties of the otic bones of a fin whale. Journal of the Acoustical Society of America, 99(4): $2421-2427,1995$.

V. Lemaire, F.L. Tobin, L.D. Greller, C.R. Cho, and L.J. Suva. Modeling the interactions between osteoblast and osteoclast activities in bone remodeling. Journal of Theoretical Biology, 229:293 - 309, 2004.

V.M. Levin, Th. Michelitsch, and I. Sevostianov. Spheroidal inhomogeneity in a transversely isotropic piezoelectric medium. Archive of Applied Mechanics, 70:673-693, 2000.

A.C. Lorenzo and E.R. Caffarena. Elastic properties, Young's modulus determination and structural stability of the tropocollagen molecule: a computational study by steered molecular dynamics. Medical Engineering and Physics, 38(7):1527 - 1533, 2005.

J.F. Mammone and S.M. Hudson. Micromechanics of bone strength and failure. Journal of Biomechanics, 26:439 - 446, 1993.

R.B. Martin, D.B. Burr, and N.A. Sharkey. Skeletal Tissue Mechanics. Springer, New York, 1998.

E.F. Morgan, J.J. Lee, and T.M. Keaveny. Sensitivity of multiple damage parameters to compressive overload in cortical bone. Journal of Biomedical Engineering, 127:557 - 562, 2005.

T. Mori and K. Tanaka. Average stress in matrix and average elastic energy of materials with misfitting inclusions. Acta Metallurgica, 21(5):571 - 574, 1973.

N.Y. Mostafa and P.W. Brown. Computer simulation of stoichiometric hydroxyapatite: Structure and substitutions. Journal of Physics and Chemistry of Solids, 68(3):431 - 437, 2007.

R.K. Nalla, J.J. Kruzic, and R.O. Ritchie. On the origin of the toughness of mineralized tissue: microcracking or crack bridging? Bone, 34:790 - 798, 2004.

J.S. Nyman, Q. Ni, D.P. Nicolella, and X. Wang. Measurements of mobile 
and bound water by nuclear magnetic resonance correlate with mechanical properties of bone. Bone, 42:193 - 199, 2008.

F.J. O'Brien, D. Taylor, and T.C. Lee. Bone as a composite material: The role of osteons as barriers to crack growth in compact bone. International Journal of Fatigue, 29:1051 - 1056, 2007.

K. Okumura and P.-G. de Gennes. Why is nacre strong? Elastic theory and fracture mechanics for biocomposites with stratified structures. The European Physical Journal E - Soft Matter, 4(1):121 - 127, 2001.

J.P.R.O. Orgel, T.C. Irving, A. Miller, and T.J. Wess. Microfibrillar structure of type I collagen in situ. Proceedings of the National Academy of Sciences of the United States of America (PNAS), 103(24):9001 - 9005, 2006.

H. Pan, J. Tao, T. Wu, and R. Tang. Molecular simulation of water behaviors on crystal faces of hydroxyapatite. Frontiers of Chemistry in China, 2:156 $-163,2007$.

F. Peters, K. Schwarz, and M. Epple. The structure of bone studied with synchrotron X-ray diffraction, X-ray absorption spectroscopy and thermal analysis. Thermochimica Acta, 361:131 - 138, 2000.

B. Pichler, St. Scheiner, and Ch. Hellmich. From micron-sized needle-shaped hydrates to meter-sized shotcrete tunnel shells: Micromechanical upscaling of stiffness and strength of shotcrete. Acta Geotechnica, 3:273 - 294, 2008.

B. Pichler, Ch. Hellmich, and J. Eberhardsteiner. Spherical and acicular representation of hydrates in a micromechanical model for cement paste: prediction of early-age elasticity and strength. Acta Mechanica, 203(3-4):137 $162,2009$.

R.M.V. Pidaparti, A. Chandran, Y. Takano, and C.H. Turner. Bone mineral lies mainly outside the collagen fibrils: Predictions of a composite model for osteonal bone. Journal of Biomechanics, 29(7):909 - 916, 1996.

R.M.V. Pidaparti, B.A. Merril, and N.A. Downton. Fracture and material degradation properties of cortical bone under accelerated stress. Journal of Biomedical Materials Research, 37:161 - 165, 1997. 
P. Pivonka, J. Zimak, D.W. Smith, B.S. Gardiner, C.R. Dunstan, N.A. Sims, T.J. Martin, and G.R. Mundy. Model structure and control of bone remodeling: A theoretical study. Bone, 43:249 - 263, 2008.

K.S. Prostak and S. Lees. Visualization of crystal-matrix structure. In situ demineralization of mineralized turkey leg tendon and bone. Calcified Tissue International, 59:474 - 479, 1996.

D.T. Reilly and A.H. Burstein. The mechanical properties of cortical bone. Journal of Bone and Joint Surgery, 56A(5):1001 - 1022, 1974a.

D.T. Reilly and A.H. Burstein. The elastic modulus for bone. Journal of Biomechanics, 7:271 - 275, $1974 \mathrm{~b}$.

G.C. Reilly and J.D. Currey. The effect of damage and microcracking on the impact strength of bone. Journal of Biomechanics, 33:337 - 343, 2000.

P. Roschger, H.S. Gupta, A. Berzlanovich, G. Ittner, D.W. Dempster, P. Fratzl, F. Cosman, M. Parisien, R. Lindsay, J.W. Nieves, and K. Klaushofer. Constant mineralization density distribution in cancellous human bone. Bone, 32:316 - 323, 2003.

J. Salencon. Handbook of Continuum Mechanics - General Concepts. Thermoelasticity. Springer, Berlin, Germany, 2001.

J. Sanahuja, L. Dormieux, S. Meille, Ch. Hellmich, and A. Fritsch. Micromechanical explanation of elasticity and strength of gypsum: from elongated anisotropic crystals to isotropic porous polycrystals. Journal of Engineering Mechanics, 2008. Submitted for publication.

N. Sasaki. Orientation of mineral in bovine bone and the anisotropic mechanical properties of plexiform bone. Journal of Biomechanics, 24:57 - 61, 1991.

M.Y. Shareef, P.F. Messer, and R. van Noort. Fabrication, characterization and fracture study of a machinable hydroxyapatite ceramic. Biomaterials, 14(1):69-75, 1993.

W.K. Sietsema. Animal models of cortical porosity. Bone, 17(4):297S - 305S, 1995. 
J.C. Simo and R.L. Taylor. Consistent tangent operators for rate- independent elastoplasticity. Computer Methods in Applied Mechanics and Engineering, 48:101 - 118, 1985.

P. Suquet. Effective behavior of nonlinear composites. In P. Suquet, editor, Continuum micromechanics, pages 197 - 264. Springer, Wien - New York, 1997.

D. Taylor. How does bone break? Nature Materials, 2:133 - 134, 2003.

D. Taylor, P. O'Reilly, L. Vallet, and T.C. Lee. The fatigue strength of compact bone in tension. Journal of Biomechanics, 36:1103 - 1109, 2003.

W.R. Taylor, E. Roland, H. Ploeg, D. Hertig, R. Klabunde, M.D. Warner, M.C. Hobatho, L. Rakotomanana, and S.E. Clift. Determination of orthotropic bone elastic constants using FEA and modal analysis. Journal of Biomechanics, 35:767 - 773, 2002.

J.B. Thompson, J.H. Kindt, B. Drake, H.G. Hansma, D.E. Morse, and P.K. Hansma. Bone indentation recovery time correlates with bond reforming time. Nature, 414(6865):773 - 776, 2001.

S. Torp, R.S.C. Arridge, C.D. Armeniades, and E. Baer. Structure-property relationships in tendon as a function of age. In E.D.T. Atkins and A. Keller, editors, Structure of Fibrous Biopolymers 26, pages 197 - 221. Butterworth, London, 1975.

M.R. Urist, R.J. De Lange, and G.A.M. Finerman. Bone cell differentiation and growth factors. Science, 220:680 - 686, 1983.

S. Vesentini, C.F.C. Fitié, F.M. Montevecchi, and A. Redaelli. Molecular assessment of the plastic properties of collagen-like homotrimer sequences. Biomechanics and Modeling in Mechanobiology, 3:224 - 234, 2005a.

S. Vesentini, A. Redaelli, and F.M. Montevecchi. Estimation of the binding force of the collagen molecule-decorin core protein complex in collagen fibril. Journal of Biomechanics, 38:433 - 438, 2005b.

M. Viceconti, F. Taddei, S. Van Sint Jan, A. Leardini, L. Cristofolini, S. Stea, F. Baruffaldi, and M. Baleani. Multiscale modelling of the skeleton for the 
prediction of the risk of fracture. Clinical Biomechanics, 23:845 - 852, 2008.

S. Weiner and H.D. Wagner. The material bone: structure - mechanical function relations. Annual Review of Materials Science, 28:271 - 298, 1998.

E.E. Wilson, A. Awonusi, M.D. Morris, D.H. Kohn, M.M.J. Tecklenburg, and L.W. Beck. Three structural roles for water in bone observed by solid-state NMR. Biophysical Journal, 90:3722 - 3731, 2006.

Z. Yosibash, N. Trabelsi, and C. Milgrom. Reliable simulations of the human proximal femur by high-order finite element analysis validated by experimental observations. Journal of Biomechanics, 40:3688 - 3699, 2007.

D. Zahn and O. Hochrein. Computational study of interfaces between hydroxyapatite and water. Physical Chemistry Chemical Physics, 5:4004 -4007, 2003.

D. Zahn, O. Hochrein, A. Kawska, J. Brickmann, and R. Kniep. Towards an atomistic understanding of apatite-collagen biomaterials: linking molecular simulation studies of complex-, crystal- and composite-formation to experimental findings. Journal of Materials Science, 42:8966 - 8973, 2007.

A. Zaoui. Continuum micromechanics: Survey. Journal of Engineering Mechanics (ASCE), 128(8):808 - 816, 2002.

A. Zaoui. Structural morphology and constitutive behavior of microheterogeneous materials. In P. Suquet, editor, Continuum micromechanics, pages 291 - 347. Springer, Wien - New York, 1997.

P. Zioupos, J.D. Currey, A. Casinos, and V. De Buffrénil. Mechanical properties of the rostrum of the whale mesoplodon densirostris, a remarkably dense bony tissue. Journal of Zoology, London, 241:725 - 737, 1997. 


\section{Figure Captions}

Figure 1: Multiscale view of bone structure, with key physical effects considered in micromechanics representation of Figure 3: (a) wet collagen; reproduced from [Orgel et al., 2006], Copyright National Academy of Sciences, U.S.A.; (b) mineralized collagen fibril; schematic sketch after [Landis et al., 1993]; (c) extrafibrillar porous polycrystal; (d) extracellular bone matrix; reproduced with kind permission from Spinger Science+Business Media: [Prostak and Lees, 1996], Fig. 5; (e) extravascular bone matrix [zoomed out of image (f)]; (f) cortical bone; reprinted from [Lees et al., 1979a], with permission from American Institute of Physics, (c)1979.

Figure 2: Multistep homogenization: Properties of phases (with characteristic lengths of $d$ and $d_{2}$, respectively) inside RVEs with characteristic lengths of $\ell$ or $\ell_{2}$, respectively, are determined from homogenization over smaller RVEs with characteristic lengths of $\ell_{2} \leq d$ and $\ell_{3} \leq d_{2}$, respectively.

Figure 3: Micromechanical representation of bone material by means of a sixstep homogenization procedure.

Figure 4: Cylindrical (needle-like) HA inclusion oriented along vector $\underline{N}$ and inclined by angles $\vartheta$ and $\varphi$ with respect to the reference frame $\left(\underline{e}_{1}, \underline{e}_{2}, \underline{e}_{3}\right)$; local base frame $\underline{e}_{r}, \underline{e}_{\vartheta}, \underline{e}_{\varphi}$ is attached to the needle.

Figure 5: Schematic representation of the loading surfaces $\mathfrak{f}_{1}=\mathfrak{f}_{1, H A \varphi \vartheta}$ and $\mathfrak{f}_{2}=\mathfrak{f}_{2, H A \varphi \vartheta}$, for a specific needle family with orientation given through $\varphi$ and $\vartheta$, in the $\sigma_{N N^{-}} \sigma_{N n}$ stress space.

Figure 6: Comparison between model predictions and experiments at the macroscopic scale [cortical bone material, Figure 3(f)]. Mean and standard deviation are depicted for experimental tensile strength (dark color) and experimental compressive strength (light color). 
Figure 7: Plastic mechanisms associated to differently oriented crystals in extrafibrillar space, provoked by uniaxial tensile loading of cortical bone material (human femur, see Table 3, line 1): (a) normal stress and (b) shear stress; (c) value of yield function; (d) normal plastic strain and (e) shear plastic strain.

Figure 8: Plastic mechanisms associated to differently oriented crystals in extrafibrillar space, provoked by uniaxial compressive loading of cortical bone material (human femur, see Table 3, line 1): (a) normal stress and (b) shear stress; (c) value of yield function; (d) normal plastic strain and (e) shear plastic strain.

Figure 9: Macrosopic stress-strain diagram for human femur in uniaxial tension and compression.

Figure 10: Model predicted macroscopic uniaxial tensile (a) and compressive (b) strength as function of vascular porosity $f_{\text {vas }}$, for $\bar{f}_{H A}=46 \%$ (human femur).

Figure 11: Model predicted macroscopic uniaxial tensile (a) and compressive (b) strength as function of ultrastructural mineral volume fraction $\bar{f}_{H A}$, for different vascular porosities $f_{\text {vas }}$. 


\section{Table Captions}

Table 1: 'Universal' (tissue and location-independent) isotropic (or transversely isotropic) phase stiffness values.

Table 2: 'Universal' (tissue and location-independent) phase strength values.

Table 3: Tissue-specific composition values.

Table 4: Specimen geometry, employed testing machines, and strain rate of the tensile and compressive tests, see also Table $5 . d_{S}$ is the diameter of the sample with length $l_{S}$, 'rcs' stands for reduced cross section with diameter $d_{c s}$ or side length $a_{c s}$.

Table 5: Tissue-specific experimental uniaxial tensile and compressive mean strength values. $n$ denotes the number of samples tested.

Table 6: Predicted and experimental strength values for different tissues tested in uniaxial tension.

Table 7: Predicted and experimental strength values for different tissues tested in uniaxial compression. 
4. Figure 1 revised

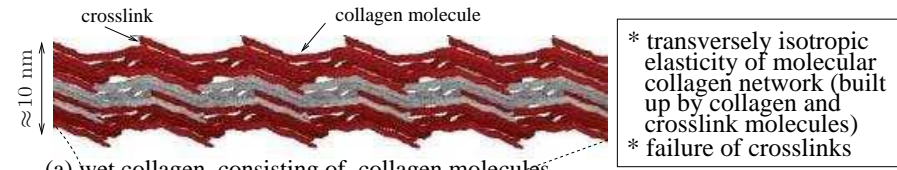

(a) wet collagen, consisting of collagen molecules, crosslinks, and intermolecular space

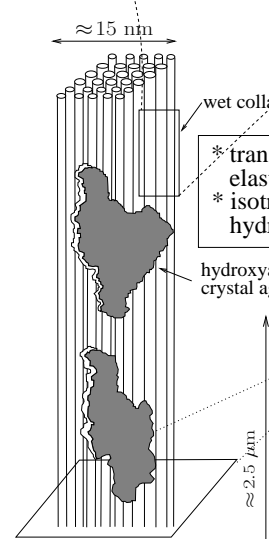

(b) collagen hydroxyapatite network (fibril)

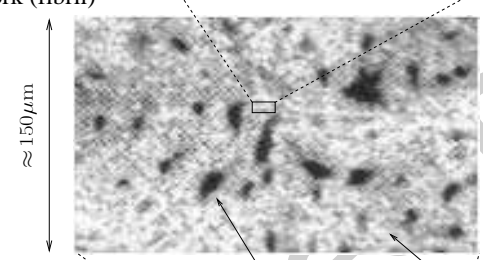

hydroxyapatite crystal aggregates elasticity of molecular collagen network (built lagen and

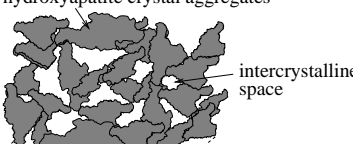

* transversely isotropic elasticity of wet collagen

isotropic elasticity of

* isotropic elasticity of

hydroxyapatite crystals

* plasticity due to ductile sliding between mineral crystals

droxyapatite
ystal aggregates mineralized collágen fibril

(c) porous hydroxyapatite polycrystal

(extrafibrillar space), consisting of

crystal aggregates and intercrystalline space

* transversely isotropic elasticity

of mineralized fibrils

* isotropic elasto-plasticity of

extrafibrillar polycrystal

extrafibrillar space (hydroxyapatite foam) (matrix)

(d) extracellular bone matrix or ultrastructure

* transversely isotropic elastoplasticity of extracellular bone material

* isotropic compressibility of lacunar pore space

(e) extravascular bone material lacunae extracellular bone matrix (ultrastructure)

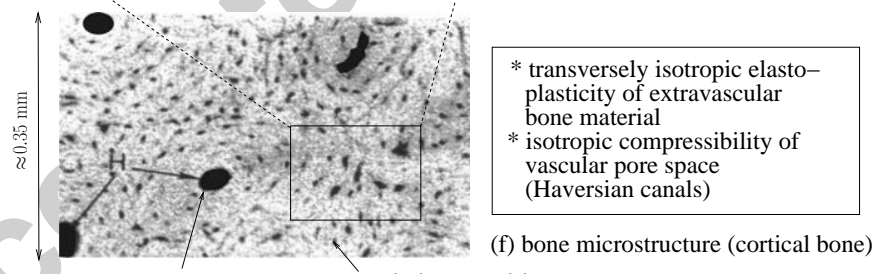

Haversian canals

extravascular bone material 


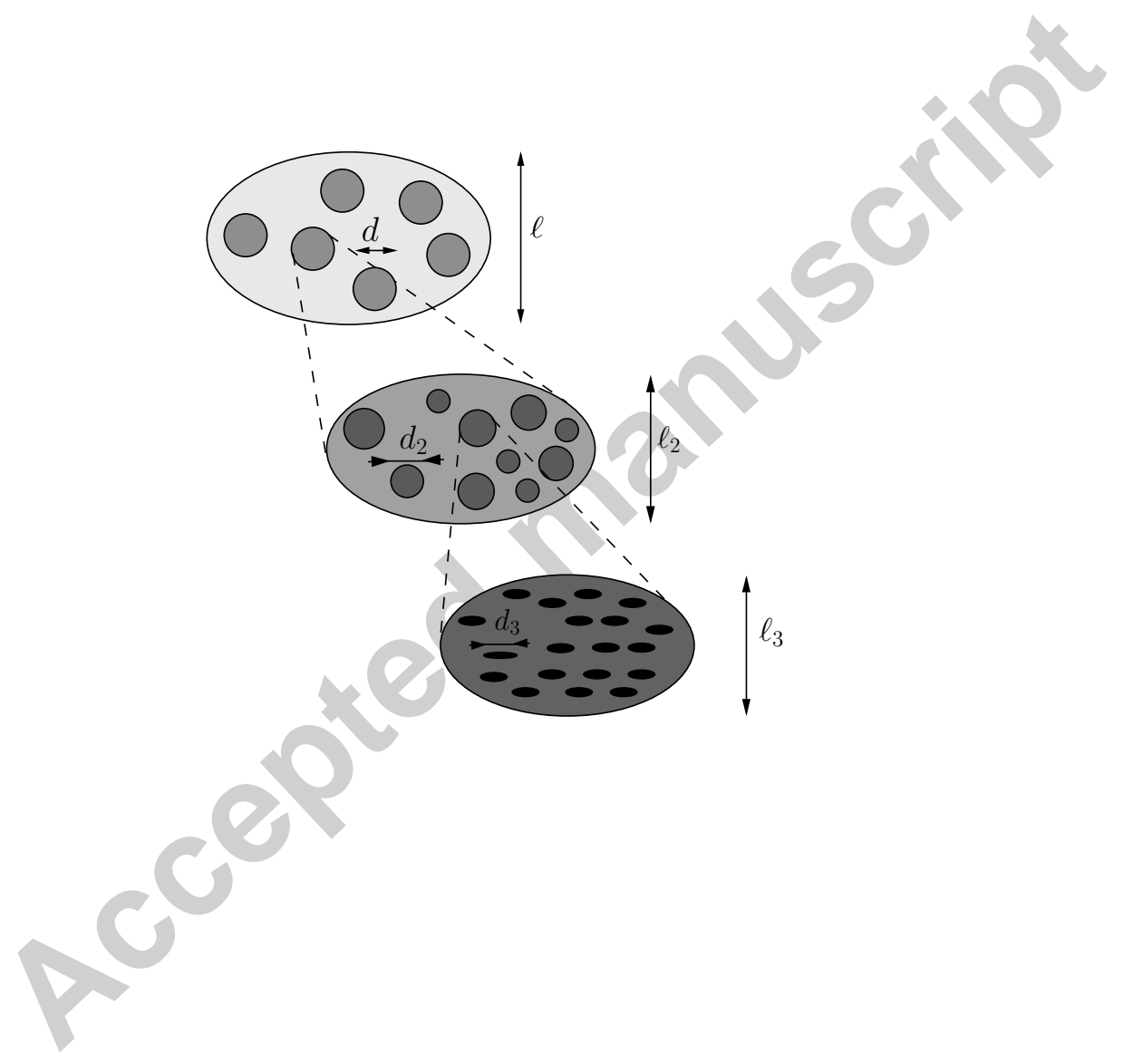

(⿸丆口 4. Figure 2 revised

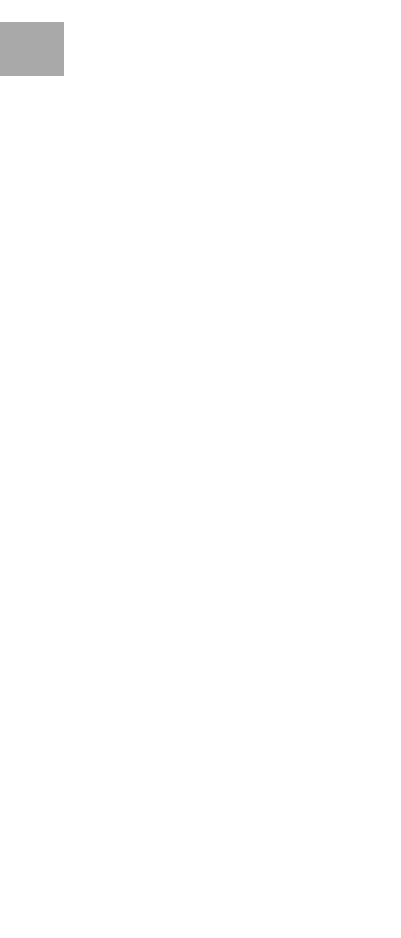

ב

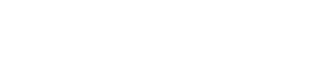




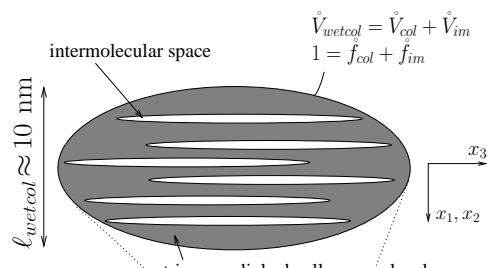

(a) wet collagen

matrix: crosslinked collagen molecules
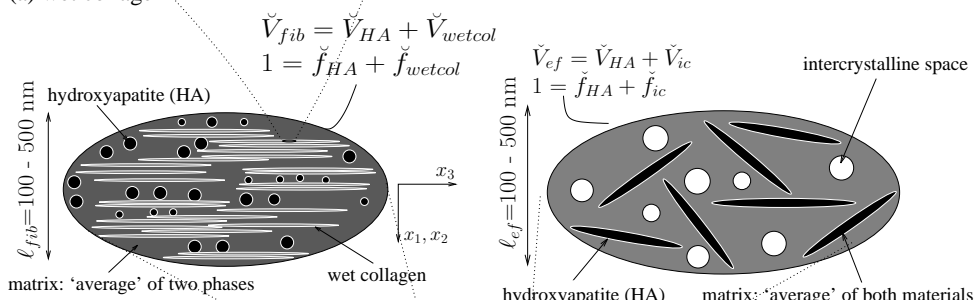

(b) collagen - hydroxyapatite network (fibril)

(c) hydroxyapatite foam (extrafibrillar space)

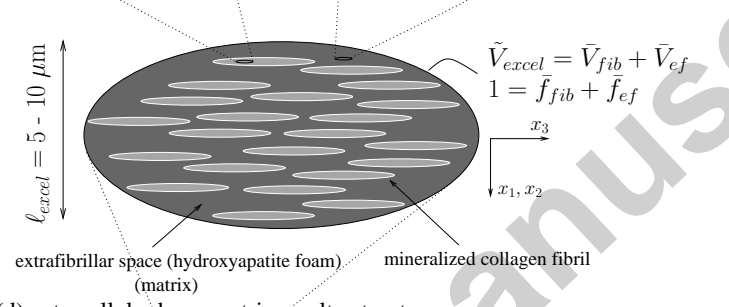

(d) extracellular bone matrix or ultrastructure $\quad \tilde{V}_{\text {exvas }}=\tilde{V}_{\text {excel }}+\tilde{V}_{\text {lac }}$

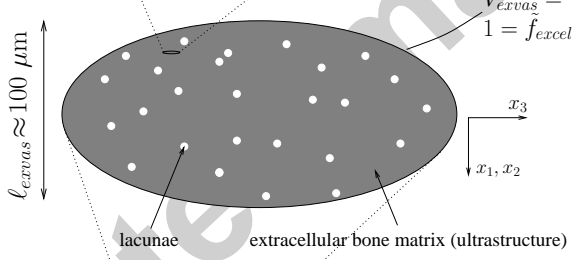

(e) extravascular bone material

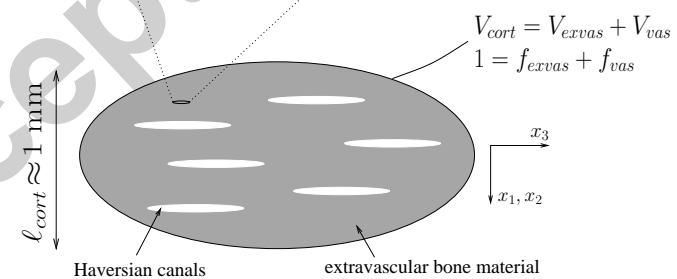

(f) bone microstructure (cortical bone) 
4. Figure 4 revised

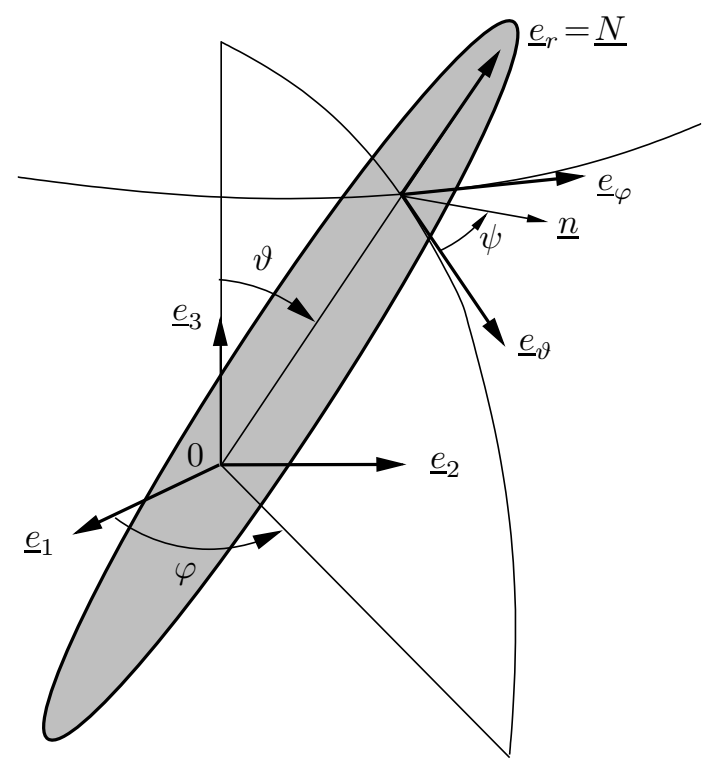


4. Figure 5 revised

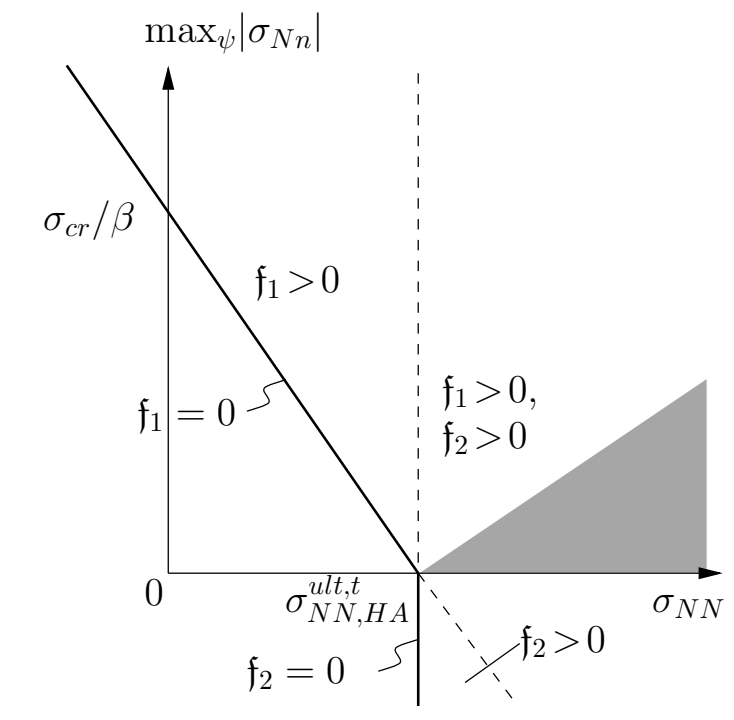


4. Figure 6 revised

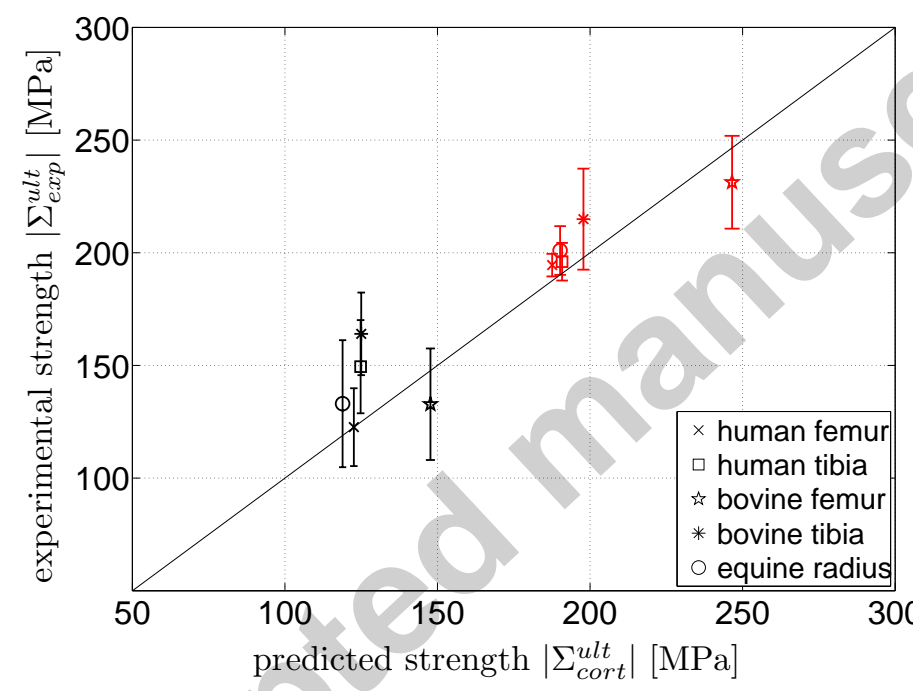




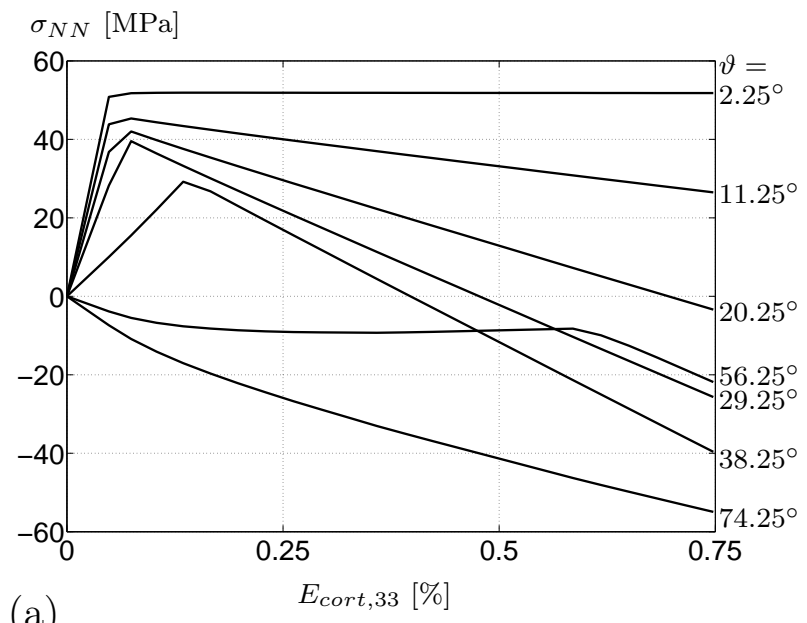

(a)

$f_{H A \varphi \vartheta}\left(\boldsymbol{\sigma}_{H A \varphi \vartheta}\right)[\mathrm{MPa}]$

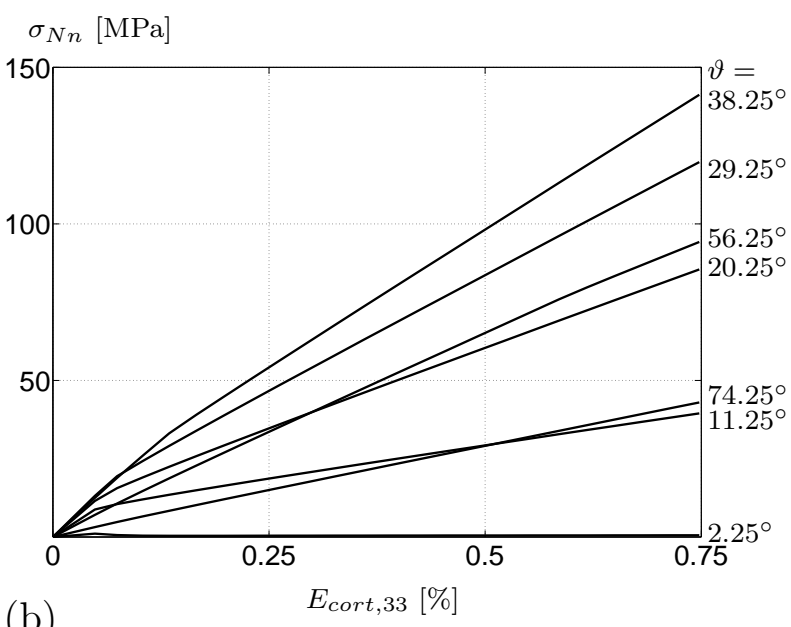

(b)

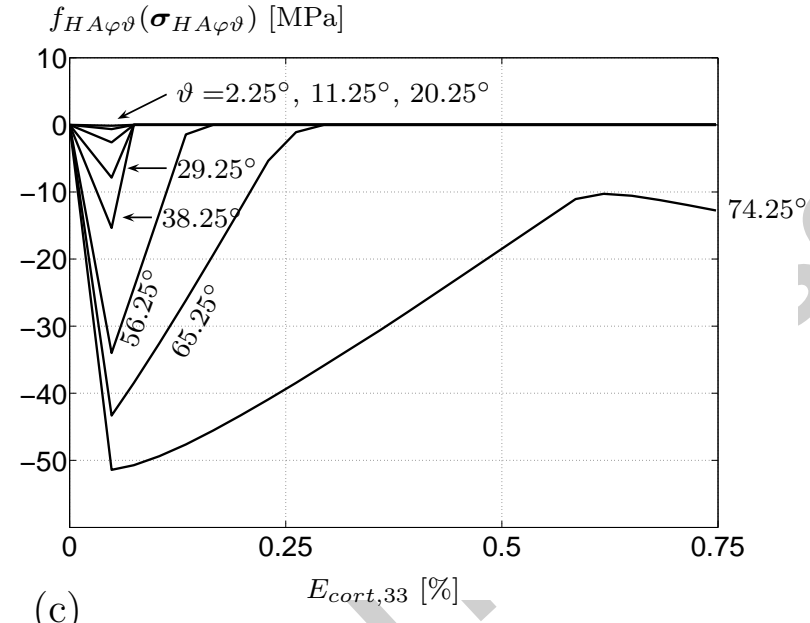

(c)

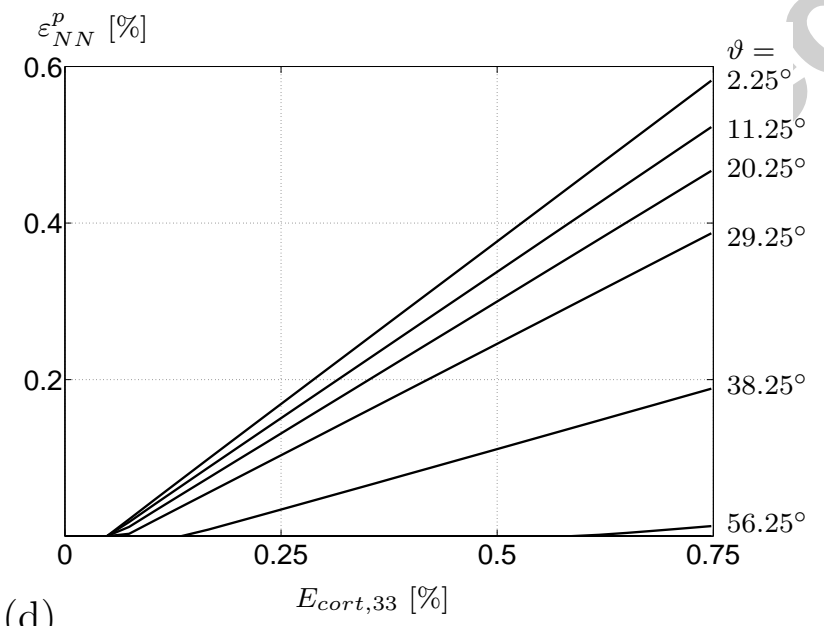

(d)

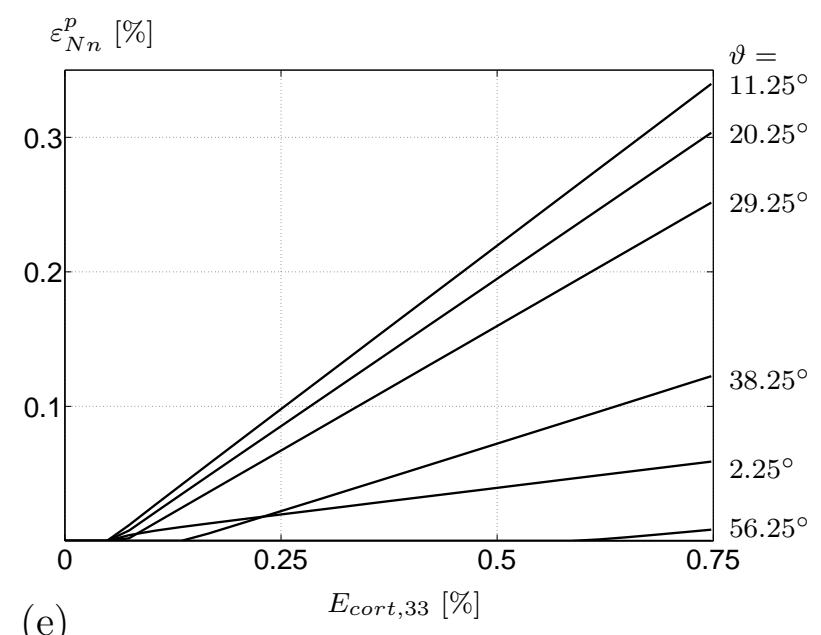

(e)

$20.25^{\circ}$

$29.25^{\circ}$

$.25^{\circ}$

$25^{\circ}$ $56.25^{\circ}$ 


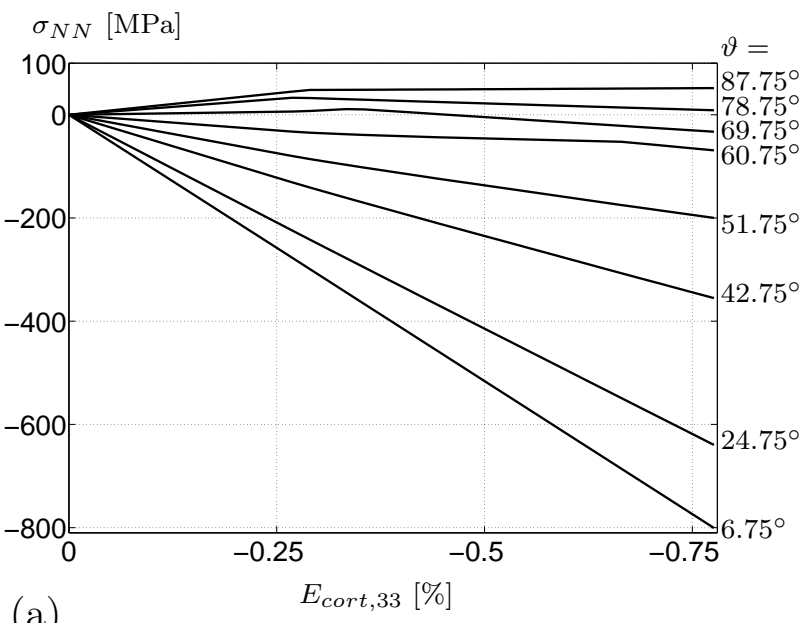

(a)

$f_{H A \varphi \vartheta}\left(\boldsymbol{\sigma}_{H A \varphi \vartheta}\right)[\mathrm{MPa}]$

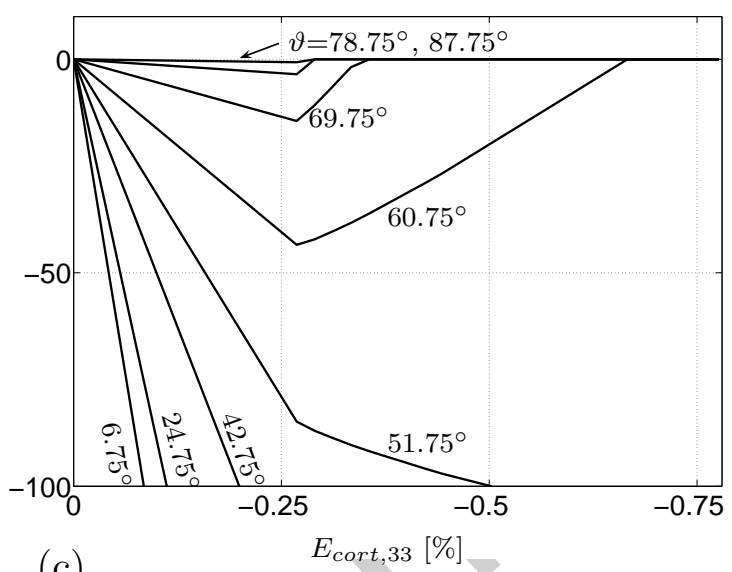

(c)

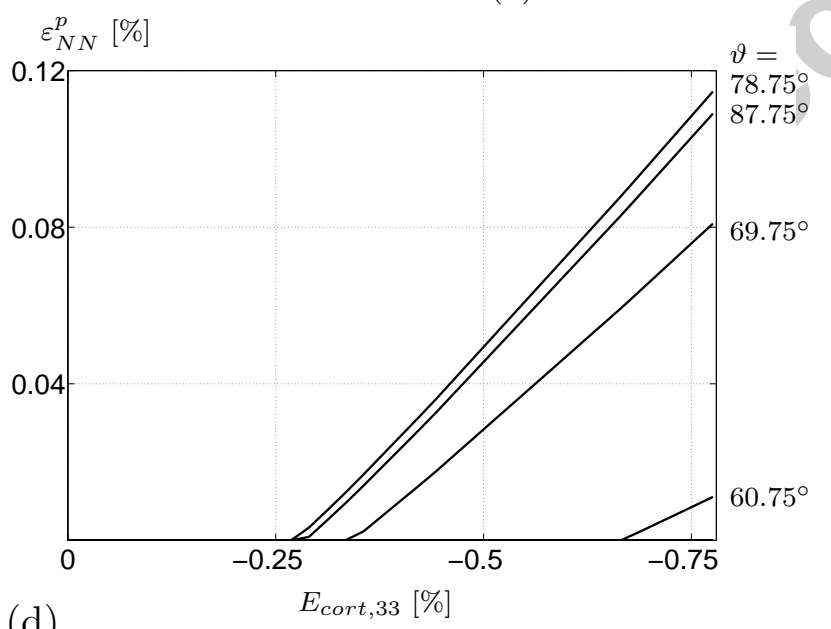

(d)

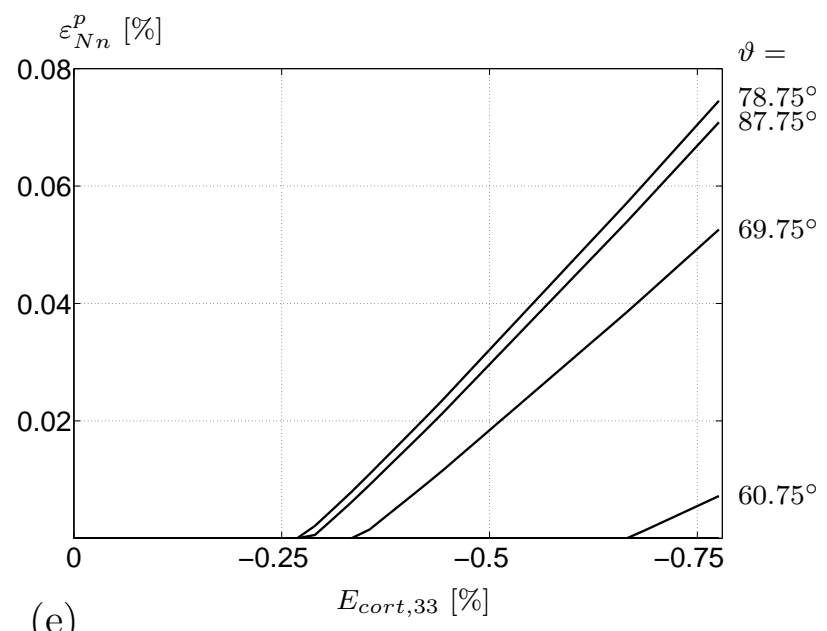

(e)

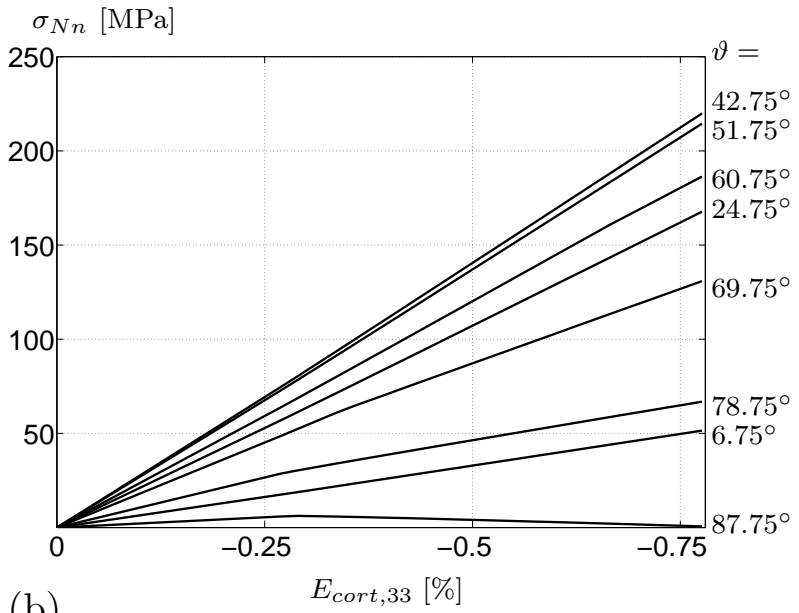

(b)
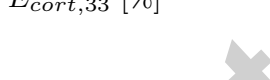

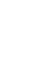


4. Figure 9 revised

$\Sigma_{\text {cort }, 33}[\mathrm{MPa}]$

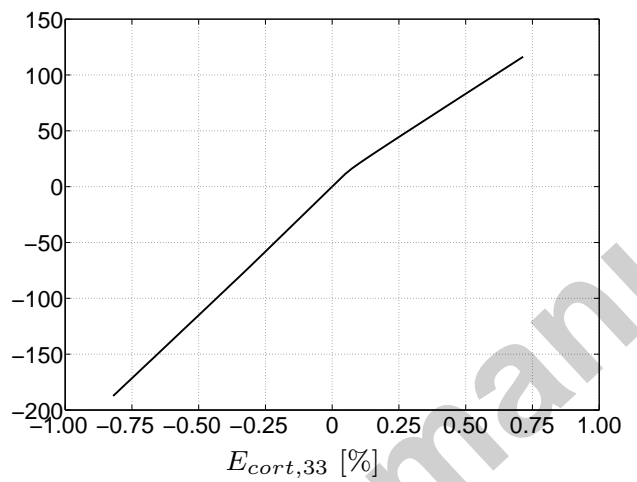

cort, $33[\%]$ 
4. Figure 10 revised
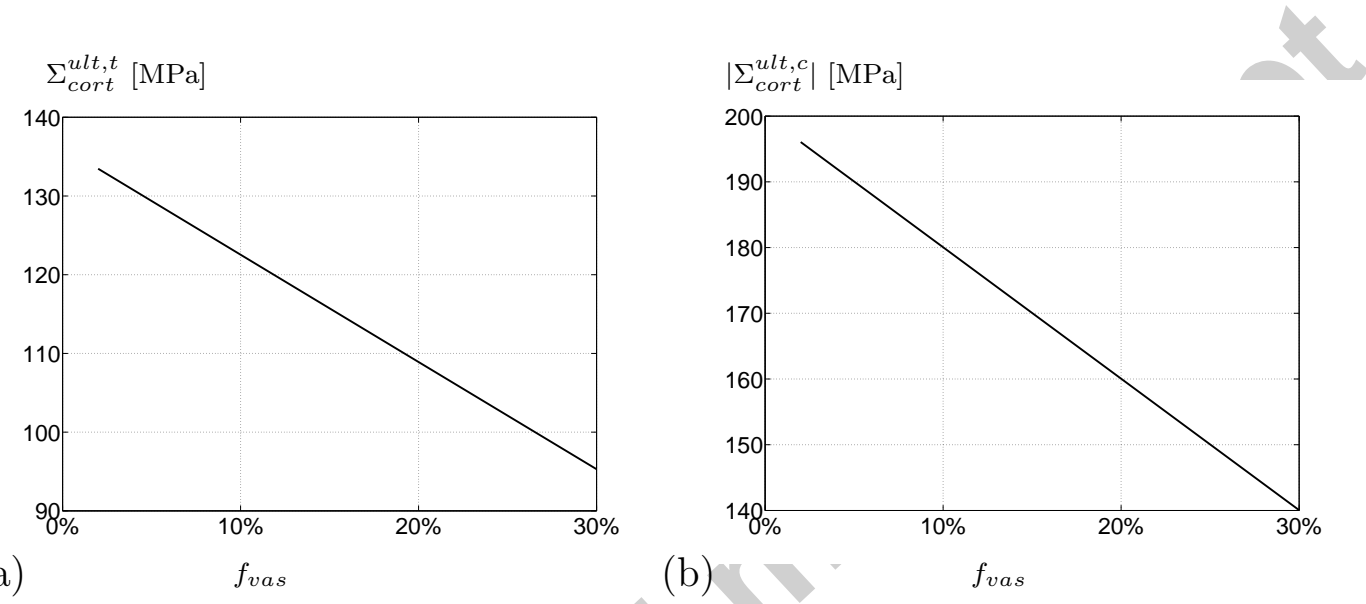

(b)

(a)

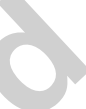


4. Figure 11 revised

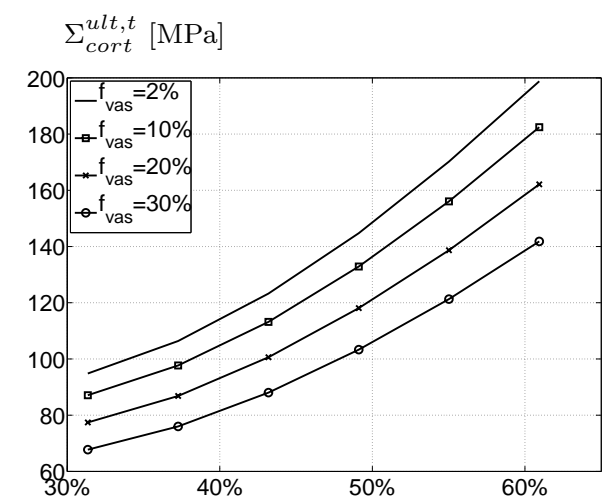

(a)

$$
\bar{f}_{H A}
$$$$
\left|\Sigma_{\text {cort }}^{u l t, c}\right| \text { [MPa] }
$$

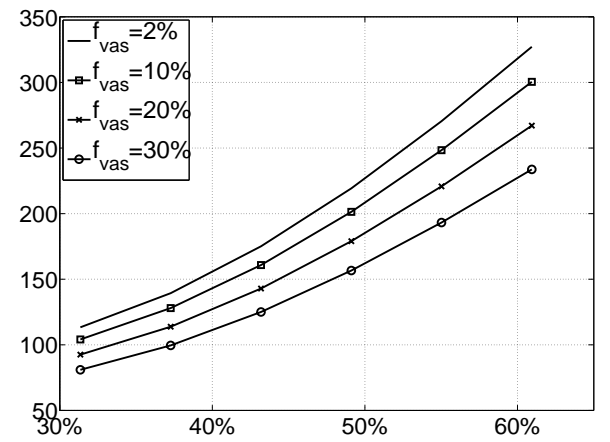

(b)

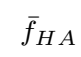




\section{Table 1}

\begin{tabular}{|c|c|c|c|}
\hline \multicolumn{4}{|c|}{ 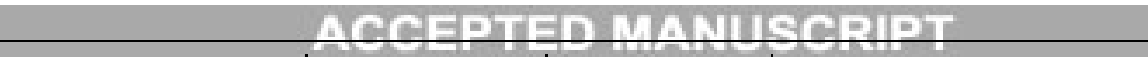 } \\
\hline Phase & $\begin{array}{l}\text { Bulk } \\
\text { modulus } \\
k[\mathrm{GPa}]\end{array}$ & $\begin{array}{l}\text { Shear } \\
\text { modulus } \\
\mu[\mathrm{GPa}]\end{array}$ & Experimental source \\
\hline Hydroxyapatite & $k_{H A}=82.6$ & $\mu_{H A}=44.9$ & [Katz and Ukraincik, 1971] \\
\hline $\begin{array}{l}\text { Water containing } \\
\text { non-collagenous } \\
\text { organics or osteocytes }\end{array}$ & $k_{\mathrm{H}_{2} \mathrm{O}}=2.3$ & $\mu_{H_{2} O}=0$ & \\
\hline & $\begin{array}{l}c_{i j k l} \\
{[\mathrm{GPa}]}\end{array}$ & $\begin{array}{l}c_{i j k l} \\
{[\mathrm{GPa}]}\end{array}$ & \\
\hline Collagen & $\begin{array}{l}c_{c o l, 3333}=17.9 \\
c_{c o l, 1111}=11.7\end{array}$ & $\begin{array}{l}c_{c o l, 1133}=7.1 \\
c_{c o l, 1122}=5.1 \\
c_{c o l, 1313}=3.3\end{array}$ & [Cusack and Miller, 1979] \\
\hline
\end{tabular}




\section{Table 2}

\begin{tabular}{l|l|l|l}
\multicolumn{4}{c}{} \\
\hline Phase & $\begin{array}{c}\text { Uniaxial tensile } \\
\text { strength }[\mathrm{MPa}]\end{array}$ & $\begin{array}{c}\text { Uniaxial shear } \\
\text { strength }[\mathrm{MPa}]\end{array}$ & Experimental source \\
\hline \hline
\end{tabular}

\begin{tabular}{l|l|l|l}
\hline \hline Hydroxyapatite & $\sigma_{H A}^{u l t, t}=52.2$ & $\sigma_{H A}^{u l t, s}=80.3$ & [Akao et al., 1981, Shareef et al., 1993] \\
\hline Collagen & $\sigma_{\text {col }}^{u l t}=144.7$ & & [Gentleman et al., 2003, Lees et al., 1984] \\
\hline
\end{tabular}




\begin{tabular}{|c|c|c|c|c|c|c|c|c|c|c|}
\hline tissue & $\begin{array}{l}\rho_{\text {cort }} \\
{\left[\mathrm{g} / \mathrm{cm}^{3}\right]} \\
\text { given }\end{array}$ & $\begin{array}{l}W F_{H A}^{c o r t} \\
{[-]} \\
\text { given }\end{array}$ & $\begin{array}{l}W F_{\text {org }}^{\text {cort }} \\
{[-]} \\
\text { given }\end{array}$ & $\begin{array}{l}\bar{f}_{H A} \\
{[-]} \\
\text { Eqs. (39), } \\
(42),(43)\end{array}$ & $\begin{array}{l}\bar{f}_{c o l} \\
{[-]} \\
\text { Eqs. (40)- } \\
(42),(44)\end{array}$ & $\begin{array}{l}d_{s} \\
{[\mathrm{~nm}]} \\
\text { Eqs. (42), } \\
(49)\end{array}$ & $\begin{array}{l}\bar{f}_{f i b} \\
{[-]} \\
\text { Eq. } \\
(48)\end{array}$ & $\begin{array}{l}\check{f}_{H A} \\
{[-]} \\
\text { Eqs. (50), } \\
(52)\end{array}$ & $\begin{array}{l}\breve{f}_{H A} \\
{[-]} \\
\text { Eqs. (50), } \\
(51)\end{array}$ & $\begin{array}{l}\dot{f}_{c o l} \\
{[-]} \\
\text { Eqs. }(53), \\
(54)\end{array}$ \\
\hline human femur & $1.98^{a}$ & $0.655^{a}$ & $0.227^{a}$ & 0.46 & 0.30 & 1.25 & 0.53 & 0.65 & 0.28 & 0.42 \\
\hline human tibia & $1.98^{a}$ & $0.659^{a}$ & $0.228^{a}$ & 0.46 & 0.30 & 1.25 & 0.53 & 0.66 & 0.28 & 0.42 \\
\hline bovine femur & $2.105^{a}$ & $0.717^{a}$ & $0.180^{a}$ & 0.53 & 0.25 & 1.23 & 0.44 & 0.71 & 0.30 & 0.36 \\
\hline bovine tibia & $2.02^{a}$ & $0.667^{a}$ & $0.209^{a}$ & 0.47 & 0.28 & 1.24 & 0.49 & 0.66 & 0.28 & 0.39 \\
\hline equine radius & $2.015^{b}$ & - & - & $0.47^{c}$ & $0.27^{c}$ & 1.25 & 0.48 & 0.65 & 0.28 & 0.38 \\
\hline
\end{tabular}

${ }^{a}$ experimental data: [Lees, 1987], Table 2

${ }^{b}$ experimental data: [Riggs et al., 1993]

${ }^{c}$ calculated with Eqs. (45)-(47) 


\begin{tabular}{|c|c|c|c|}
\hline literature source & $\begin{array}{l}\text { specimen geometry } \\
{[\mathrm{mm}]}\end{array}$ & machine & $\begin{array}{l}\text { strain rate } \\
{[1 / \mathrm{s}]}\end{array}$ \\
\hline [Burstein et al., 1972] & $\begin{array}{l}\text { cylindrical }\left(d_{S}=5\right) \text { with rcs } \\
\left(d_{c s}=2.9\right)\end{array}$ & not given & not given \\
\hline [Burstein et al., 1975] & cuboidal $(\approx 15 \times 5 \times 5)$ with $\operatorname{rcs}(a=2)$ & not given & not given \\
\hline [Burstein et al., 1976] & cuboidal $(\approx 15 \times 5 \times 5)$ with $\operatorname{rcs}(a=2)$ & not given & 0.05 \\
\hline [Cezayirlioglu et al., 1985] & $\begin{array}{l}\text { cuboidal }(4-5 \times 4 \times 45) \text { with } \mathrm{rcs} \\
\left(d_{c s}=2.5-3\right)\end{array}$ & Instron 1230 & $0.01-0.06$ \\
\hline [Currey, 1959] & $\begin{array}{l}\text { cylindrical }\left(l_{S}=28\right) \\
\text { with } \operatorname{rcs}\left(d_{c s}=1.9-2.7\right)\end{array}$ & not given & not given \\
\hline [Currey, 1975] & cuboidal with $\operatorname{rcs}\left(a_{c s}=1.8\right)$ & Instron table model & $1.3 \times 10^{-4}-0.16$ \\
\hline [Currey, 1990] & cuboidal with $\operatorname{rcs}\left(a_{c s}=1.8\right)$ & Instron 1122 & 0.2 \\
\hline [Currey, 2004] & cuboidal with $\operatorname{rcs}\left(a_{c s}=1.8\right)$ & Instron 1122 & 0.2 \\
\hline [Dickenson et al., 1981] & $\begin{array}{l}\text { cylindrical }\left(l=30, d_{S}=5.5\right) \\
\text { with } \operatorname{rcs}\left(d_{c s}=2.4\right)\end{array}$ & hydraulic servo-controlled & not given \\
\hline [Hellmich et al., 2006] & cylindrical $\left(l_{S}=10, d_{S}=5\right)$ & $\begin{array}{l}\text { LFM 150, Wille } \\
\text { Geotechnik }\end{array}$ & 0.001 \\
\hline [Kotha and Guzelsu, 2002] & cuboidal with $\operatorname{rcs}(2 \times 5)$ & Instron & 0.0005 \\
\hline [Lee et al., 1997] & $\begin{array}{l}\text { cylindrical }\left(l_{S}=40, d_{S}=4.5\right) \\
\text { with } \operatorname{rcs}\left(d_{c s}=3\right)\end{array}$ & Instron 1331 & 0.5 \\
\hline [Martin and Ishida, 1989] & $\begin{array}{l}\text { cuboidal }(45 \times 18 \times 5) \text { with } \mathrm{rcs} \\
\left(a_{c s}=5\right)\end{array}$ & Instron 1122 & 0.004 \\
\hline [McCalden et al., 1993] & $\begin{array}{l}\text { cuboidal }(32 \times 5 \times 5) \text { with } \mathrm{rcs} \\
\left(a_{c s}=2\right)\end{array}$ & J.J. Lloyd M30K & 0.03 \\
\hline [Reilly and Burstein, 1974] & cuboidal $(\approx 15 \times 5 \times 5)$ with $\operatorname{rcs}(a=2)$ & not given & 0.05 \\
\hline [Reilly and Burstein, 1975] & cuboidal $(\approx 15 \times 5 \times 5)$ with $\operatorname{rcs}(a=2)$ & not given & $0.02-0.05$ \\
\hline [Riggs et al., 1993] & $\begin{array}{l}\text { cuboidal }\left(l_{S}<10\right) \text { with res (tension), } \\
\text { cubes }\left(l_{S}=8, \text { compression }\right)\end{array}$ & Instron 6025 & 0.001 \\
\hline [Sedlin and Hirsch, 1966] & cuboidal $(\approx 50 \times 5 \times 2)$ with $\mathrm{rcs}$ & Instron TT-CM & not given \\
\hline
\end{tabular}




\begin{tabular}{|c|c|c|c|c|c|}
\hline \multirow{4}{*}{ literature source } & $D T=\mathrm{D} M$ & MI & $\mathrm{se}=$ & $=7$ & \\
\hline & \multirow[t]{3}{*}{ tissue } & \multicolumn{2}{|c|}{ tension } & \multicolumn{2}{|c|}{ compression } \\
\hline & & \multirow[t]{2}{*}{$n$} & \multirow{2}{*}{$\begin{array}{l}\Sigma_{\text {exp }}^{u l t, t} \\
{[\mathrm{MPa}]}\end{array}$} & \multirow{2}{*}{$n$} & \multirow{2}{*}{$\begin{array}{l}\sum_{e x p}^{u l t, c} \\
{[\mathrm{MPa}]}\end{array}$} \\
\hline & & & & & \\
\hline [Burstein et al., 1972] & bovine femur & 25 & 172 & $?$ & 283 \\
\hline [Burstein et al., 1975] & bovine tibia & 10 & 188 & & \\
\hline [Burstein et al., 1976] & human femur & 178 & 132 & 95 & 192 \\
\hline [Burstein et al., 1976] & human tibia & 123 & 155 & 38 & 192 \\
\hline [Cezayirlioglu et al., 1985] & human femur & 37 & 136 & 19 & 206 \\
\hline [Cezayirlioglu et al., 1985] & human tibia & 13 & 158 & 9 & 213 \\
\hline [Cezayirlioglu et al., 1985] & bovine femur & 27 & 162 & 25 & 217 \\
\hline [Currey, 1959] & bovine femur & 46 & 106.0 & & \\
\hline [Currey, 1975] & bovine femur & 35 & 124.5 & & \\
\hline [Currey, 1990] & bovine femur & 4 & 148 & & \\
\hline [Currey, 1990] & bovine tibia & 4 & 146 & & \\
\hline [Currey, 2004] & human femur & 4 & 165.7 & & \\
\hline [Currey, 2004] & bovine femur & 10 & 142.4 & & \\
\hline [Dickenson et al., 1981] & human femur & 29 & 117 & & \\
\hline [Hellmich et al., 2006] & bovine tibia & & & 3 & 180 \\
\hline [Kotha and Guzelsu, 2002] & bovine femur & 9 & 106.6 & & \\
\hline [Lee et al., 1997] & human tibia & 11 & 77.0 & & \\
\hline [Martin and Ishida, 1989] & bovine femur & 10 & 112 & & \\
\hline [McCalden et al., 1993] & human femur & 38 & 91.6 & & \\
\hline [Reilly and Burstein, 1974] & human femur & 101 & 128.5 & 95 & 192.5 \\
\hline [Reilly and Burstein, 1974] & bovine femur & 11 & 133.1 & 10 & 249.6 \\
\hline [Reilly and Burstein, 1974] & bovine tibia & 152 & 228 & & \\
\hline [Reilly and Burstein, 1975] & human femur & 21 & 135 & 20 & 205 \\
\hline [Reilly and Burstein, 1975] & bovine femur & 3 & 144 & 3 & 272 \\
\hline [Riggs et al., 1993] & equine radius & 40 & 161 & 13 & 185 \\
\hline [Riggs et al., 1993] & equine radius & 40 & 105 & 13 & 217 \\
\hline [Sedlin and Hirsch, 1966] & human femur & 52 & 87.5 & & \\
\hline
\end{tabular}


5. Table 6

\begin{tabular}{|c|c|c|}
\hline tissue & $\begin{array}{l}\text { model } \\
\Sigma_{\text {cort }}^{u l t, t} \\
{[\mathrm{MPa}]}\end{array}$ & $\begin{array}{l}\text { experiments } \\
\Sigma_{\text {exp }}^{u l t, t} \\
\text { mean } \pm \text { std.dev. } \\
{[\mathrm{MPa}]}\end{array}$ \\
\hline human femur & 122.59 & $122.59 \pm 17.28$ \\
\hline human tibia & 124.82 & $149.43 \pm 20.69$ \\
\hline bovine femur & 147.69 & $132.77 \pm 24.75$ \\
\hline bovine tibia & 125.00 & $164.00 \pm 18.33$ \\
\hline equine radius & 118.91 & $133.00 \pm 28.18$ \\
\hline
\end{tabular}

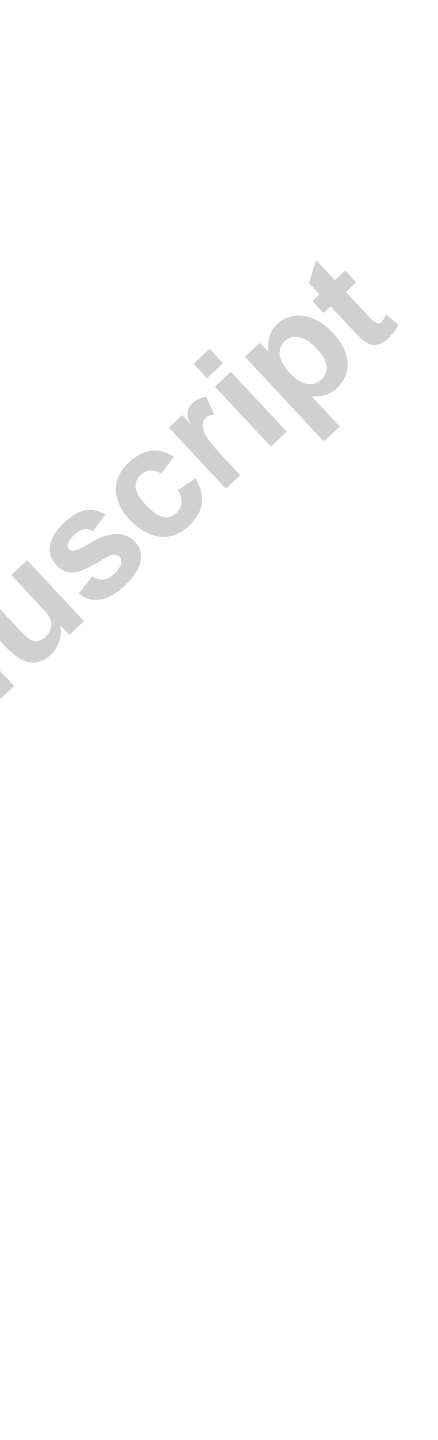

(n)

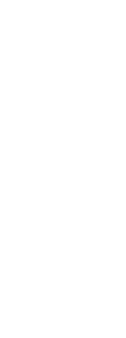

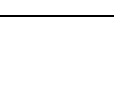

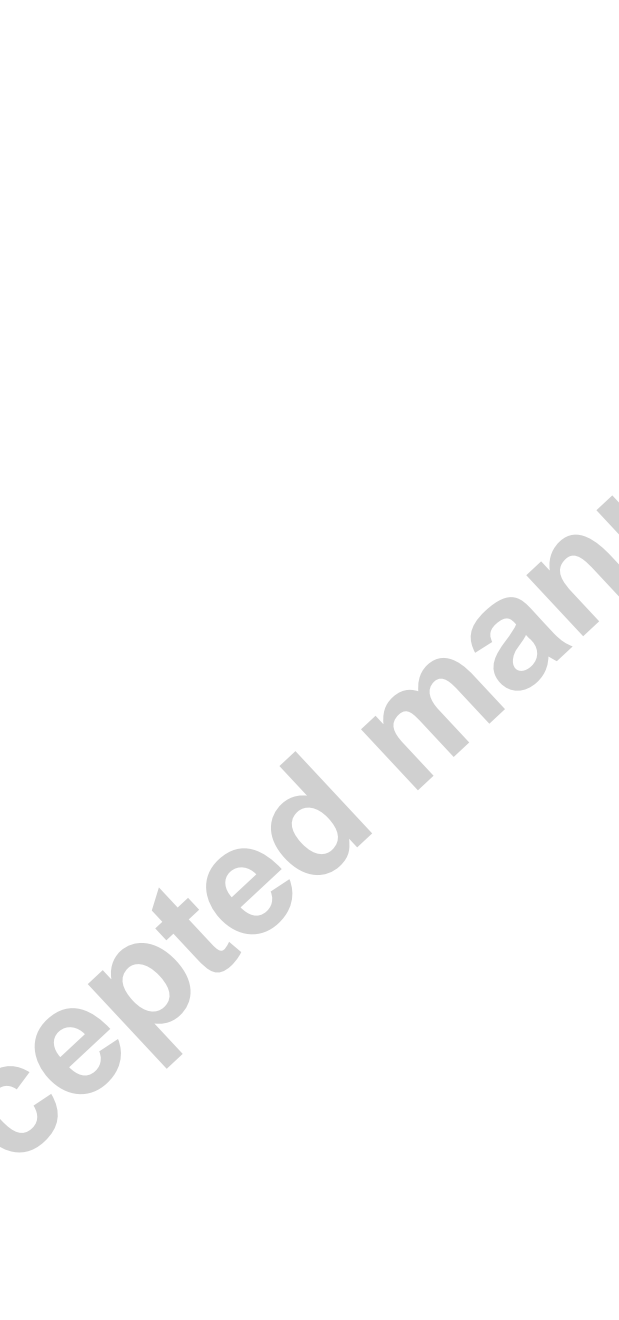


